SILVANA APARECIDA RINALDI

USO DE MACROINVERTEBRADOS BENTÔNICOS NA AVALIAÇÃO DO IMPACTO ANTROPOGÊNICO ÀS NASCENTES DO PARQUE ESTADUAL DO JARAGUÁ, SÃO PAULO, SP

SÃO PAULO 


\section{USO DE MACROINVERTEBRADOS BENTÔNICOS NA AVALIAÇÃO DO IMPACTO ANTROPOGÊNICO ÀS NASCENTES DO PARQUE ESTADUAL DO JARAGUÁ, SÃO PAULO, SP}

Dissertação apresentada ao Instituto de Biociências da Universidade de São Paulo para a obtenção do Título de Mestre em Ciências, na área de Ecologia.

Orientadora: Ana Lúcia Brandimarte

SÃO PAULO 
Ficha catalográfica

Rinaldi, Silvana Aparecida

Uso de Macroinvertebrados Bentônicos na Avaliação do Impacto Antropogênico às Nascentes do Parque Estadual do Jaraguá, São Paulo, SP.

$54 \mathrm{p}+$ anexos.

Dissertação (Mestrado) - Instituto de Biociências da Universidade de São Paulo. Departamento de Ecologia.

1. Macroinvertebrados Bentônicos 2.Poções 3. Corredeiras 4. Métricas 5. Impacto Antropogênico.

Universidade de São Paulo. Instituto de Biociências. Departamento de Ecologia.

Comissão Julgadora:

$\operatorname{Prof(a).~Dr(a).~}$

Prof(a). Dr(a).

$\operatorname{Prof(a).~Dr(a).~}$

$\operatorname{Prof(a).~Dr(a).~}$

Profa. Dra. Ana Lúcia Brandimarte

Orientadora 


\section{AGRADECIMENTOS}

Agradeço à Profa. Dra. Ana Lúcia Brandimarte, pela orientação, paciência e amizade.

Ao Prof. Dr. Sérgio Tadeu Meirelles por auxiliar nas análises estatísticas.

Ao Prof. Dr. Sergio Antonio Vanin pela identificação de alguns Coleoptera.

À banca examinadora da qualificação: Gisela Yuka Shimizu, Maurício Anaya e Marcelo Pompêo, pelas preciosas críticas e sugestões.

Ao Hélio Rubens Victorino Imbimbo pela ajuda na identificação de Odonata, Ephemeroptera e, especialmente, Trichoptera.

A todos os funcionários do Departamento de Ecologia.

A todos os funcionários da biblioteca IB-USP, especialmente à Maria Inês Conte, pelo auxílio com as referências bibliográficas.

À COTEC por permitir a realização do trabalho no Parque Estadual do Jaraguá.

A todos os funcionários do Parque, especialmente ao seu Diretor, Vladimir Arrais, que nos recebeu tão prestativamente e aos funcionários Edimilson Sampaio (monitor) e Gilson Antonio da Silva, que nos acompanharam e auxiliaram nas coletas.

Aos meus pais, sem os quais eu não chegaria até aqui.

Aos meus irmãos, pelo apoio.

Ao Rogério que, além da paciência, carinho e apoio, ainda ajudou nas coletas.

A todos os demais que de alguma forma colaboraram para a realização deste trabalho. 


\section{ÍNDICE}

$\begin{array}{ll}\text { ABSTRACT/RESUMO } & 01\end{array}$

INTRODUÇÃO GERAL 02

Recursos Hídricos e Conservação 02

Biomonitoramento de Recursos Hídricos 04

A Reserva da Biosfera do Cinturão Verde da Cidade de São Paulo 07

REFERÊNCIAS BIBLIOGRÁFICAS 08

CAPÍTULO I - COMUNIDADE DE INVERTEBRADOS BENTÔNICOS EM POÇÕES

E CORREDEIRAS DE QUATRO NASCENTES DO PARQUE ESTADUAL DO JARAGUÁ, SÃO PAULO, SP.

ABSTRACT/RESUMO 13

INTRODUÇÃO 14

MATERIAL E MÉTODOS

Local de trabalho $\quad 15$

$\begin{array}{ll}\text { Coleta e análise de dados } & 17\end{array}$

RESULTADOS 19

DISCUSSÃO 25

CONCLUSÃO 29

REFERÊNCIAS BIBLIOGRÁFICAS 29

CAPÍTULO II - APLICAÇÃO DE MÉTRICAS UTILIZANDO MACROINVERTEBRADOS BENTÔNICOS PARA AVALIAÇÃO DO IMPACTO ANTROPOGÊNICO ÀS NASCENTES DO PARQUE ESTADUAL DO JARAGUÁ, SÃO PAULO, SP.

ABSTRACT/RESUMO 36

INTRODUÇÃO

MATERIAL E MÉTODOS $\quad 40$

Local de trabalho $\quad 40$

Coleta e análise de dados $\quad 41$ 
Tratamento de dados

Obtenção do índice multimétrico para as nascentes do Parque Estadual do Jaraguá $\quad 45$

RESULTADOS 45

DISCUSSÃO

CONCLUSÃO 49

REFERÊNCIAS BIBLIOGRÁFICAS

CONSIDERAÇÕES FINAIS 


\begin{abstract}
The use of benthic macroinvertebrates for the assessment of anthropogenic impact on streams of Jaraguá State Park, São Paulo, SP. Due to the importance of benthic macroinvertebrates to assess water quality and the advantages of their utilization as bioindicators, these organisms were employed to assess the possible antropogenic impact in four streams located in Jaraguá State Park (São Paulo, SP). In each stream the benthic macroinvertebrates were collected in 5 pools and 5 riffles with a Surber sampler $\left(0,04 \mathrm{~m}^{2}, 500 \mu \mathrm{m}\right.$ mesh size $)$. This study is divided in two chapters. The first compares the benthic macroinvertebrate community structure between pools and riffles. The families Cyclopidae, Talitridae, Leptoceridae, Psychodidae and Stratiomyidae were present exclusively in pools, while Perlidae and Simuliidae were exclusive of riffles. In both habitats, Chironomidae relative abundance was high. In the second chapter, eleven metrics were tested for the analysis of environmental quality of streams. Four of them (Shannon-Wiener diversity, dominance, EPT/Total, and IBMF) showed differences related to the degree of impact anthropogenic on streams and were used to compose a multimetric index.
\end{abstract}

Key-words: benthic macroinvertebrates - pools - riffles - anthropogenic impact - metrics.

\title{
RESUMO
}

O uso de macroinvertebrados bentônicos na avaliação do impacto antropogênico às nascentes do Parque Estadual do Jaraguá, São Paulo, SP. Devido à importância dos macroinvertebrados bentônicos como bioindicadores da qualidade ambiental e às vantagens de seu emprego como tal, estes organismos foram utilizados para avaliar a possível existência de impacto antropogênico às nascentes localizadas no Parque Estadual do Jaraguá (São Paulo, SP). Para isso, selecionaram-se quatro nascentes, em cada uma das quais foram nas quais foram coletadas amostras de água em cada nascente para a análise de coliformes fecais e das concentrações de nitrogênio e fósforo totais. A coleta de macroinvertebrados bentônicos foi realizada, com o auxílio de um delimitador Surber (área de $0,04 \mathrm{~m}^{2}$, malha de $500 \mu \mathrm{m}$ ), em poções e corredeiras da cada nascente. Este trabalho divide-se em dois capítulos. O primeiro capítulo trata da estrutura da comunidade de invertebrados bentônicos nas nascentes do Parque Estadual do Jaraguá e mostra uma diferenciação entre poções e corredeiras, sendo que as famílias Cyclopidae, Talitridae, Leptoceridae, Psychodidae e Stratiomyidae foram exclusivas de poções, enquanto Perlidae e Simuliidae foram exclusivas de corredeiras, sendo que abundância relativa de Chironomidae foi elevada em ambos os habitats. No segundo capítulo, foram testadas onze métricas para a análise da qualidade ambiental das nascentes do Parque Estadual do Jaraguá (São Paulo, SP), das quais apenas quatro (diversidade de Shannon-Wiener, dominância, EPT/Total e IBFM) mostraram-se úteis para a diferenciação das nascentes não impactadas e impactadas.

Palavras-chave: invertebrados bentônicos - poções - corredeiras - impacto antropogênico - métricas. 


\section{INTRODUÇÃO GERAL}

\section{Recursos Hídricos e Conservação}

A humanidade depende de ecossistemas aquáticos saudáveis para o fornecimento de água potável, alimentação e uma vasta gama de outros bens e serviços ambientais. A proximidade dos corpos d'água atrai agrupamentos humanos há milhares de anos, e as alterações antropogênicas em ecossistemas aquáticos estão intimamente relacionadas com o desenvolvimento econômico e social (UNESCO, 2006). Os diversos usos do solo podem afetar as águas doces devido à descarga de nutrientes, acúmulo de sedimentos no corpo d'água, variações na temperatura da água e aumento da poluição. Portanto, as alterações na vegetação terrestre e no solo têm reflexos sobre a qualidade da água e do ambiente aquático, com efeitos negativos nas taxas de natalidade, sucesso reprodutivo, crescimento e desenvolvimento dos organismos aquáticos (Lynch et al., 1984; Saunders et al., 2002; Abramowicz, 1996).

Atualmente, a urbanização acelerada, o desmatamento, o desenvolvimento agrícola, a drenagem do solo, a remoção da vegetação ripária e obras para a regulagem de fluxo, tais como canais e diques, estão entre as atividades humanas que mais alteram os rios (Boon, 1996). Como resultado, a humanidade do século XXI confronta-se com desafios inéditos impostos pela escassez de água, poluição e degradação da qualidade da água (Mokaya e Mathooko, 2004).

No Brasil, a partir da década de 1960, acentuou-se o processo de urbanização, concentrada em regiões metropolitanas, nas capitais dos Estados e em pólos regionais (Tucci, 1999) e gerando cidades com infra-estrutura inadequada. Particularmente no Brasil, a abundância em águas doces tem servido à cultura do desperdício, à não realização dos investimentos necessários ao seu uso e proteção mais eficientes, e à sua baixa valorização econômica (Rebouças, 1999).

O aumento da área metropolitana impacta uma porção crescente das bacias hidrográficas. Devido à lavagem das ruas, transporte de material sólido e ligações clandestinas de esgoto cloacal e pluvial, a urbanização tem levado à crescente degradação da qualidade da água (Tucci, 1999). O número de rios que correm em áreas urbanizadas tem aumentado desde o século passado e provavelmente essa tendência continuará no futuro (Meyer et al., 2005). Tais rios estão sujeitos a alterações em comum que podem ser chamadas 
de síndrome urbana: elevadas concentrações de nutrientes e contaminantes, menor número de pequenos rios nas bacias, alteração da morfologia do canal e da sua estabilidade, redução da riqueza da biota com a dominância de espécies mais tolerantes (Paul e Meyer, 2001; Walsh et al., 2005).

Além do abastecimento de água, rios em regiões metropolitanas podem fornecer oportunidades de recreação, renovação espiritual, apreciação estética e um meio para que as crianças explorem parte do mundo natural (Meyer et al., 2005), contribuindo para a qualidade de vida urbana (Bolund e Hunhammar 1999; Palmer et al., 2004).

Muitos países têm reservado uma porção de seus territórios para a proteção e preservação de ambientes naturais. Há diferentes categorias e níveis de conservação, mas em geral, todas as áreas são criadas para promover a persistência das espécies, comunidades e ecossistemas que, de outra forma, declinariam ou se tornariam extintos (Lunney et al., 1997) e para preservar paisagens de excepcional beleza que fornecem oportunidades para recreação e estudos científicos (USNPS, 1996). A criação de áreas protegidas, na forma de parques, por exemplo, apresenta-se como uma solução parcial para a proteção dos recursos hídricos, pois a maioria delas é criada visando recursos terrestres e os hídricos são englobados apenas acidentalmente, como parte de sua inclusão nas reservas terrestres (Lake, 1980; Skelton et al., 1995). Infelizmente, a inclusão não garante a proteção, pois as unidades de conservação geralmente falham em garantir a integridade de toda a bacia de drenagem e em impedir a introdução de espécies exóticas (Lake, 1980; Skelton et al., 1995; Moyle e Randall, 1998). Inclusive porque muitas atividades exercem efeitos mínimos sobre habitats terrestres, mas podem causar impactos negativos nos habitats de água doce, devido ao aumento da taxa de sedimentação, tais como a construção de estradas dentro dos parques (Skelton et al., 1995).

Apesar de ser uma ferramenta útil para promover a conservação dos recursos naturais, o turismo ecológico, realizado em unidades de conservação pode afetar a qualidade ambiental ao levar à degradação de recursos não renováveis. Paisagens com elevado valor estético, estruturas hidrológicas naturais, água limpa, ar puro e diversidade de espécies podem sofrer com a poluição e, dessa forma, perder sua atratividade (Petrosillo et al., 2006).

Em contraste com outros recursos, os problemas de manutenção dos recursos estéticos são particularmente complicados. Exatamente pela sua natureza, a recreação ao ar livre é descontrolada e relativamente não gerenciada, sendo uma atividade exploradora que tende a reduzir os recursos dos quais depende. Assim, o perigo de degradação do recurso é muito grande, pois o impacto físico gerado é alto e amplamente concentrado em áreas localizadas e, freqüentemente, em habitats frágeis (Tivy e O’Hare, 1981). 
A recreação difere acentuadamente dos outros métodos mais tradicionais de exploração de dois modos principais. Primeiro, porque diferentemente da agricultura e da silvicultura é uma atividade não produtiva. Segundo porque o benefício fornecido por ela é o nível ou grau de satisfação experimentado pela pessoa envolvida. Já que o objetivo mais importante para quem pratica a recreação ao ar livre é a apreciação da paisagem, o valor estético da cobertura vegetal associado aos habitats de vida selvagem representa um recurso importante (Tivy e O'Hare, 1981).

O impacto físico mais comum em todos os tipos de recreação ao ar livre é a compactação do solo por pisoteamento humano e por ação de rodas de veículos. Dentre os sinais de deterioração dos recursos do meio pela atividade recreacional podem ser citados:

redução da biomassa e cobertura vegetal;

decréscimo na densidade florística;

substituição das espécies mais sensíveis por aquelas mais tolerantes ao impacto ou ao pisoteamento (Tivy e O’Hare, 1981).

\section{Biomonitoramento de Recursos Hídricos}

Nossa habilidade para proteger recursos biológicos está diretamente relacionada a nossa habilidade para identificar e prever os efeitos da ação humana sobre os sistemas biológicos, especialmente para distinguir entre variações naturais e as causadas pelo homem (Karr e Chu, 1999).

Segundo Iliopoulou-Georgudaki et al. (2003), no caso de ambientes aquáticos, o ideal é avaliar a qualidade da água concomitantemente através de variáveis físicas, químicas e biológicas, de modo a se obter um panorama geral da situação, o que possibilitaria um gerenciamento adequado do recurso hídrico. Entretanto, os mesmos autores aferiram que esse tipo de estudo requer mais tempo e dinheiro que o estudo dos parâmetros biológicos, que são amplamente aceitos e podem fornecer informações confiáveis. Até recentemente, de acordo com as leis brasileiras, a qualidade da água deveria ser determinada por variáveis físicas, químicas e bacteriológicas, as quais podem levar a falsos julgamentos. Tais medidas são apropriadas para propósitos agrícolas, industriais e domésticos, mas não para os estéticos, ecológicos e recreacionais (Silveira et al., 2005).

Muitos autores reconhecem que a análise das variáveis físicas e químicas reflete uma situação momentânea do corpo d'água, enquanto os parâmetros biológicos representam uma somatória temporal dos fatores ambientais (Shimizu, 1978), de forma que a análise apenas dos 
parâmetros abióticos pode levar a conclusões falsas sobre a qualidade do ambiente aquático (Ranson e Doris, 1972), que se modifica em resposta à ação antrópica (Cummins, 1973).

Além disso, o simples monitoramento das alterações das variáveis físicas e químicas da água não é um meio seguro de avaliação dos impactos, pois, muitas vezes, ocorrem em um período de tempo tão curto que não são detectadas (Brandimarte, 1997).

O estudo das variáveis biológicas ou monitoramento biológico pode ser definido como o uso sistemático das respostas de organismos vivos, especialmente aqueles que apresentam sensibilidade ou tolerância a vários fatores para avaliar alterações ocorridas no ambiente (Washington, 1984; Buss et al., 2004) e utilizar as informações assim obtidas num programa de controle de qualidade do meio (Silveira et al., 2005).

Qualquer estresse imposto a um ecossistema aquático manifesta seu impacto nos organismos que vivem naquele ecossistema (Loeb, 1994). As alterações físicas ou as causadas pela presença de substâncias nocivas no meio aquático podem produzir uma série de efeitos nos organismos aquáticos, dentre os quais os mais comuns são: mudanças na composição de espécies, no desenvolvimento, no metabolismo dos organismos e deformações morfológicas. Como todos esses efeitos são produzidos por mudança na qualidade do meio aquático, podem ser incorporados aos métodos biológicos de monitoramento para fornecer informações sobre ampla gama de assuntos e problemas relacionados à qualidade da água (Friedrich et al., 1996).

O biomonitoramento apresenta várias vantagens em relação aos métodos físicos e químicos (Hellawell, 1989). Enquanto dados físicos e químicos fornecem um indicador pontual das condições do ecossistema, mostrando apenas o momento da coleta, os dados biológicos fornecem um indicador cumulativo das condições ao longo do tempo (Metcalfe, 1989) e as comunidades biológicas refletem a integridade biológica geral, incluindo a física e química (Karr e Chu, 1999). Isto porque os organismos integram efeitos do seu meio por todo o seu ciclo de vida, possibilitando a avaliação do estado tanto passado quanto atual do meio aquático, permitindo que a avaliação biológica seja utilizada com bastante eficiência na detecção tanto de ondas tóxicas intermitentes agudas quanto de lançamentos crônicos contínuos (De Pauw e Vanhooren, 1983). Se as coletas de água forem realizadas longe da fonte poluente, as medições químicas não serão capazes de detectar perturbações sutis sobre o ecossistema, porém as metodologias biológicas são bastante eficazes na avaliação de poluição não pontual (difusa), tendo, portanto, grande valor para avaliações em escala regional (Pratt e Coler, 1976). Ainda, métodos físicos e químicos requerem testes específicos para a pesquisa de cada tipo de poluente, mas os organismos reagirão a uma vasta gama de compostos tóxicos que podem estar presentes nos sistemas naturais (Rosenberg e Resh, 1993). Assim, o 
monitoramento biológico é um elemento essencial necessário para avaliar a saúde ambiental do ecossistema aquático, sendo que os organismos podem ser usados em medidas quantitativas, funcionando como diagnóstico para determiná-la. O biomonitoramente rotineiro pode ser relativamente barato, especialmente quando comparado ao custo da avaliação de poluentes tóxicos, com testes químicos ou de toxicidade (Karr e Chu, 1999). Além disso, fornecem ao público expressões mais familiares de saúde ecológica que aquelas fornecidas pelos resultados de tais testes (Gibson, 1996).

Para ser considerado um bom indicador biológico, o organismo deve apresentar as seguintes características: ser de fácil coleta e identificação mesmo por não especialistas; ser abundante e apresentar distribuição geográfica ampla, apresentando a mesma sensibilidade em todos os pontos de distribuição; apresentar baixa variabilidade genética e ecológica; apresentar baixa mobilidade e ciclo de vida longo; ter características ecológicas bem conhecidas; e ter possibilidade de uso em estudos de laboratório (Johnson et al., 1993, Junqueira e Campos, 1998).

Muitos programas de avaliação da qualidade da água utilizam macroinvertebrados bentônicos (Hering et al., 2004), por serem atrativos para o biomonitoramento, pois além de apresentarem as características acima, são onipresentes e apresentam grande diversidade de formas e habitats, o que oferece um grande espectro de respostas aos estresses ambientais (Friedrich et al., 1996; Rosenberg e Resh, 1993). Seu modo de vida basicamente sedentário permite análise espacial dos poluentes ou distúrbios. Como vivem em íntimo contato com os sedimentos, seguramente entram em contato com muitos poluentes. Deste modo, a carga de toxinas acumula-se neles em níveis facilmente detectáveis (Reice e Wohlenberg, 1993). Além disso, apresentam ciclos de vida relativamente longos, se comparados com outros grupos, o que permite a elucidação de mudanças temporais causadas pela perturbação (Friedrich et al., 1996). Ainda, as amostragens qualitativas e análises das amostras podem ser feitas usando equipamentos baratos e simples; a taxonomia dos grupos é bem conhecida e há boa disponibilidade de chaves de identificação. Além disso, muitos métodos de análise de dados, incluindo índices bióticos e de diversidade têm sido desenvolvidos e são amplamente utilizados no biomonitoramento da comunidade e as respostas dos diferentes táxons aos diferentes tipos de poluição já são bem determinadas (Rosenberg e Resh, 1993).

Apesar do emprego dos macroinvertebrados bentônicos ainda ser restrito no Brasil (Junqueira et al., 2000), desde a década passada, instituições de pesquisa e agências de proteção ambiental brasileiras têm desenvolvido estudos baseados no uso das comunidades bentônicas para avaliar a qualidade das condições ambientais dos rios (Baptista et al., 2007). 


\section{A Reserva da Biosfera do Cinturão Verde da Cidade de São Paulo}

A Região Metropolitana de São Paulo concentra mais de $10 \%$ da população brasileira em menos de um milésimo do território nacional, com baixíssimos índices de área verde por habitante. Essa foi uma das razões que motivaram a declaração do Cinturão Verde da Cidade de São Paulo como Reserva da Biosfera.

As Reservas de Biosfera, constituídas pela UNESCO em determinadas áreas do globo, já somam 360 em todo o mundo e são consideradas de relevante valor ambiental e humano. Têm como objetivo a gestão correta de seus ambientes naturais e modificados e a busca do desenvolvimento sustentável, através da pesquisa científica, da conservação da biodiversidade, da promoção social e da integração dos diversos agentes atuando em seu espaço. Porém, devido à sua localização, a Reserva da Biosfera do Cinturão Verde da Cidade de São Paulo, está sujeita aos impactos ambientais causados pela urbanização da região e a ameaças, tais como: especulação imobiliária; o desenvolvimento de grandes obras de infraestrutura (ex. Rodoanel Mário Covas); legislação inadequada e descumprida; regulamentação fundiária precária; extração ilegal de recursos florestais; mineração; deposição de lixo urbano; poluição atmosférica; depredação do ambiente por indivíduos não conscientes (Instituto Florestal, 2007).

$\mathrm{Na}$ área abrangida pelo Cinturão Verde situam-se vários parques, reservas ambientais, áreas de proteção ambiental e áreas naturais tombadas, dentre eles, o Parque Estadual do Jaraguá que, além de abrigar um dos últimos remanescentes da Mata Atlântica na cidade de São Paulo e oito microbacias, é uma importante opção de lazer para a população mais carente do entorno (Instituto Florestal, 2007). Assim, nesta unidade de conservação, ao impacto causado pela urbanização da cidade soma-se aquele causado pela visitação pública.

No município de São Paulo, as áreas verdes atraem cada vez mais pessoas interessadas na recreação ao ar livre. Uma vez que esse tipo de atividade causa impacto nos recursos naturais do local visitado, espera-se que corpos d'água presentes em parques públicos exibam algum sinal desse impacto, que seja proporcional à facilidade de acesso e procura para visitação e, ainda, que seja passível de avaliação pela análise de invertebrados bentônicos. Assim, o objetivo desse trabalho é primeiramente obter informações sobre a fauna de macroinvertebrados bentônicos presentes em poções e corredeiras e posteriormente utilizá-la para a avaliação da ocorrência de impacto sobre nascentes localizadas no Parque Estadual do Jaraguá. 


\section{REFERÊNCIAS BIBLIOGRÁFICAS}

ABRAMOWICZ, J.N. Impetiled waters, impouverished the future: the decline of freshwater ecosystems. Paper 128. Washington, DC: Worldwatch Institute, 1996.

BAPTISTA, D.F. et al. A multimetric index based on benthic macroinvertebrates for evaluation of Atlantic Forest streams at Rio de Janeiro State, Brazil. Hydrobiologia, v. 575, p. 83 - 94, 2007.

BOLUND, P.; HUNHAMMAR, S. Ecosystem services in urban areas. Ecological Economics, v. 29 , p. 293 - 301, 1999.

BOON, P.J. Essential elements in the case of river conservation. In: BOON, P.J.; CALOW, P.; PETTS; G.E. (Orgs.) River conservation and management. New York : Wiley, 1996. cap. 2. p $11-34$.

BRANDIMARTE, A.L. Impactos limnológicos da construção do reservatório de aproveitamento múltiplo do rio Mogi-Guaçu (SP, Brasil). 97 p. Tese (Doutorado em Ecologia) - Instituto de Biociências da Universidade de São Paulo, 1997.

BUSS. D.F.; BAPTISTA, D.F., NESSIMIAN, J.L.; EGLER, M.. Substrate specificity, environmental degradation and disturbance structuring macroinvertebrate assemblages in neotropical streams. Hydrobiologia, v. 518, p. 179 - 188, 2004.

CUMMINS. K.W. Trophic relations of aquatic insects. Ann. Ver. Entomol., v. 18, p.183 - 206, 1973.

DE PAUW, N. \& VANHOOREN, G.,. Method for biological quality assessment of watercourses in Belgium. Hydrobiologia, v.100, p.53 - 168, 1983.

FRIEDRICH, G. et al. The use of biological material. In: CHAPMAN, D (Orgs). Water quality assessments : a guide to use of biota, sedimentd and water in environment monitoring.

Cambridge: University Press, 1996. cap. 5, p 175 - 242.

GIBSON, G.R. et al. Biological criteria:Technical guidance for streams and small rivers (revised edition). U.S. Environmental Protection Agency, Office of Water, Washington, D. C. EPA 822-B-96-001. 1996

HELLAWELL, J.M. Biological Indicators of Freshwater Pollution and Environmental

Management. Pollution Monitoring Series. New York: Elsevier Applied Science, 1989. 546p.

HERING D. et al. Assessing streams in Germany with benthic invertebrates: selection of candidate metrics. Limnologica, v. 34, p. 398 - 415, 2004.

ILIOPOULOU-GEORGUDAKI, J. et al. An application of different bioindicators for assessing water quality: a case study in the rivers Alfeios and Pineios (Peloponnisos, Greece) Ecological Indicators, v. 2 p. 345 - 360, 2003. 
INSTITUTO FLORESTAL. 2007. Unidades do Instituto Florestal. São Paulo, Instituto Florestal da Secretaria de Estado do Meio Ambiente. Disponível em:

http://www.iflorestal.sp.gov.br/unidades_conservacao/informacoes.asp?cod=13. Acesso em: 20/01/2007.

JOHNSON, R. K.; WIEDERHOLM, T.; ROSENBERG, D. M. Freshwater biomonitoring using individual organisms, populations, and species assemblages of benthic macroinvertebrates. In: ROSENBERG, D.M.; RESH, V.H. (Orgs.) Freshwater biomonitoring and benthic macroinvertebrates. New York: Chapman e Hall, 1993. cap. 4. p. 40 - 158.

JUNQUEIRA, V.M.; CAMPOS, S.C.M. Adaptation of the "BMWP" method for water quality evaluation to Rio das Velhas watershed (Minas Gerais, Brazil). Acta Limnologica Brasiliensia, v. 10 , p. $125-135.1998$.

JUNQUEIRA, M.V. et al. Biomonitoramento da qualidade das águas da bacia do alto Rio das Velhas (MG/Brasil) através de macroinvertebrados. Acta Limnologica Brasiliencia. v. 12, p. 73 $-87,2000$.

KARR, J.R.; CHU, E.W. Restoring life in running waters: better biological monitoring. Covelo: Island Press. 1999. 206p.

LAKE, P.S. Conservation. In: W.D. Williams (Org.) An ecological basis for water resource management. Canberra: Australian University Press, 1980. cap. 5, p. 163 - 173.

LOEB, S.L. An ecological context for biological monitoring. In LOEB, S.L.; SPACIE, A. (Orgs.). Biological monotoring aquatic system. Boca Roton: Lewis Publishers, 1994. cap. 1, p 3 -7 .

LUNNEY, D., PRESSEY, B., ARCHER, M., HAND, S., GODTHELP, H., CURTIN, A. Integrating ecology and economics. Ecological Economics, v. 23, p. 135 143, 1997.

LYNCH, J.A.; RISHEL, G.B.; CORBETT, E.S. Thermal alteration of streams draining clearcut watersheds: quantification and biologica implications. Hydrobiologia v. 111, p. 160 - 169, 1984.

METCALFE, J. L. Biological water quality assessment of running waters based on macroinvertebrates communities: history and present status in Europe. Environmental Pollution, v. 60 , p. $101-139,1989$.

MOKAYA, S.K.; MATHOOKO, M.L. Influence of anthropogenic activities on water quality of a tropical stream ecosystem. African Journal of Ecology, v. 42, p. 281 - 288. 2004.

MOYLE, P.B.; RANDALL, P.J. Evaluation of the biotic integrity of watersheds in the Sierra Nevada, California. Conservation Biology, v. 12, p. 1318 - 1326, 1998.

MEYER, J.L; PAUL, M.J.; TAULBEE, W. K. Stream ecosystem function in urbanizing landscapes. Journal of North American Benthological Society, v.24, p. 602 - 612, 2005.

PALMER, M. et al. 2004. Ecology for a crowded planet. Science, v. 304, p. 1251 - 1252, 2004. 
PAUL, M.J.; MEYER, J.L. Streams in the urban landscape. Annual Review of Ecology and Systematics, v.32, p. 333 - 365, 2001.

PETROSILLO, I. et al. N. Indicating fragility of socio-ecological tourism-based systems. Ecological Indicators, v.6, p. 104 - 113, 2006.

PRATT, J. M.; COLER, R. A. A procedure for the routine biological evaluation of urban runoff in small rivers. Water Research, v.10, p.1019 - 1025, 1976.

RANSON, J.D.; DORIS, T.C. Analysis of a benthic community strutucture in a reservoire by use of diversity indices. Am. Midl. Nat., v. 87, p. 434 - 447. 1972

REBOUÇAS, A.C. Água doce no Mundo e no Brasil. In: Rebouças, A.C.; BRAGA, B.; TUNDISI, J.G. Águas Doces no Brasil: Capital Ecológico, Uso e Conservação. Instituto de Estudos Avançados da USP. São Paulo: Academia Brasileira de Ciências, 1999. cap. 1, p. 01 - 37.

REICE, S. R.; WOHLENBERG, M. Monitoring freshwater benthic macroinvertebrates and benthic processes: measures for assessment of ecossystem health. In: ROSENBERG, D.M.; RESH, V.H. (Orgs.) Freshwater biomonitoring and benthic macroinvertebrates. New York: Chapman e Hall, 1993. cap 8, p. 287 - 305.

ROSENBERG, D.M.; RESH, V.H. Intruduction to freshwater biomonitoring and benthic macroinvertebrates. In: ROSENBERG, D.M.; RESH, V.H. (Orgs.) Freshwater biomonitoring and benthic macroinvertebrates. New York: Chapman e Hall, 1993. cap. 1. p. 1 - 9.

SAUNDERS D.L.; MEEUWIG, J.J.; VINCENT, A.C.J. Freshwater Protected areas: Strategies for conservation. Conservation Biology, v.16, p. 30 - 41, 2002.

SHIMIZU, G.Y. Represa de Americana: aspectos do bentos litoral. 117 p. Dissertação (Mestrado em Ecologia) - Instituto de Biociências da Universidade de São Paulo, 1978.

SILVEIRA, M. P. et al. Application of biological measures for stream integrity assessment in south-east Brazil. Environmental Monitoring and Assessment, v. 101, p. 117 - 128, 2005.

SKELTON, P.H. et al. Patterns of distribution and conservation status of freshwater fishes in South África. South African Journal of Ichthyology, v. 30, p. 71 - 81, 1995.

TIVY, J.; O’ HARE, G. Human impact on the ecossystem. New York: Longman Inc, 1981. $243 p$.

TUCCI. C.E.M. Água no meio urbano. In: Rebouças, A.C.; BRAGA, B.; TUNDISI, J.G. 1999.

Águas Doces no Brasil: Capital Ecológico, Uso e Conservação. São Paulo: Instituto de Estudos Avançados da USP. Academia Brasileira de Ciências, 1999. cap. 14, p. 475 - 508.

USNPS, 1996. Criteria for Parklands. Disponível em: http://www.nps.gov/legacy/citeria.html. Acesso em: 03/08/2007.

UNESCO. The 2nd. World Water Development Report: "Water, a Shared Responsibility." 2006. Disponível em www.http://unesdoc.unesco.org/images/0014/001444/144409E.pdf. Acesso em 01/03/2007. 
WALSH, C.J. et al. The urban stream syndrome: current knowledge and the search for a cure. Journal of the North American Benthological Society, v. 24, p. 706 - 723, 2005.

WASHINGTON, H. G. Diversity, biotic and similarity indices: a review with special reference to aquatic ecosystems. Water Research, v.18, p.653 - 694, 1984. 


\section{CAPÍTULO I}

COMUNIDADE DE MACROINVERTEBRADOS BENTÔNICOS EM POÇÕES E CORREDEIRAS DE QUATRO NASCENTES DO PARQUE ESTADUAL DO JARAGUÁ, SÃO PAULO, SP. 


\begin{abstract}
Benthic macroinvertebrate community in pools and riffles of four streams of Jaraguá State Park, São Paulo, SP. The purpose of this work was to compare the benthic macroinvertebrate community structure in pools and riffles habitats of four first order streams of Jaraguá State Park, which integrates the Core Zone of the Biosphere Reserve of São Paulo Green Belt. The benthic macroinvertebrates were sampled in May 2004. In each stream it was delimited a segment of 40 meters, where five pools and five riffles were choosen, totaling 40 sampling unities collected with a Surber sampler $\left(0,04 \mathrm{~m}^{2}, 500 \mu \mathrm{m}\right.$ mesh size $)$. There were calculated richness, dominance, Shannon-Wiener diversity and relative abundance of Orders and Families present in both habitats. The comparison of the metrics was realized by non-parametric statistical test of Mann-Whitney. In order to compare the composition and families density between pools and riffles a DCA was carried out. There were collected 6014 benthic macroinvertebrates, distributed among 33 taxa. The communities found in pools revealed higher values of density, richness and dominance and lower diversity than those found in riffles. The families Cyclopidae, Talitridae, Leptoceridade, Psychodidae and Stratiomyidae were exclusive of pools, while Perlidae e Simuliidae were found only in riffles. In both habitats, Chironomidae relative abundance was high. The richness of detritivore families was higher in pools.
\end{abstract}

Key words: benthic macroinvertebrates - pools - riffles.

\title{
RESUMO
}

Comunidade de macroinvertebrados bentônicos em poções e corredeiras de quatro nascentes do Parque Estadual do Jaraguá, São Paulo, SP. O presente trabalho objetivou a comparação da estrutura da comunidade de macroinvertebrados bentônicos nos habitats de poção e corredeira de quatro nascentes do Parque Estadual do Jaraguá, que integra a Zona Núcleo da Reserva de Biosfera do Cinturão Verde da Cidade de São Paulo. As coletas foram realizadas em campanha única no mês de maio de 2004. Em cada nascente, foi delimitado um trecho de 40 metros, no qual foram escolhidos 5 poções e 5 corredeiras, totalizando 40 unidades amostrais coletadas com auxílio de um Surber (área de $0,04 \mathrm{~m}^{2}$, e malha de $500 \mu \mathrm{m}$ ). Foram calculados os valores de riqueza, dominância, diversidade e abundância relativa das ordens e famílias presentes nos dois habitats. A comparação dos valores das métricas foi realizada pelo teste não paramétrico U de Mann-Whitney. De modo a comparar a composição e a densidade de famílias entre corredeiras e poções, foi realizada uma DCA. Foram coletados 6014 invertebrados bentônicos, distribuídos em 33 táxons. As comunidades encontradas nos poções apresentaram maior densidade, riqueza e dominância e menor diversidade que as encontradas em corredeiras. As famílias Cyclopidae, Talitridae, Leptoceridae, Psychodidae e Stratiomyidae foram exclusivas de poções, enquanto Perlidae e Simuliidae foram exclusivos de corredeiras. Em ambos os habitats, a abundância relativa de Chironomidae foi elevada. A riqueza de famílias detritívoras foi superior em poções.

Palavras-chave: macroinvertebrados bentônicos - poções - corredeiras. 


\section{INTRODUÇÃO}

Os rios tropicais suportam uma biota rica, mas quase desconhecida (Tomanova et al., 2006). No Brasil, por exemplo, e especialmente na região da Floresta Atlântica, falta conhecimento básico sobre a taxonomia e sobre os padrões de distribuição dos macroinvertebrados bentônicos (Silveira et al., 2006), sendo necessárias pesquisas básicas sobre o tema (Tomanova et al., 2006).

A questão da estrutura da comunidade bentônica é importante, pois auxilia nas avaliações de qualidade ambiental (Rosenberg e Resh, 1993), na conservação da biodiversidade (New, 1995) e em projetos envolvendo manejo e recuperação ambientais (O’Neill, 1999 apud Roque, 2003). É um assunto bastante complexo e muitos estudos têm sido dedicados ao tema, envolvendo o papel de diversas variáveis na estruturação de comunidades, tais como: estabilidade do substrato (Death e Winterbourn, 1995), tipo de substrato (Douglas e Lake, 1994), sasonalidade (Flecker e Feifarek, 1994, Hose et al., 2005), interações biológicas (Peckarsky, 1979; Helms e Creed, 2005), distribuição de material orgânico (Nakajima et al., 2006), dentre outras.

A distribuição de invertebrados bentônicos é controlada pela produtividade e pelas interações bióticas (Townsend, 1989), tais como competição e predação (Mackay, 1992) e pela qualidade da água (Hellawell, 1989). A heterogeneidade do habitat também é um fator importante (Townsend, 1989), sendo que em ambientes heterogêneos há alta diversidade de nichos ecológicos, que influenciam positivamente a diversidade bentônica (Callisto et al., 2004), possibilitando o desenvolvimento de comunidades diferenciadas, na medida das especializações dos organismos a cada um desses habitats (Hynes, 1970; Allan, 1995; Wetzel 2001).

Nos ambientes lóticos, a velocidade da água é considerada o principal fator abiótico de interesse biológico (Hynes, 1970), pois modela o leito do rio, determinando uma heterogeneidade ambiental observável mesmo em trechos curtos (Uieda e Gajardo, 1996). Em regiões de águas lentas (poções), ocorre acúmulo de folhas e outros detritos sobre sedimento mais fino (Allan, 1995). Em regiões de águas rápidas (corredeiras), o leito é constituído de substrato mais grosseiro (Egglishaw, 1957; Allan, 1995), podendo conter pedras de vários diâmetros, entre as quais também ficam retidos detritos vegetais (Uieda e Gajardo, 1996). A quantidade de detritos é de grande importância para a determinação da 
abundância de macroinvertebrados bentônicos (Barber e Kevern, 1973), pois além de servirem como substrato alimentar (Richardson, 1992), especialmente para os fragmentadores (Petersen e Cummins, 1974; Wallace et al., 1982), também proporcionam abrigo contra a correnteza, mais espaço para colonização, locais para fixação e refúgio contra predadores (Egglishaw, 1964; Reice 1980). Em pequenos rios de regiões florestadas, por exemplo, folhas oriundas da vegetação ripária fornecem a maior base trófica para as cadeias alimentares (Minshall e Minshall, 1977).

Com base no exposto, pode-se aventar a hipótese de que comunidades com densidades maiores, embora com menor riqueza e diversidade serão encontradas em poção, devido ao maior acúmulo de matéria orgânica e o subseqüente desenvolvimento de táxons representados, em sua grande maioria, por indivíduos detritívoros. Por outro lado, em corredeiras, esperam-se comunidades com densidades menores, porém com riqueza e diversidade mais altas.

Este trabalho foi elaborado com o objetivo de comparar a estrutura das comunidades encontradas em habitats de poção e corredeira de nascentes localizadas no Parque Estadual do Jaraguá e seu limite, na cidade de São Paulo (SP). A escolha deste local de trabalho justificase pelo fato do Parque constituir uma importante área verde para a cidade de São Paulo, pois além de proporcionar opções de lazer para a população local, ainda faz parte da Reserva de Biosfera do Cinturão Verde da Cidade de São Paulo (Instituto Florestal, 2007).

\section{MATERIAL E MÉTODOS}

\section{Local de trabalho}

O trabalho foi desenvolvido no Parque Estadual do Jaraguá, situado a $23^{\circ} 24^{\prime}$ S e 4544'W, na cidade de São Paulo (SP). Sua área equivale a 491,98 ha. e sua altitude média corresponde a $900 \mathrm{~m}$. Seu clima caracteriza-se por apresentar duas estações climáticas bem definidas: verão quente e úmido e inverno frio e seco, com temperatura média anual de $20^{\circ} \mathrm{C}$. A precipitação pluviométrica média anual é de aproximadamente $1600 \mathrm{~mm}$, estando entre 30 e $60 \mathrm{~mm}$ no mês mais seco,. Localiza-se em área de relevo montanhoso em solo de complexo cristalino, formado por rochas ferromagnesianas, granito e gnaisses, filitos e micaxistos, quartzitos e calcário. Sua vegetação constitui-se de floresta ombrófila densa e floresta estacional semidecidual em diferentes estados sucessionais. Criado em 1961, e tombado como 
patrimônio da humanidade pela UNESCO em 1994, o Parque integra atualmente a Zona Núcleo da Reserva de Biosfera do Cinturão Verde da Cidade de São Paulo (Instituto Florestal, 2007).

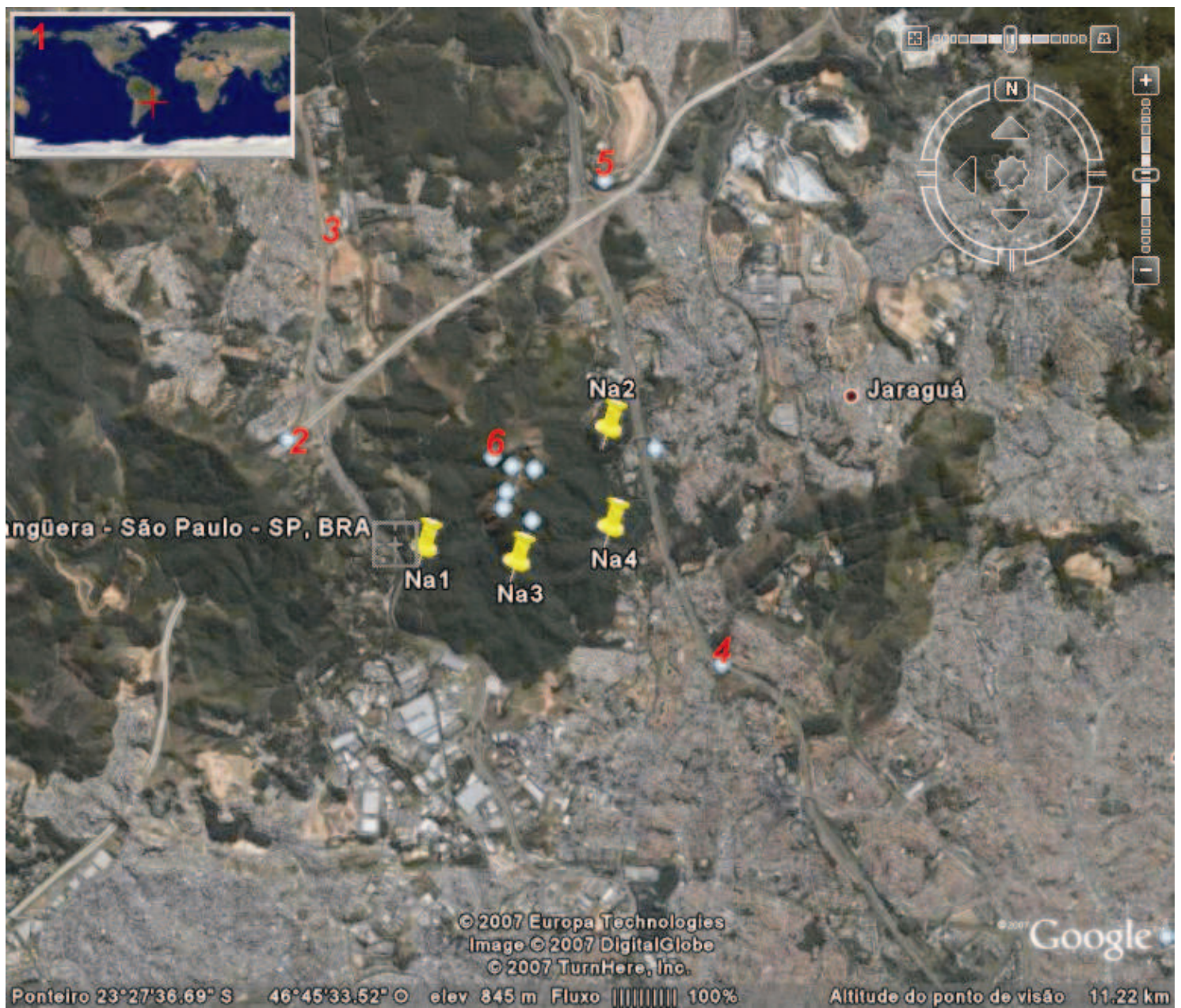

Figura 1 - Imagem de satélite do Parque Estadual do Jaraguá (São Paulo, SP) a localização dos pontos de amostragem. (Fonte: Google Earth). 1: Detalhe da localização geral do Parque; 2: Rodoanel Mario Covas; 3: Rodovia Anhanguera; 4: Rodovia dos Bandeirantes; 5: Aterro Sanitário Bandeirantes; 6: Pico do Jaraguá.

O entorno do Parque caracteriza-se por uma grande variedade de usos da terra, dentre os quais se destacam áreas com atividades agrícolas e pecuária doméstica, áreas industriais, bairros com início de processo de loteamento e instalação de infra-estrutura básica (Sol Nascente e Chica Luiza), áreas ocupadas por movimentos sociais organizados (Sem Terra), bairros em etapas mais avançadas de urbanização (Vila Sulina e São Domingos) e área indígena (Carneiro, 2002; PROJETO BIOTA-JARAGUÁ, 1999). Além disso, outras ameaças à área são a caça e a extração ilegal de recursos florestais, mineração, poluição atmosférica, 
deposição de lixo urbano e depredação do ambiente por indivíduos não conscientes (Instituto Florestal, 2007) Apesar disso, até o momento, poucos estudos relacionados à sua biota, especialmente de água doce, foram realizados.

\section{Coleta e análise de dados}

A amostragem foi realizada em três nascentes ( $\mathrm{Na} 1, \mathrm{Na} 2, \mathrm{Na} 3)$ localizadas no interior do Parque e em uma (Na4) localizada a aproximadamente 70 metros do limite externo do mesmo (Tab. I).

O critério de escolha das nascentes baseou-se na semelhança do substrato e na presença de mata nas margens. O substrato das corredeiras era composto de frações granulométricas compreendendo areia, cascalhos e pedras, enquanto que nos poções, além de areia, havia grande acúmulo de detritos vegetais de origem alóctone. A localização dos pontos e profundidade média dos habitats amostrados estão apresentadas na Tabela I.

De todas as nascentes, a Na3 é a de mais difícil acesso, seguida pela Na1. A Na2 localiza-se em área de acesso muito fácil, enquanto a $\mathrm{Na} 4$, localiza-se fora do Parque, e próxima a residências, embora esparsas.

As coletas foram realizadas em campanha única durante o mês de maio de 2004. Essa época foi escolhida por representar um período intermediário entre os meses mais chuvosos e mais secos do ano. Desta forma, evitou-se amostrar em períodos de estresse para a fauna, pois na época seca o volume de água nas nascentes diminui muito. Por outro lado, na época chuvosa, o grande volume de água pode deslocar os organismos do substrato.

Tabela I - Localização das nascentes, profundidade média dos habitats amostrados e indícios de impacto antropogênico (Parque Estadual do Jaraguá, São Paulo, SP).

\begin{tabular}{|c|c|c|c|c|}
\hline \multirow[b]{2}{*}{ Ponto } & \multirow[b]{2}{*}{ Latitude } & \multirow[b]{2}{*}{ Longitude } & \multicolumn{2}{|c|}{ Profundidade média (m) } \\
\hline & & & Poções & Corredeiras \\
\hline $\mathrm{Na} 1$ & $23^{\circ} 27^{\prime} 57.6^{\prime \prime} \mathrm{S}$ & $46^{\circ} 46^{\prime} 44.6^{\prime \prime} \mathrm{W}$ & 0,08 & 0,04 \\
\hline $\mathrm{Na} 2$ & $23^{\circ} 27^{\prime} 17.8^{\prime \prime} \mathrm{S}$ & $46^{\circ} 45^{\prime} 29.9^{\prime \prime} \mathrm{W}$ & 0,15 & 0,06 \\
\hline $\mathrm{Na} 3$ & $23^{\circ} 28^{\prime} 01.8^{\prime \prime} \mathrm{S}$ & $46^{\circ} 46^{\prime} 03.0^{\prime \prime} \mathrm{W}$ & 0,06 & 0,04 \\
\hline $\mathrm{Na} 4$ & $23^{\circ} 27^{\prime} 50.5^{\prime \prime} \mathrm{S}$ & $46^{\circ} 45^{\prime \prime 29.1 ” W}$ & 0,11 & 0,05 \\
\hline
\end{tabular}


Em cada nascente foi delimitado um trecho de 40 metros no qual foram amostrados 5 poções e 5 corredeiras. Em cada habitat, retirou-se uma unidade amostral com auxílio de um delimitador Surber com malha de $500 \mu \mathrm{m}$ e área de $0,04 \mathrm{~m}^{2}$. Após posicionar o amostrador sobre o substrato, este era agitado de forma padronizada durante um minuto. No caso dos poções, produziu-se uma correnteza artificial, forçando a passagem do material pela malha do amostrador. Em laboratório, as amostras foram submetidas à flutuação com solução saturada de $\mathrm{NaCl}$ (Brandimarte e Anaya, 1998) e selecionadas em rede com abertura de malha de 500 $\mu \mathrm{m}$. O material retido foi preservado em formalina $4 \%$ e corado com floxina-B, de modo a facilitar a triagem dos invertebrados.

Os organismos foram identificados sempre que possível até o nível taxonômico de família usando-se as chaves taxonômicas apresentadas em: Borror e Delong (1988), Pennak (1989), Merritt e Cummins (1996), Wiggins (1998), Costa et al. (2006).

Os táxons encontrados foram classificados segundo o hábito alimentar, de acordo com Merritt e Cummins (1996), em detritívoros (D), herbívoros (H), predadores (P) e múltiplas opções (M), esta última categoria aplicada aos casos em que não foi possível associar uma família a um único hábito alimentar.

Calculou-se a densidade total de indivíduos (ind. $\mathrm{m}^{-2}$ ); a soma das densidades de Ephemeroptera, Plecoptera e Trichoptera (EPT) (ind.m ${ }^{-2}$ ); a abundância relativa de cada táxon, calculada pela razão entre o número de indivíduos de uma família (ni) e o total de indivíduos $(\mathrm{N})$ presentes na amostra, multiplicada por 100; a riqueza de famílias, como a simples somatória das mesmas; o índice de dominância, como o maior valor da razão ni/ $\mathrm{N}$; a diversidade de famílias, através da utilização do Índice de Shannon-Wiener (Pielou, 1966); e a riqueza de famílias apresentando cada um dos hábitos alimentares acima mencionados.

De forma a comparar os valores de riqueza, dominância, diversidade, densidade e abundância relativa totais de cada uma das ordens e das famílias presentes nos dois habitats foi utilizado o teste não paramétrico U de Mann-Whitney (Zar, 1996).

Com o objetivo de explorar os padrões de distribuição e abundância das comunidades e suas relações com os dois tipos de habitats amostrados, foi realizada uma análise de ordenação do tipo DCA (Análise de Correspondência "Detrending”) (Hill e Gausch, 1980). A análise foi efetuada a partir de uma matriz contendo dados de densidade dos táxons de macroinvertebrados bentônicos e construída com 40 pontos de amostragem e 33 táxons. A matriz original foi padronizada por "ranging" (Sneath e Sokal, 1973), segundo a fórmula abaixo: 
$\mathrm{y}-\mathrm{y} \min / \mathrm{y}_{\max }-\mathrm{y}_{\min }$, onde

y: número de organismos do mesmo táxon no ponto amostrado;

$\mathrm{y}_{\min }$ : número mínimo de organismos do mesmo táxon em todos os pontos amostrados;

$\mathrm{y}_{\max }$ : número máximo de organismos do mesmo táxon em todos os pontos amostrados.

Os cálculos foram realizados mediante a utilização do pacote estatístico MVSP versão 3.11 (Kovach, 2000).

\section{RESULTADOS}

Foram coletados 6014 organismos, distribuídos em 33 táxons, sendo 31 famílias e 2 ordens (Mollusca e Hydracarina não foram identificados no nível taxonômico de famílias). Desse total, 4748 estavam presentes nas amostras de poções, e 1266 nas de corredeiras. A densidade média total de indivíduos foi, dessa forma, maior em poções (Figura 2), resultado confirmado estatisticamente pelo teste U (Tab. II).

A densidade média de EPT também foi superior em poções (Fig 3), resultado estatisticamente confirmado pelo teste U (Tab II).

Das 31 famílias encontradas, Leptophlebiidae, Perlidae, Hydrobiosidae, Hydropsychidae, Psephenidae, Simuliidae e Paleomonidae apresentaram densidades superiores em corredeiras, resultado estatisticamente confirmado pelo Teste U (Tab II); sendo que Perlidae, Hydrobiosidae e Simuliidae restringiram-se a este habitat. A maioria das famílias apresentou abundância relativa superior em corredeiras, exceto Tubificidae, Calamoceratidae, Hydroptilidae, Leptoceridae, Polycentropodidae, Aeshnidae, Gomphidae, Chironomidae, Psychodidae, Stratiomyidae, Tabanidae, Cyclopidae e Talitridae, o que foi estatisticamente comprovado pelo Teste U (Tab II). As famílias Leptoceridae, Calamoceratidae, Psychodidae, Stratiomyidae, Tabanidae, Cyclopidae e Talitridae estiveram restritas aos poções. 
Tabela II. Comparação entre riqueza, dominância, diversidade de Shannon-Wiener, densidades e abundâncias relativas de poções $(\mathrm{P})$ e corredeiras $(\mathrm{C})$, resultando diferenças significativas, segundo o teste $\mathrm{U}$ de Mann-Whitney $(\alpha=0,05$ e U crítico = 273). (Parque Estadual do Jaraguá, São Paulo, SP).

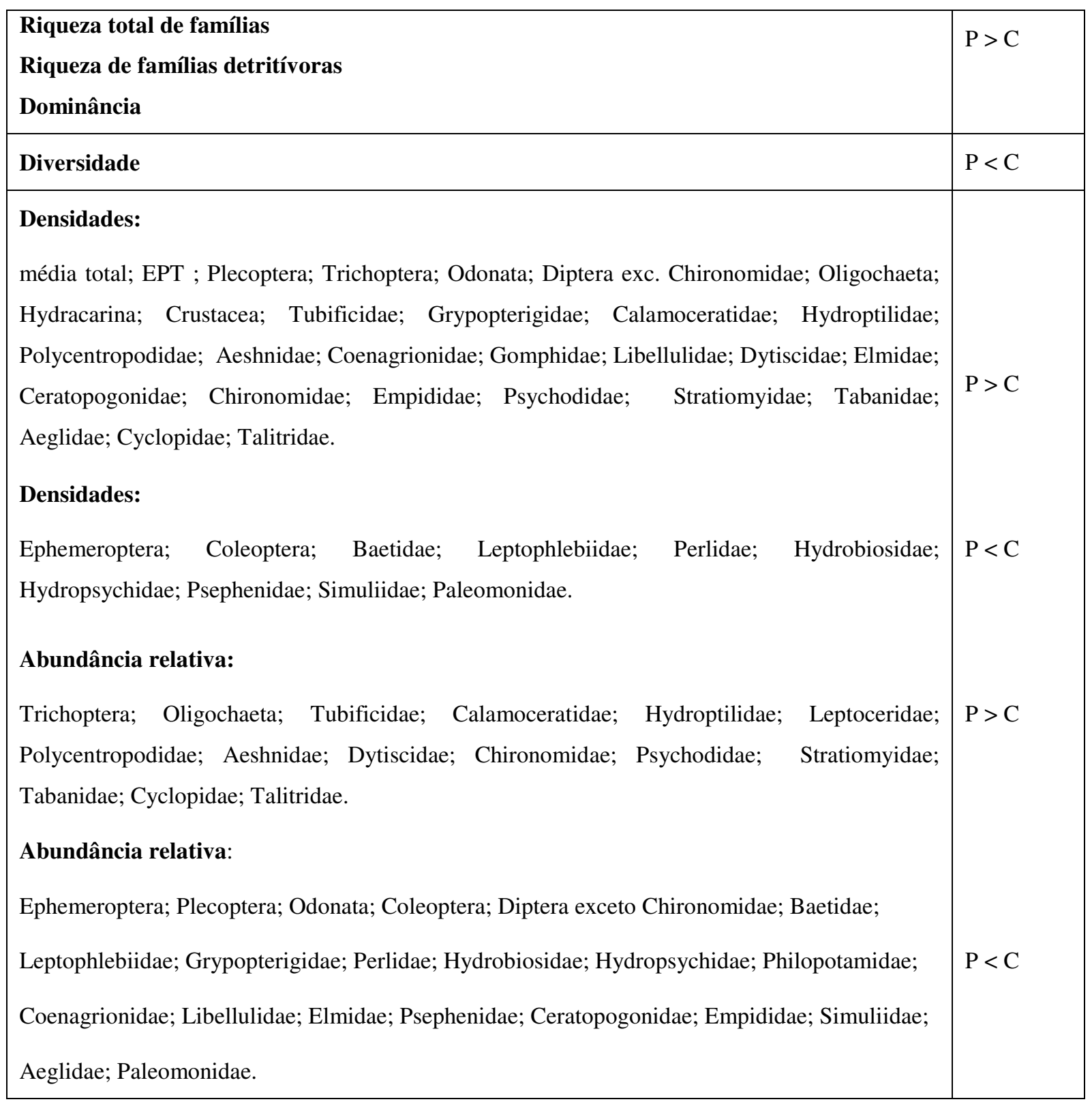




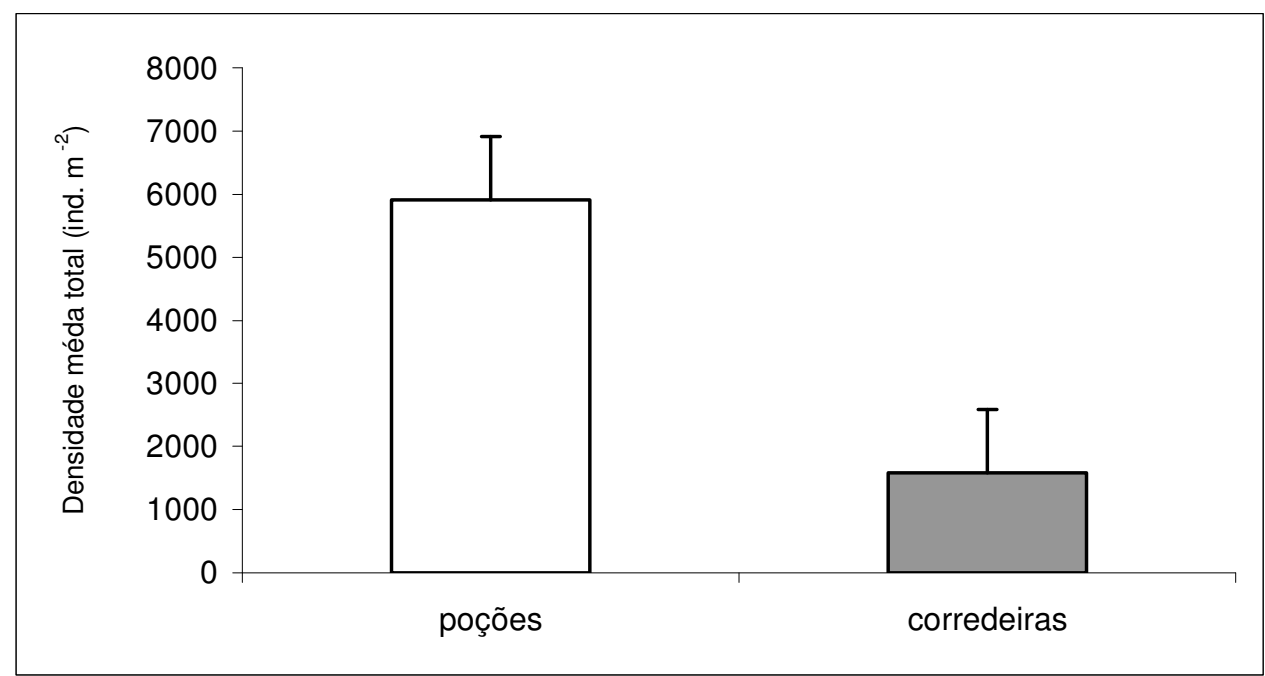

Figura 2 - Densidade média (ind. $\mathrm{m}^{-2}$ ) e desvio padrão de macroinvertebrados bentônicos em poções e corredeiras (Parque Estadual do Jaraguá, São Paulo, SP).

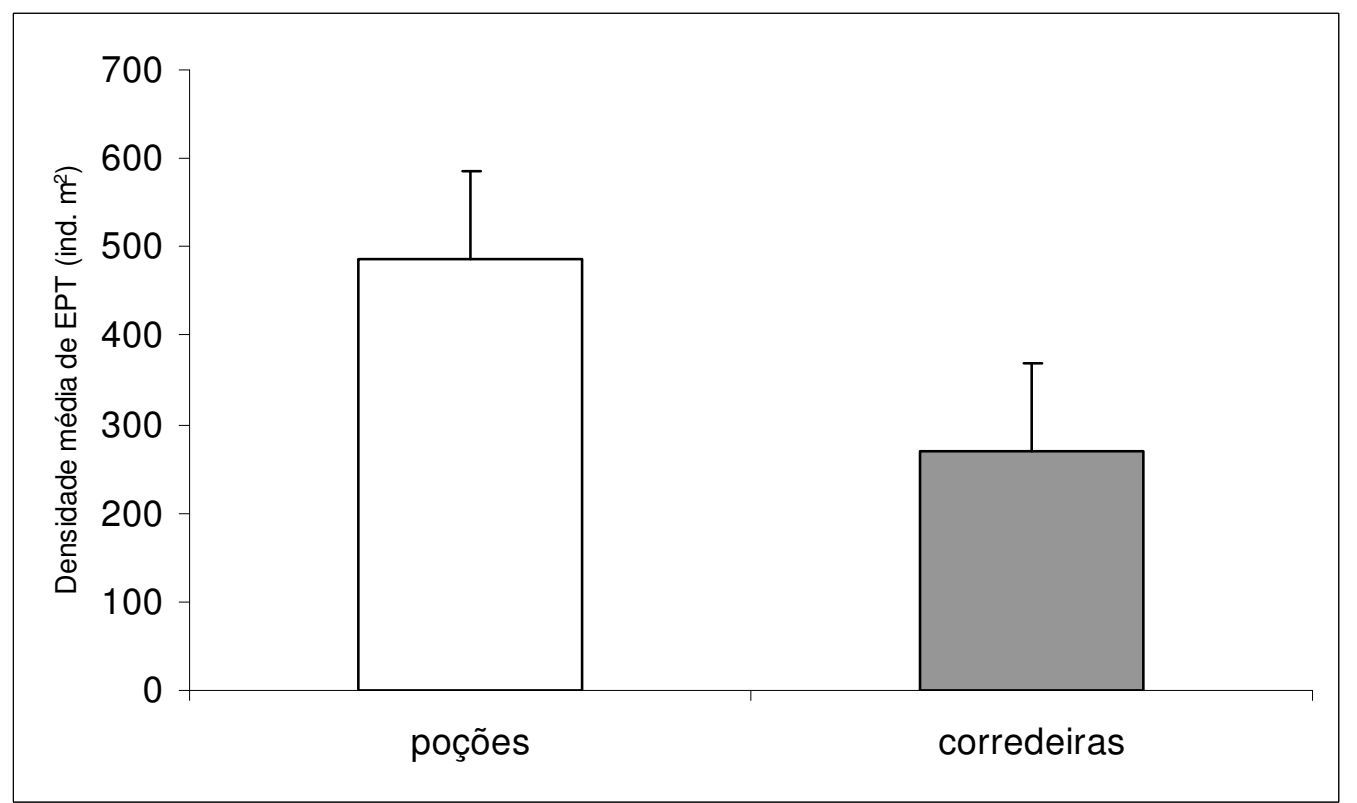

Figura 3 - Densidade média de EPT (ind. $\mathrm{m}^{-2}$ ) e desvio padrão em, São Paulo, SP). poções e corredeiras (Parque Estadual do Jaraguá, São Paulo, SP). 
Tabela III - Densidade média e abundância relativa de táxons de macroinvertebrados bentônicos em poções e corredeiras (Parque Estadual do Jaraguá, São Paulo, SP). A sigla entre parênteses refere-se à utilizada na DCA. (ni - não identificados); H: herbívoro; D: detritívoro; P: predador; M: múltiplos hábitos alimentares.

\begin{tabular}{|c|c|c|c|c|c|}
\hline & \multirow[b]{2}{*}{$\begin{array}{l}\text { Hábito } \\
\text { Alimentar }\end{array}$} & \multicolumn{2}{|c|}{ POÇÕEES } & \multicolumn{2}{|c|}{ CORREDEIRAS } \\
\hline & & $\begin{array}{l}\text { Densidade } \\
\text { média }\end{array}$ & $\begin{array}{l}\text { Abundância } \\
\text { relativa }\end{array}$ & $\begin{array}{l}\text { Densidade } \\
\text { média }\end{array}$ & $\begin{array}{l}\text { Abundância } \\
\text { relativa }\end{array}$ \\
\hline Hydracarina (ni) (hydc) & $\mathrm{P}$ & 62 & 1 & 11 & 1 \\
\hline Bivalvia (ni) (biva) & $\mathrm{H}$ & 59 & 1 & 22 & 1 \\
\hline Tubificidae (tubi) & $\mathrm{D}$ & 141 & 3 & 24 & 2 \\
\hline Cyclopidae (cycl) & M & 17 & 0 & 0 & 0 \\
\hline Talitridae (tali) & $\mathrm{D}$ & 16 & 0 & 0 & 0 \\
\hline Paleomonidae (pale) & $\mathrm{D}$ & 4 & 0 & 14 & 1 \\
\hline Aeglidae (aegl) & $\mathrm{P}$ & 30 & 1 & 6 & 1 \\
\hline Baetidae (baet) & $\mathrm{D}$ & 110 & 2 & 110 & 12 \\
\hline Leptophlebiidae (lepc) & $\mathrm{D}$ & 40 & 1 & 50 & 3 \\
\hline Aeshnidae (aesh) & $\mathrm{P}$ & 17 & 0 & 1 & 0 \\
\hline Coenagrionidae (coen) & $\mathrm{P}$ & 16 & 0 & 11 & 1 \\
\hline Gomphidae (gomp) & $\mathrm{P}$ & 41 & 1 & 7 & 1 \\
\hline Libellulidae (libe) & $\mathrm{P}$ & 70 & 2 & 69 & 4 \\
\hline Grypopterigidae (gryp) & $\mathrm{P}$ & 99 & 2 & 49 & 6 \\
\hline Perlidae (perl) & $\mathrm{P}$ & 0 & 0 & 17 & 2 \\
\hline Calamoceratidae (cala) & $\mathrm{D}$ & 4 & 0 & 0 & 0 \\
\hline Hydrobiosidae (hydb) & $\mathrm{P}$ & 0 & 0 & 4 & 0 \\
\hline Hydropsychidae (hydp) & $\mathrm{D}$ & 1 & 0 & 30 & 1 \\
\hline Hydroptilidae (hydt) & $\mathrm{H}$ & 10 & 0 & 2 & 0 \\
\hline Leptoceridae (lepb) & $\mathrm{D}$ & 210 & 3 & 0 & 0 \\
\hline Philopotamidae (phil) & $\mathrm{D}$ & 1 & 0 & 1 & 0 \\
\hline Polycentropodidae (poly) & $\mathrm{D}$ & 11 & 0 & 5 & 0 \\
\hline Dytiscidae (dyti) & $\mathrm{P}$ & 12 & 0 & 5 & 0 \\
\hline Elmidae (elmi) & $\mathrm{D}$ & 87 & 2 & 45 & 3 \\
\hline Psephenidae (psep) & $\mathrm{H}$ & 6 & 0 & 56 & 8 \\
\hline Ceratopogonidae (cera) & $\mathrm{P}$ & 45 & 1 & 24 & 2 \\
\hline Chironomidae (chir) & M & 4710 & 77 & 900 & 43 \\
\hline Empididae (empi) & $\mathrm{P}$ & 12 & 0 & 9 & 0 \\
\hline Psychodidae (psyc) & $\mathrm{D}$ & 6 & 0 & 0 & 0 \\
\hline Simuliidae (simu) & $\mathrm{D}$ & 0 & 0 & 64 & 5 \\
\hline Stratiomyidae (stra) & $\mathrm{D}$ & 15 & 0 & 0 & 0 \\
\hline Tabanidae (taba) & $\mathrm{P}$ & 6 & 0 & 0 & 0 \\
\hline Tipulidae (tipu) & $\mathrm{D}$ & 72 & 2 & 45 & 3 \\
\hline
\end{tabular}




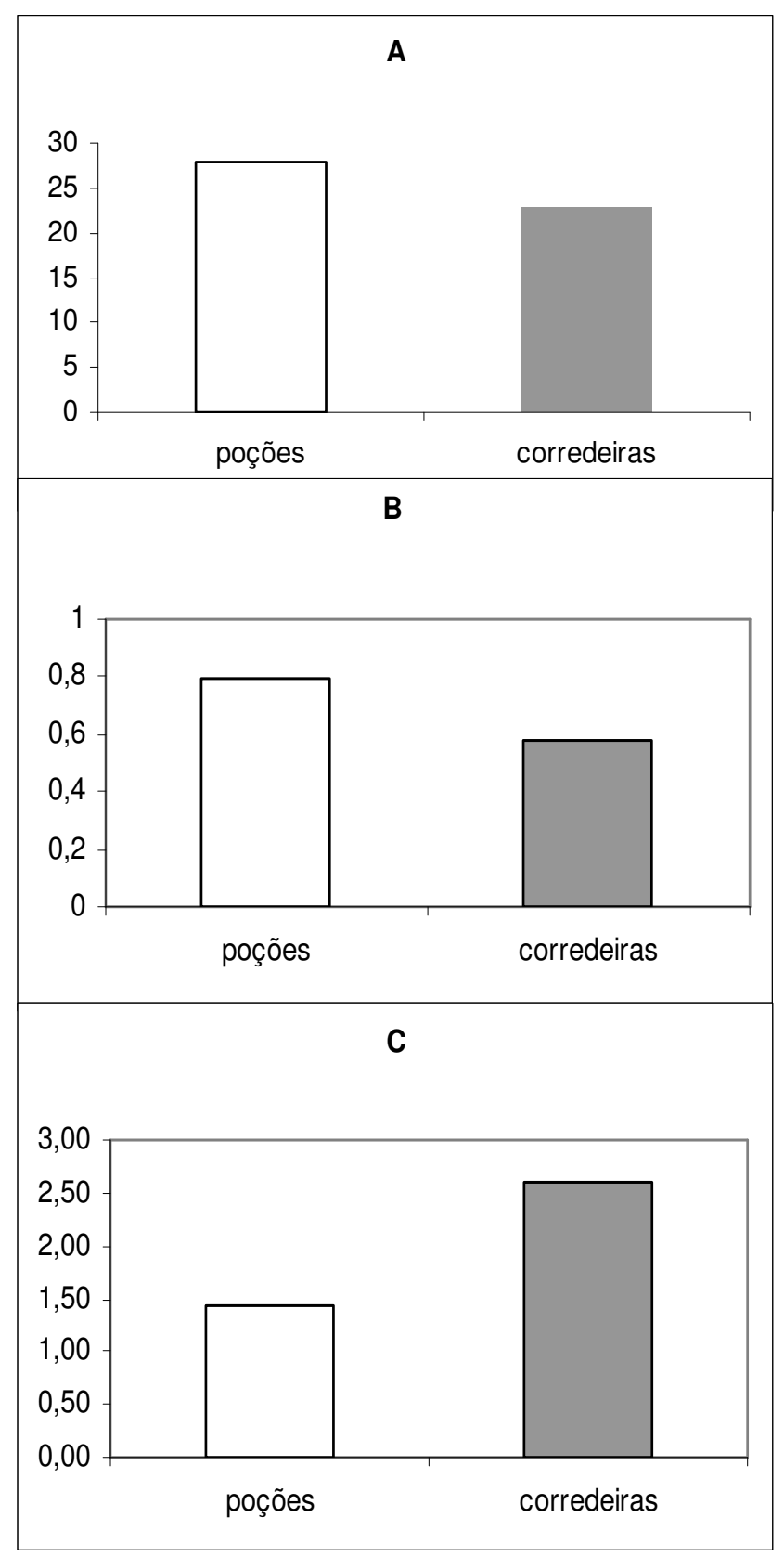

Figura 4 - Valores de riqueza (A), dominância (B) e diversidade (C) de famílias em poções e corredeiras (Parque Estadual do Jaraguá, São Paulo, SP).

A riqueza total de famílias é significativamente maior em poções (Fig. 4; Tab. II). Ainda nos poções, o valor da dominância foi mais elevado (Fig 4; Tab II), devido à alta abundância relativa de Chironomidae (Tab.III), acarretando redução da diversidade nesse habitat (Fig. 4), resultado estatisticamente confirmado pelo teste U (Tab. II). 
A riqueza de famílias detritívoras é superior em poções, resultado estatisticamente confirmado pelo teste $U$ (Tab. II), enquanto que a riqueza de famílias predadoras apresenta tendência a ser superior em corredeiras (Fig 5).

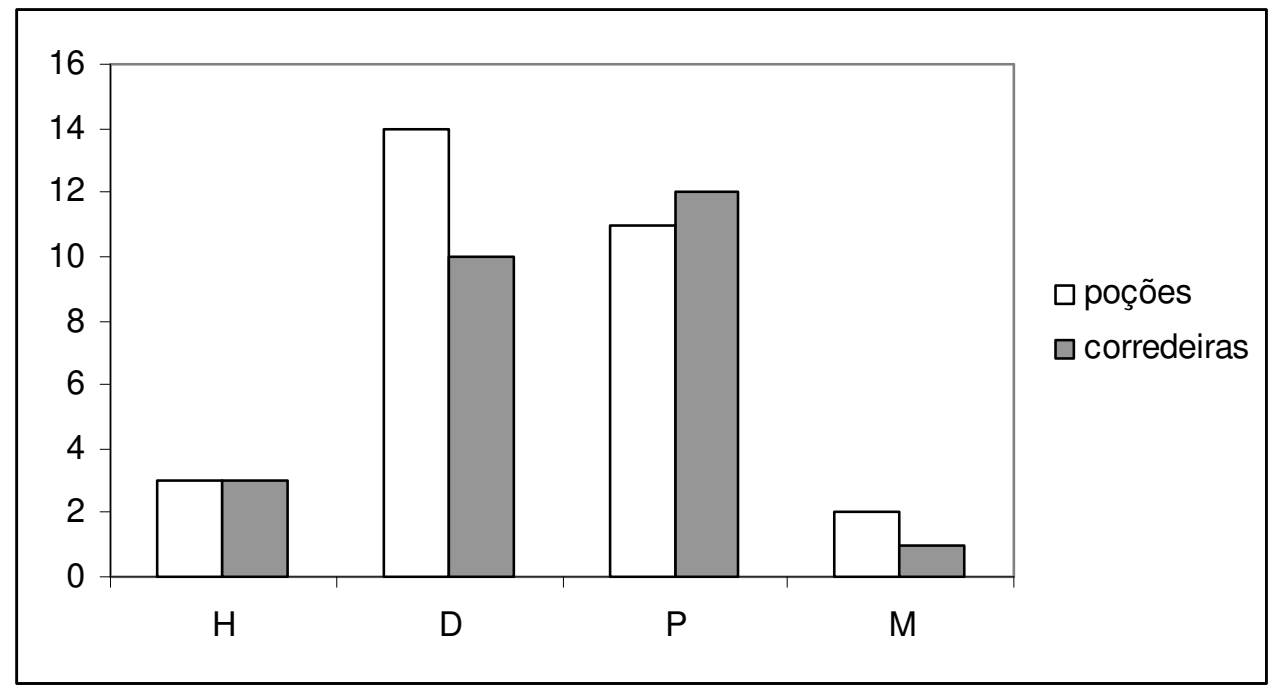

Figura 5 - Riqueza de famílias herbívoras (H), detritívoras (D), Predadoras (P) e que apresentam múltiplos hábitos alimentares (M.) encontradas em poções e corredeiras (Parque Estadual do Jaraguá, São Paulo, SP).

A análise dos padrões associados à composição da comunidade bentônica dos habitats, através da DCA, resultou numa segregação entre poções e corredeiras, mostrada no primeiro eixo. O percentual de variação nos dois eixos explica $32,1 \%$ da variância total da matriz, sendo $12 \%$ no primeiro eixo e $20,1 \%$ no segundo eixo. Observou-se um gradiente no qual os poções e as corredeiras estão associados à fauna da seguinte forma: os poções são caracterizados, principalmente, pelas maiores densidades de Chironomidae, Tubificidae e Gomphidae, enquanto as corredeiras caracterizam-se pelas maiores densidades de Baetidae, Leptophlebiidae, Coenagrionidae e Elmidae (Fig. 6). 


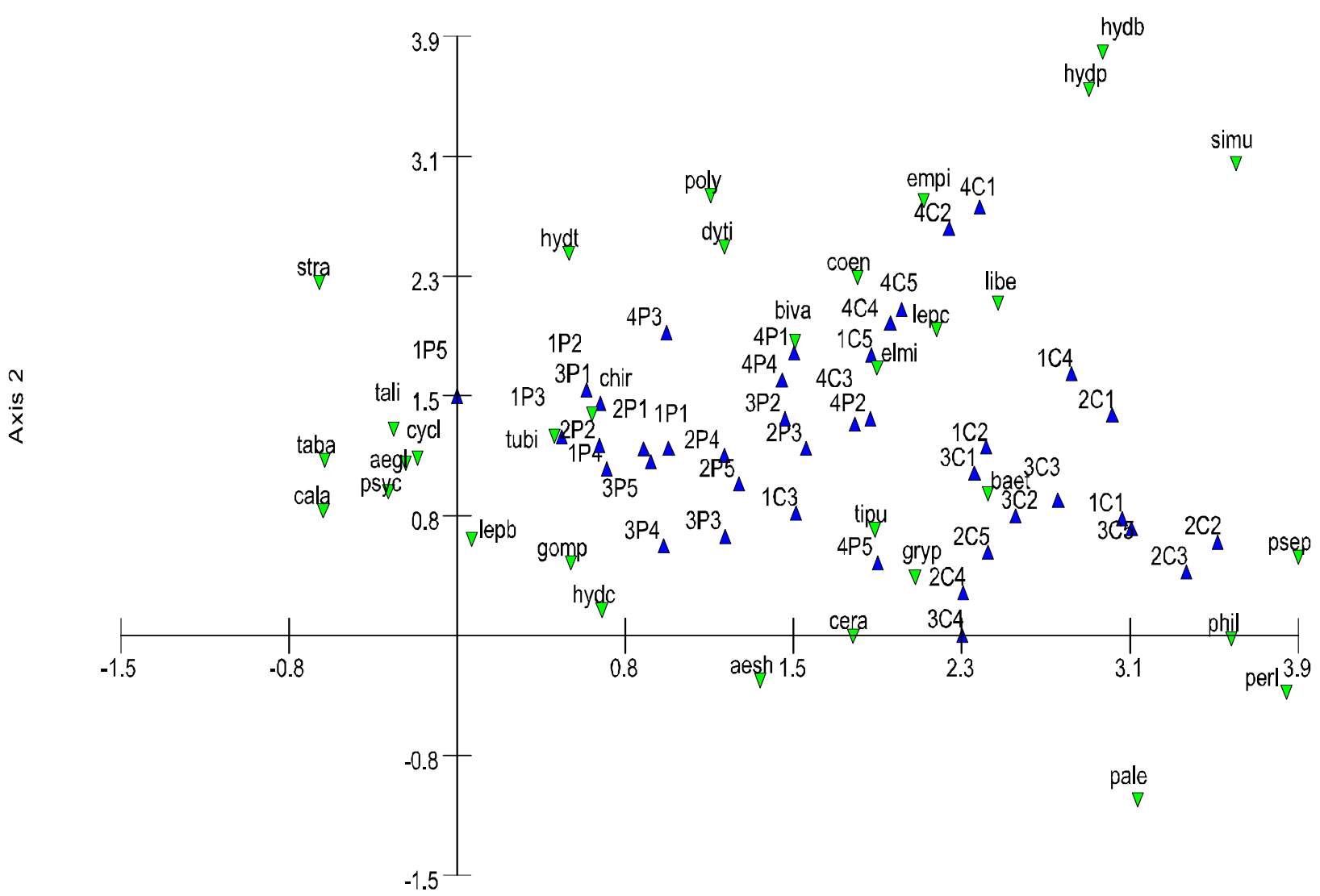

Axis 1

Figura 6 - Interpolação dos dois primeiros eixos resultantes da Análise de Correspondência "Detrending", baseada na matriz de densidade de invertebrados bentônicos em poções e corredeiras do Parque Estadual do Jaraguá, São Paulo, SP. $\nabla$ : táxons; $\boldsymbol{\Delta}$ : habitats, ex.:2P3: Nascente 2, Poção 3.

\section{DISCUSSÃO}

Tal como em muitos outros estudos sobre a comunidade bentônica em poções e corredeiras (Deluchi, 1988; Brown e Brussock, 1991), neste trabalho, evidenciou-se uma diferença entre os dois habitats, demonstrada pela DCA. As diferenças da velocidade da água possibilitam a formação de habitats variados que podem ser explorados por uma biota diferenciada (Pedersen e Friberg, 2006) na medida de suas adaptações morfológicas e comportamentais, e também da abundância e disponibilidade de recursos alimentares (Slobodchikoff e Parrot, 1977).

A presença de detritos vegetais acumulados nos poções parece ter sido determinante para que estes apresentassem densidade populacional e riqueza superior em relação às corredeiras. O acúmulo de detritos fornece aos macroinvertebrados bentônicos maior quantidade de 
recursos alimentares (Hoover et al., 2006; Kobayashi e Kagaya, 2002; Richardson e Neil, 1991), além de mais espaço para colonização e refúgio (Richardson, 1992), permitindo assim, o estabelecimento de uma fauna com maior número de indivíduos (Egglishaw, 1964; Mackay e Kalf, 1969; Hildrew et al., 1980; Gee, 1982; Dobson, 1991). As folhas, depositadas no fundo do rio, podem fornecer abrigo e alimento para raspadores e detritívoros e servir como substrato alimentar direto para coletores e indireto para predadores (Afonso e Henry, 2002). A possibilidade de suportar um grande número de indivíduos, no entanto, não garante necessariamente uma alta diversidade, pois a elevada dominância observada em poções, devido à alta abundância relativa de Chironomidae, contribuiu para a redução daquela métrica.

Em corredeiras, a velocidade da correnteza é extremamente variável entre as pedras, o que proporciona o surgimento de vários microhabitats que podem ser explorados pelos macroinvertebrados (Patrick, 1970; Halwas e Church, 2005). Ainda, as pedras no leito do rio facilitam o acúmulo de folhas e outros detritos vegetais em suas faces superiores (Death, 1995; Uieda e Gajardo, 1996) que, por sua vez, fornecem abrigo contra a correnteza direta, mais espaços para fixação e colonização e refúgio contra predadores (Richardson, 1992; Dobson, 1994). Desta forma, esperar-se-ia maior diversidade neste tipo de corredeira.

Muitos trabalhos têm relatado valores superiores de diversidade, riqueza e densidade populacional em corredeiras em comparação aos poções do mesmo rio (Huryn e Wallace, 1988; Brown e Brussock, 1991). Outros trabalhos, no entanto, têm encontrado valores superiores para esses atributos em poções (McCulloch, 1986, Buss et al., 2004). Apesar destes resultados de certa forma conflitantes, em todos os trabalhos fica evidente que a capacidade de retenção foliar do leito do rio exerce grande importância, pois os valores das métricas acima citadas foram superiores em poções de rios com leito arenoso, e superiores em corredeiras em rios com leito rochoso. No primeiro caso, o leito arenoso não é capaz de reter detritos que, então, ficam concentrados nos poções. No segundo caso, como citado anteriormente, o tipo de substrato permite o acúmulo de detritos.

O leito das nascentes amostradas neste trabalho caracterizava-se pela presença de areia e pequenas pedras não fixas ao substrato, que podem ser facilmente carreadas pela correnteza, e que, portanto, não agem como bons elementos de retenção do folhiço, enquanto os poções caracterizavam-se por elevado acúmulo de folhas. De acordo com Richardson (1992), as densidades de macroinvertebrados bentônicos são geralmente superiores em leaf packs, naturais ou artificiais, que no substrato circundante, o que explica os valores superiores de 
densidade e riqueza encontrados nos poções em relação às corredeiras do Parque Estadual do Jaraguá, visto que os primeiros apresentam maior quantidade de detritos.

Neste trabalho, em ambos os habitats, chamam atenção as altas porcentagens de Chironomidae, cujas larvas são frequentemente consideradas como indicadoras de poluição. Entretanto é comum que rios não poluídos tenham grande abundância de Chironomidae (McCulloch, 1986; Pinder, 1986). Esta família é onipresente nos sistemas aquáticos e frequentemente é o grupo dominante na fauna de invertebrados bentônicos (Coffman e Ferrington, 1996). Assim, não se pode dizer que a dominância de Chironomidae, por si só, encontrada em todas as nascentes deste trabalho, relacione-se à presença de poluição.

Neste trabalho, nota-se que algumas famílias mostraram preferências ou restringiramse a um dos dois habitats amostrados, o que fica claro ao observarem-se os valores de suas abundâncias relativas. As famílias pertencentes às ordens Ephemeroptera, Plecoptera, algumas famílias de Odonata e algumas de Coleoptera, como Elmidae e Psephenidae, obtêm maior sucesso em águas correntes (Hynes, 1970) e, tal como esperado, atingiram abundâncias relativas superiores em corredeiras.

Estudos têm mostrado a ordem Ephemeroptera, de forma geral, como restrita a águas bem oxigenadas (Wetzel, 2001) e adaptada a uma larga gama de velocidades de correnteza em habitats fluviais (Hynes, 1970), o que explica sua maior abundância relativa em corredeiras observada neste trabalho. Buss e Salles (2007), estudando a família Baetidae em rios da Mata Atlântica no estado do Rio de Janeiro, verificaram que apenas duas das nove espécies amostradas estavam restritas a poções, sendo as demais associadas a substratos rochosos e corredeiras. Segundo esses autores, isso se deve ao fato da maioria das espécies do sudeste brasileiro serem raspadoras e alimentarem-se predominantemente de perifíton, além de apresentarem adaptações morfológicas para resistirem ao estresse hidráulico.

Dentro da ordem Plecoptera, Perlidae apresenta necessidade por água limpa com alta concentração de oxigênio dissolvido e baixa siltação (McClelland e Brusven, 1980), o que explica sua ausência nos poções.

Ainda, a siltação da superfície das rochas, comum em poções, afeta adversamente grupos raspadores, como Baetidae, Leptophlebiidae e Psephenidae e interfere na adesão de Simuliidae, tornando as corredeiras habitats preferenciais para esses grupos (Freeden, 1959).

A família Simuliidae é basicamente coletora-filtradora e apresenta estruturas especiais de fixação ao substrato, o que a torna capaz de se beneficiar do fluxo d'água para obtenção de alimentos (Scullion et al., 1982; Anderson e Wallace, 1996; Peterson, 1996), o que explica sua preferência pelas corredeiras, tal como observado nesse trabalho. 
Da mesma forma, as famílias que se encontraram restritas ou apresentaram preferência pelos poções exibem adaptações para suportar as condições deste tipo de habitat onde ocorre grande deposição de sedimentos finos, de forma que os organismos são adaptados para escalar e cavar, freqüentemente apresentando mecanismos que previnem a obstrução das superfícies respiratórias devido ao excesso de pequenas partículas existentes no meio (Cummins, 1975; Allan 1995; Uieda e Gajardo, 1996). Neste trabalho, Tubificidae, Gomphidae Aeshnidae, Trichoptera e Chironomidae apresentaram densidade relativa superior em poções.

A presença de Tubificidae pode ser explicada pelo fato de se alimentar em substratos com folhas (Richard e Moreau, 1982) e ricos em matéria orgânica (Michael, 1968). Aeshnidae e Gomphidae são geralmente encontradas em habitats lóticos deposicionais. A família Gomphidae pode viver enterrada sob os sedimentos (Westfall, 1996), deixando apenas algumas partes do corpo expostas, tais como olhos (Hynes, 1970) e estruturas respiratórias retais (Westfall, 1996). Grande parte dos gêneros de Aeshnidae ocupa habitats deposicionais, onde vivem sob detritos e rochas (Westfall, 1996).

Em relação a Trichoptera, ao contrário do esperado com base na literatura, que se refere à Ordem como exibindo preferência por habitats lóticos erosionais (Merritt e Cummins, 1996), tanto a densidade média quanto a abundância relativa foram superiores em poções. Resultados semelhantes aos do presente trabalho, em que a ordem foi mais abundante em poções, foi encontrado por Uieda e Gajardo (1996) em seu trabalho no Córrego de Itaúna, onde Trichoptera apresentou maior número de indivíduos em poção na época seca. As coletas para o presente trabalho foram realizadas em maio, ao final do período chuvoso do ano, quando o volume de água em alguns riachos existentes no Parque, mas não amostrados neste trabalho, já havia diminuído muito, especialmente nas corredeiras. Isso poderia explicar a similaridade dos resultados. Observa-se também que Leptoceridae, a família de Trichoptera mais abundante e exclusiva dos poções, corresponde a indivíduos detritívoros que podem se beneficiar da grande quantidade de matéria orgânica ali depositada.

Aventou-se que as comunidades de poções seriam dominadas por táxons detritívoros, que, de acordo com Merritt e Cummins (1996), são todos aqueles que se alimentam de matéria orgânica morta: fragmentadores e coletores. Tal hipótese foi confirmada, sendo que os detritívoros foram beneficiados nos poções pelo acúmulo de matéria orgânica alóctone. 


\section{CONCLUSÃO}

Neste trabalho, poções e corredeiras apresentaram grandes diferenças, como resultado das variações da velocidade de correnteza entre ambos os habitats e do acúmulo de folhas e detritos vegetais em poções. Os poções apresentaram populações com maior densidade e riqueza de táxons e dominância superior às corredeiras, cuja diversidade foi mais elevada.

\section{REFERÊNCIAS BIBLIOGRÁFICAS}

AFONSO, A. A.; HENRY, R. Retention of particulate organic matter in a tropical headstream. Hydrobiologia, v. 482, p. 161-166, 2002.

ALLAN, D. J. Stream ecology: estructure and function of running waters. New York: Chapman e Hall, 1995. 397 p.

ANDERSON, N.H.; WALLACE, J.B. Habitat, life history, and behavioral adaptations of aquatic insects. In: MERRITT, R.W.; CUMMINS, K. W. (Orgs.) An introduction to the Aquatic Insects of North America. $3^{\text {a }}$ ed. Dubuque: Kendall/Hunt Publishers, 1996. cap. 5, p. 38 - 58.

BARBER, W. E.; KEVERN, N. R. Ecological factors influencing macroinvertebrates standing crop distribution. Hydrobiologia, v. 43, p. 53 - 75, 1973.

BORROR, D. J.; DELONG, D. M. Introdução ao estudo dos insetos. São Paulo: Edusp, 1988. $563 p$.

BRANDIMARTE, A. L.; ANAYA, M. Bottom fauna flotation using a solution of sodium chloride. Verhandlng für Internationale für Theoritische and Angewandte Limnologie, v. 26, p. 2358 - 2359, 1998.

BROWN, A. V.; BRUSSOCK, P. P. Comparisons of benthic invertebrates between riffles and pools. Hydrobiologia, v. 22, p.: 99 - 108, 1991.

BUSS, D. F. et al. Substrate specificity, environmental degradation and disturbance structuring macroinvertebrate assemblages in neotropical streams. Hydrobiologia, v. 518, p. 179 - 188, 2004.

BUSS, D.F.; SALLES, F.F. Using Baetidae Species as Biological Indicators of Environmental Degradation in a Brazilian River Basin. Environ Monit Assess., v. 130, p. 365 - 372, 2007.

CALLISTO, M; GONÇALVES Jr., J.F., MORENO, P. Invertebrados aquáticos como bioindicadores. In: GOULART, E.M.A. (Org.) Navegando o Rio das Velhas das Minas aos Gerais. UFMG, Belo Horizonte, v.1, p 555 - 567, 2004.

CARNEIRO, C.D.R. 2002. Cavas de Ouro Históricas do Jaraguá, SP - Os primórdios da mineração no Brasil. In: SCHOBBENHAUS, C. et al. (Orgs.). Sítios Geológicos e 
Paleontológicos do Brasil. Brasilia: DNPM/CPRM - Comissão Brasileira de Sítios Geológicos e Paleobiológicos (SIGEP), 2002, v. 1, p.511-515. Disponível em:

http://www.unb.br/ig/sigep/sitio098/sitio098.pdf. Acesso em: 05/03/2007.

COFFMAN, W. P.; FERRINGTON, L. C. Chironomidae. In: MERRITT, R.W.; CUMMINS, K. W. (Orgs.) An introduction to the Aquatic Insects of North America. $3^{\mathrm{a}}$ ed. Dubuque:

Kendall/Hunt Publishers, 1996. cap. 26, p. 551 - 652.

COSTA, C.; IDE, S.; SIMONKA, C. E. (Orgs.). 2006. Insetos Imaturos: Metamorfose e Identificação. Ribeirão Preto: Holos. 249p.

CUMMINS, K.W. Macroinvertebrates. In: Whitton, B.A. (Org.) River Ecology. Studies in Ecology vol. 2. Bekerley: Univ. California Press, 1975. cap. 8, p. 170-198.

DEATH, R. G. Spatial patterns in benthic invertebrate community structure: products of habitat stability or are they habitat specific? Freshwater Biology, v. 33, p. 455 - 467, 1995.

DEATH, R. G.; WINTERBOURN, M. J. Diversity patterns in stream benthic invertebrate communities: the influence of habitat stability. Ecology, v. 76, p. 1446 - 1460, 1995.

DELUCCHI, C.M. Comparison of community structure among streams with different temporal flow regimes. Canadian Journal of Zoology, v. 66, p. 579 - 586, 1988.

DOBSON, M.. An assessment of mesh bags and plastic leaf traps as tools for studying macroinvertebrate assemblages in natural leaf packs. Hydrobiologia, v. 222, p. 19 - 28, 1991.

DOBSON, M. Microhabitat as a determinant of diversity: stream invertebrates colonizing leaf packs. Freshwater Biology, v. 32, p. 565 - 572, 1994.

DOUGLAS, M; LAKE, P. S. Species richness of stream stones: an investigation of the mechanism generating the species-area relationship. Oikos, v. 69, p. 387 - 396, 1994.

EGGLISHAW, H. J. The distributional relationship between the bottom fauna and plant detritus in streams. Journal of Animal Ecology, v. 33, p. 463 - 476, 1957.

EGGLISHAW, H. J. The distributional relationship between the bottom fauna and plant detritus in streams. Journal of Animal Ecology, v.33, p. 463 - 476, 1964.

FLECKER, A. S.; FEIFAREK, B. Disturbance and the temporal variability of invertebrate assemblages in two Andean streams. Freshwater Biology, v. 31, p. 131 - 142, 1994.

FREEDEN, J.H. Rearing Black-flies in the laboratory. Canadian Entomologist, v. 91, p. 78 - 83, 1959.

GEE, J. H. R. Resource utilization by Gammarus pulex (Amphipoda) in a Cotswold stream: a microdistribution study. Journal of Animal Ecology, v. 51, p. 817 - 832, 1982.

Google Earth. Disponível em: http://www.earth.google.com/intl/pt/. Acesso em: 05/10/2007. 
HALWAS, K. L.; CHURCH, M. Benthic assemblage variation among channel units in highgradient streams on Vancouver Island, British Columbia. Journal of the North American Benthological Society, v. 24, p. 478 - 494, 2005.

HELLAWELL J.M. Biological Indicators of Freshwater Pollution and Environmental Management. New York: Elsevier Applied Science, 1989. 576p.

HELMS. B. S.; CREED, R. P. The effects of two coexisting crayfish on an Appalachian river community. Journal of the North American Benthological Society, v. 24, p. 113 - 122, 2005.

HILDREW, A.G.; TOWNSEND, C.R.; HENDERSON, J. Interactions between larval size, microdistribution and substrate in stoneflies of an iron-rich stream. Oikos, v.35, p. 387 - 396, 1980.

HILL, M. O.; GAUSCH, H. G. Detrended correspondence analysis, an improved ordination technique. Vegetatio, v. 42, p. 47-58, 1980.

HOOVER, T. M.; RICHARDSON, J. S.; YONEMITSU, N. Flow-substrate interactions create and mediate leaf litter. Freshwater Biology, v. 51, p. 435 - 447, 2006.

HOSE, G. C.; JONES, P.; LIM, R. P. Hyporheic macroinvertebrtes in riffle and pool areas of temporary streams in south eastern Australia. Hydrobiologia, v. 532, p. 81 - 90, 2005.

HURYN, A. D.; WALLACE, J. B. Community structure of Trichoptera in a mountain stream: spatial patterns of production and functional organization. Freshwater Biology, v. 20, p. 141$155,1988$.

HYNES, H.A. 1970. The ecology of running waters. Liverpool: Liverpool University Press, $1970.555 \mathrm{p}$.

INSTITUTO FLORESTAL. 2007. Unidades do Instituto Florestal. São Paulo, Instituto Florestal da Secretaria de Estado do Meio Ambiente. Disponível em: http://www.iflorestal.sp.gov.br/unidades_conservacao/informacoes.asp?cod=13. Acesso em: 20/01/2007.

KOBAYASHI, S.; KAGAYA, T.. Differences in litter characteristics and macroinvertebrate assemblages between litter patches and riffles in a headwater stream. Limnology, v. 3, p. 37 - 42, 2002.

KOVACH COMPUTING SERVICES. MVSP versão 3.11. Anglesey. Pacote estatístico. 2000.

MACKAY R.J. Colonization by lotic macroinvertebrates: a review of processes and patterns. Canadian Journal of Fish Aquatic Science, v. 49, p. 617 - 628, 1992.

MACKAY, R. J.; KALFF, J. Seasonal variation in standing crop and species diversity communities in a small Quebec stream. Ecology, v. 50, p. 101 - 109, 1969.

McCLELLAND, W. T.; M. A. BRUSVEN. Effects of sedimentation on the behaviour and distribution of riffle insects in a laboratory stream. Aquatic Insects, v. 2, p. 161 - 169, 1980. 
McCULLOCH, D. L. 1986. Benthic macroinvertebrate distributions in the riffle-pool communities of two east Texas streams. Hydrobiologia, v. 135, p. 61 - 70, 1986.

MERRITT, R.W.; CUMMINS, K.W. (Org.). An introduction to the aquatic insects of North America. $3^{\text {a }}$ ed. Dubuque: Kendall/Hunt Publishers, 1996. 862 p.

MICHAEL, R. G.. Studies on the bottom fauna in a tropical freshwater fish pond. Hydrobiologia, v. 31, p. 203 - 230. 1968.

MINSHALL, G.W.; MINSHALL, J.N. Microdistribution of benthic macroinvertebrates in a Rocky Mountain (U.S.A.) stream. Hydrobiologia, v. 55, p. 231 - 249, 1977.

NAKAJIMA, T.; ASAEDA, T., FUJINO, T., NANDA, A. Coarse particulate organic matter distribution in the pools and riffles of a second-order stream. Hydrobiologia, v. 559, p. 275 - 283, 2006.

NEW, T. R.. An introduction to invertebrate conservation biology. Oxford: Oxford University Press, 1995. 194 p.

PATRICK, R. Benthic stream communities. American Scientist, v. 58, p. 546 - 549, 1970.

PECKARSKY, B. L. Biological interactions as determinants of distributions of benthic invertebrates within the substrate of stony streams. Limnol. Oceanogr., v. 24 (1), p. 59 - 68, 1979.

PENNAK, R. W. Fresh-water invertebrates of the United States. Protozoa to Mollusca. $3^{\mathrm{a}}$. ed. New York : Wiley, 1989. 628 p.

PEDERSEN, M. L.; FRIBERG, N. Two lowland stream riffles - linkages between physical habitats and macroinvertebrates across multiple spatial scales. Aquatic Ecology, 2006.

PETERSEN, R.C.; CUMMINS, K.W. Leaf processing in a woodland stream. Freshwater Biology, v. 4, p. 343 - 368, 1974.

PETERSON, B. V. Simuliidae. In: MERRITT, R.W.; CUMMINS, K. W. (Eds.) An introduction to the Aquatic Insects of North America. $3^{\mathrm{a}}$ ed. Dubuque: Kendall/Hunt Publishers, 1996. cap. 25 , p. $534-550$.

PIELOU, E. C. Shannon's formula as a measure of specific diversity:its use and misuse. The American Naturalist, v. 100, p. 463 - 465, 1966.

PINDER, L. C. V. Biology of Freshwater Chironomidae. Annu. Rev. Entomol., v. 31, p. 1 - 23, 1986.

PROJETO BIOTA-JARAGUÁ, Parque Estadual do Jaraguá, Relatório Técnico Científico, PPGERN, Ciências Biológicas - UFSCAR, Movimento Ecocultural e Instituto Florestal do Jaraguá, $1999.162 \mathrm{p}$.

REICE, S. R. The role of substratum in benthic macroinvertebrate microdistibution and litter decomposition in a woodland stream. Ecology, v.61, p. 580 - 590, 1980. 
RICHARD, Y.; MOREAU, G. 1982. Utilisation des feuilles de différentes epècies dárbres (peuplier, aulne, myrique) par la fauna benthic dans des aux oligotrohes du Bouclier canadien. Hydrobiologia, v. 96, p. 77 - 89, 1982.

RICHARDSON, J.S.; NEIL, W.E. Indirect effects of detritus manipulation in a montane stream. Canadian Journal of Fisheries and Aquatic Sciences, v. 48, p. 776 - 783, 1991.

RICHARDSON, J. S. Food, microhabitat, or both? Macroinvertebrate use of leaf accumulations in a montane stream. Freshwater Biology, v. 27, p.169 - 176, 1992.

ROQUE, F. O. et al. Benthic macroinvertebrates in streams of the Jaragua State Park (Southeast of Brazil) considering multiple spatial scales. Journal of Insect Conservation, v.7, p. 63 - 72. 2003.

ROSENBERG, D.M.; RESH, V.H. Intruduction to freshwater biomonitoring and benthic macroinvertebrates. In: ROSENBERG, D.M.; RESH, V.H. (Orgs.) Freshwater biomonitoring and benthic macroinvertebrates. New York: Chapman e Hall, 1993. cap 1. p. 1 - 9.

SCULLION, J. et al. Comparison of benthic macroinvertebrate fauna and substratum composition in riffles and pools in the impounded River Elan and the unregulated River Wye, mid-Wales. Freshwater Biology, v. 12, p. 579 - 595, 1982.

SILVEIRA, M. P. et al. Spatial and temporal distribution of benthic macroinvertebrates in a southeastern brazilian river. Brazilian Journal of Biology, v. 66, p. 623 - 632, 2006.

SLOBODCHIKOFF, C. N.; PARROT, J. E. Seasonal Diversity in aquatic insect communities in an all-year stream system. Hydrobiologia, v. 52, p. 143 - 151, 1977.

SNEATH, P.H.A.; SOKAL, R.R. Numerical taxonomy. San Francisco: W. Freeman, 1973. $537 \mathrm{p}$.

TOMANOVA, S.; GOITIA, E., HELESIC, J. Trophic levels and functional groups of macroinvertebrates in neotropical streams. Hydrobiologia, v. 556, p 251 - 264, 2006. TOWNSEND C.R. The patch dynamics concept of stream community ecology. Journal of the North American Benthological Society, v. 8, p.36-50, 1989.

UIEDA, V.S.; GAJARDO, I. C.. Macroinvertebrados perifíticos encontrados em poções e corredeiras de um riacho. Naturalia, v. 21, p.31 - 47, 1996.

WALLACE, J.B.; WEBSTER, J.R.; CUFFNEY, T.F. Stream detritus dynamics: regulation by invertebrate consumers. Oecologia, v. 53, p. 197-200, 1982.

WESTFALL, Jr. M.J. Odonata. In: MERRITT, R.W.; CUMMINS, K. W. (eds.) An introduction to the Aquatic Insects of North America. $3^{\text {a }}$ ed. Dubuque: Kendall/Hunt Publishers, 1996. Cap.11 p. $126-176$.

WETZEL, R. G. Limnology: lake and river ecosystems. 3.ed. San Diego: Academic Pres, 2001. 1006 p. 
WIGGINS, G. B. Larvae of the North American caddisfly genera (Trichoptera). $2^{\mathrm{a}}$ ed. Toronto: Univ. Toronto Press, 1998. 457p.

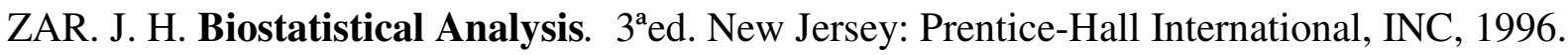
620 p. 


\section{CAPítulo II}

APLICAÇÃO DE MÉTRICAS UTILIZANDO MACROINVERTEBRADOS BENTÔNICOS PARA AVALIAÇÃO DO IMPACTO ANTROPOGÊNICO ÀS NASCENTES DO PARQUE ESTADUAL DO JARAGUÁ, SÃO PAULO, SP. 


\begin{abstract}
Application of metrics using benthic macroinvertebrates for assessment of the anthropogenic impact on streams of Jaraguá State Park, São Paulo, SP. The purpose of the present work was to test metrics using benthic macroinvertebrate community of pools and riffles of four streams of Jaraguá State Park in order to stablish those that would be used for water assessment quality of those streams. The samples were carried out in May 2004. In each stream a segment of 40 meters was delimited, where 5 pools and 5 riffles were sampled, totaling 40 sampling unities collected with a Surber sampler $\left(0,04 \mathrm{~m}^{2}, 500 \mu \mathrm{m}\right.$ mesh size $)$. After sorting and identification of the benthic macroinvertebrates, the following metrics were applied: total mean density, total family richness, Shannon-Wiener diversity, dominance, richness of EPT, EPT/total, \%EPT/\%Chironomidae, non-Diptera/Total, Odonata/Total, MBFI (modified family biotic index). The last one was obtained through the multiplication of the tolerance score of each family by its relative abundance. Of the metrics tested, only four were useful to discriminate the non-impacted streams from the impacted one, and they were included in a multimetric index for Jaraguá State Park.
\end{abstract}

Key-words: benthic macroinvertebrates - anthropogenic impact - metrics.

\title{
RESUMO:
}

Aplicação de métricas utilizando macroinvertebrados bentônicos para avaliação do impacto antropogênico às nascentes do Parque Estadual do Jaraguá, São Paulo, SP. O presente trabalho objetivou a utilização de métricas obtidas a partir da comunidade de macroinvertebrados bentônicos nos habitats de poção e corredeira de quatro nascentes do Parque Estadual do Jaraguá para a avaliação da qualidade da água destas nascentes. As coletas foram realizadas em campanha única no mês de maio de 2004. Em cada nascente, foi delimitado um trecho de 40 metros, no qual foram escolhidos 5 poções e 5 corredeiras, totalizando 40 unidades amostrais coletadas com auxílio de um Surber com malha de $500 \mu \mathrm{m}$ e área de $0,04 \mathrm{~m}^{2}$. Em cada nascente foi retirada uma amostra de água para a análise de coliformes fecais e das concentrações de nitrogênio e fósforo. Após a triagem e identificação dos macroinvertebrados bentônicos amostrados, foram aplicadas as seguintes métricas: densidade média total, riqueza total de famílias, diversidade de Shannon-Wiener, dominância, riqueza de famílias de EPT, EPT/Total, \%EPT/\%Chironomidae, Não Diptera/Total, Odonata/Total, Oligochaeta/Total, IBFM. A última métrica foi obtida através da multiplicação dos valores de tolerância de cada família pela sua abundância relativa. Das métricas testadas, apenas diversidade de Shannon-Wiener, dominância, EPT/Total e IBFM mostraram-se úteis para a diferenciação das nascentes não impactadas e impactadas foram posteriormente agrupadas num índice multimétrico.

Palavras-chave: invertebrados bentônicos - impacto antropogênico - métricas. 


\section{INTRODUÇÃO}

Em uma escala global, a biodiversidade dos ecossistemas de água doce tem sofrido rápida deterioração como resultado das atividades humanas (Klemm et al., 2003). Muitos estudos têm sugerido a necessidade de entender os processos de degradação da água em ambientes urbanos como base para projetos de recuperação, manutenção e uso sustentável desse recurso natural (Walsh, 2000; Karr e Chu, 1999).

O monitoramento biológico é essencial para avaliar a saúde dos ecossistemas aquáticos (Loeb, 1994). Seu propósito é caracterizar o status do recurso aquático e monitorar tendências na condição das comunidades biológicas associadas aos impactos antropogênicos (Resh et al., 1995), antes que danos irreversíveis, ou cuja reversão seja demasiado cara, ocorram (Furse et al., 2006).

O biomonitoramento tem se desenvolvido em todo o mundo, avaliando mudanças na composição da comunidade e funcionamento do ecossistema, na composição genética de populações específicas, na bioacumulação de toxinas e ocorrência de deformidades morfológicas (Moretti e Callisto, 2005).

As comunidades biológicas relacionam-se às características ecológicas do meio (químicas, físicas e biológicas), integrando efeitos de diferentes estressores e, assim, fornecendo uma ampla medida da combinação de impactos (Moretti e Callisto, 2005). O uso de organismos como indicadores se baseia no pressuposto de que quando os organismos são submetidos a condições adversas, ou morrem ou se adaptam (Moretti e Callisto, 2005). Assim, os organismos que vivem num determinado ecossistema são adaptados às condições ambientais ali presentes e devem, então, indicar o nível de preservação das condições naturais ou alterações causadas pela emissão de poluentes (Hynes, 1970).

Vários grupos de organismos podem ser utilizados no biomonitoramento, mas os macroinvertebrados bentônicos estão entre os mais usados, com grande sucesso em todo o mundo, devido a seus atributos, tais como: serem cosmopolitas, abundantes e possuírem grande tamanho (muitos são visíveis a olho nu); serem sedentários (ou com mobilidade restrita) e bentônicos, e por isso, representativos das condições locais do sedimento; a maioria possuir características ecológicas bem conhecidas; caracterizarem a qualidade das águas não apenas no instante de sua coleta, mas refletirem a situação do meio em um período de tempo consideravelmente mais longo, o que permite avaliar os efeitos de um poluente de forma segura e precisa em diferentes escalas temporais; participarem das cadeias alimentares 
aquáticas, podendo atuar como agentes vitais de entrada de metais pesados ou outros contaminantes nas cadeias (Rosenberg e Wiens, 1976; Myslinski e Ginsburg, 1977; Hellawell, 1989; Lynch et al., 1988; Hare e Campbell, 1992; Rosenberg e Resh, 1993; Goodyear e Mcneill, 1999).

Os invertebrados bentônicos têm sido utilizados com bioindicadores há muito tempo. Na década de 1920, já se havia estabelecido relações entre o grau de poluição do habitat e os grupos de invertebrados bentônicos que poderiam habitá-lo (Cairns e Pratt, 1993). Atualmente, grande parte das avaliações de qualidade da água baseadas na comunidade bentônica baseia-se em índices multimétricos (Hering et al., 2004). Uma única métrica, por refletir um único atributo da biota, pode falhar em revelar o efeito de múltiplos estressores, enquanto a abordagem multimétrica, ao incluir muitos aspectos da estrutura da comunidade, pode ser uma ferramenta mais poderosa para avaliar os efeitos da poluição sobre a biota aquática (Barbour et al., 1996), pois fornece informações sobre atributos biológicos diversos que quando integrados oferecem uma indicação geral das condições da comunidade biológica (Barbour et al., 1995). Assim sendo, a vantagem do sistema multimétrico é que todo o gradiente de poluição pode ser efetivamente avaliado, apesar da sensibilidade limitada das métricas individuais (Thorne e Williams, 1997).

Comparado aos extensivos estudos de biodiversidade e ecologia dos rios temperados, nosso conhecimento sobre os rios tropicais é muito limitado (Tomanova et al., 2006). Poucos estudos têm sido realizados em ecossistemas tropicais visando o desenvolvimento de protocolos regionais específicos de biomonitoramento. $\mathrm{O}$ entendimento sobre como avaliar e interpretar as comunidades biológicas ainda é limitado, e os parâmetros usados são frequentemente aqueles desenvolvidos em regiões temperadas (Marques e Barbosa, 2001).

Segundo Thorne e Williams (1997), no nível taxonômico de família, as comunidades de macroinvertebrados bentônicos dos rios tropicais estudados são bastante similares às comunidades temperadas em suas respostas à poluição. Isso sugere que os métodos de biomonitoramento baseados em família, que se mostraram úteis em outras partes do mundo, podem fornecer um ponto de partida bastante útil para o desenvolvimento de sistemas em paises em desenvolvimento. Comparações entre a riqueza de famílias e a de espécies, ou entre índices que utilizem estes dois índices taxonômicos, mostram que ambos apresentam comportamentos similares (Rico et al., 1992; Bournard et al., 1996).

No Brasil, o emprego dos macroinvertebrados bentônicos é ainda restrito (Junqueira et al., 2000), sendo que muitos dos programas de monitoramento dos ecossistemas aquático, em geral, consideram apenas as análises químicas da água (Baptista et al., 2007). Porém, desde a 
década passada, instituições de pesquisa e agências brasileiras de proteção ambiental têm desenvolvido estudos baseados no uso das comunidades bentônicas para avaliar a qualidade das condições ambientais dos rios (Baptista et al., 2007).

As crescentes pressões sobre os ecossistemas aquáticos continentais resultam em sua degradação (Paul e Meyer, 2001). O rápido crescimento populacional, associado à industrialização e à urbanização tem exercido crescente pressão sobre os recursos de água doce nos paises em desenvolvimento (Thorne e Williams, 1997). Assim, aumenta também a necessidade de biomonitoramento, especialmente nas unidades de conservação, porque nossa capacidade para proteger os recursos biológicos depende da capacidade para identificar e predizer os efeitos das ações humanas sobre os sistemas biológicos (Karr e Chu, 1999). A preocupação com a conservação dos recursos hídricos de unidades de conservação é particularmente importante nos grandes centros urbanos em que a garantia da disponibilidade de água, em qualidade e quantidade adequadas, muitas vezes é conflitante com as atividades que a população deseja realizar naquelas áreas. Um caso emblemático é o do Parque Estadual do Jaraguá, que se localiza no município de São Paulo e integra a Reserva da Biosfera do Cinturão Verde da Cidade de São Paulo. Na área abrangida por esta reserva, situam-se vários outros parques, reservas ambientais, áreas de proteção ambiental e áreas naturais tombadas, que têm como objetivo a gestão correta de seus ambientes naturais e a busca pelo desenvolvimento sustentável, através da pesquisa cientifica, da conservação da biodiversidade e da promoção social. Devido à sua localização, no entanto, a Reserva da Biosfera do Cinturão Verde da Cidade de São Paulo está sujeita aos impactos ambientais causados pela urbanização da região e a algumas ameaças, tais como: especulação imobiliária; o desenvolvimento de grandes obras de infra-estrutura (ex. Rodoanel Mário Covas); legislação inadequada e descumprida; regulamentação fundiária precária; extração ilegal de recursos florestais; mineração; deposição de lixo urbano; poluição atmosférica; depredação do ambiente por indivíduos não conscientes (Instituto Florestal, 2007). Apesar disso, poucos estudos visando o conhecimento e a conservação dos recursos naturais tem sido realizados na área, especialmente no Parque Estadual do Jaraguá. O parque está sujeito a intensas pressões em função do uso e ocupação do entorno. Além disso, nos finais de semana e feriados, é visitado por milhares de pessoas oriundas, principalmente, dos bairros vizinhos, muitas das quais desconhecem os possíveis impactos resultantes da visitação. Portanto é imprescindível uma preocupação com os recursos hídricos ali presentes, visando a conservação da diversidade biológica. 
O objetivo deste trabalho é testar várias métricas baseadas em invertebrados bentônicos a fim de avaliar a qualidade da água de nascentes localizadas no Parque Estadual do Jaraguá, SP e escolher quais seriam mais adequadas para serem utilizadas em um futuro programa de biomonitoramento.

\section{MATERIAL E MÉTODOS}

\section{Local de trabalho}

O trabalho foi desenvolvido no Parque Estadual do Jaraguá, situado a $23^{\circ} 24^{\prime} \mathrm{S}$ e 4544'W, na cidade de São Paulo (SP). Sua área equivale a 491,98 ha. e sua altitude média corresponde a $900 \mathrm{~m}$. O clima da região caracteriza-se por apresentar duas estações bem definidas: verão quente e úmido e inverno frio e seco, com temperatura média anual de $20^{\circ} \mathrm{C}$. A precipitação pluviométrica média anual é de aproximadamente $1600 \mathrm{~mm}$, estando, no mês mais seco, entre 30 e $60 \mathrm{~mm}$. Localiza-se em área de relevo montanhoso em solo de complexo cristalino, formado por rochas ferromagnesianas, granito e gnaisses, filitos e micaxistos, quartzitos e calcário. Sua vegetação constitui-se de floresta ombrófila densa e floresta estacional semidecidual em diferentes estados sucessionais. Criado em 1961, e tombado como patrimônio da humanidade pela UNESCO em 1994, o Parque integra atualmente a Zona Núcleo da Reserva de Biosfera do Cinturão Verde da Cidade de São Paulo (Instituto Florestal, 2007).

O entorno do Parque caracteriza-se por uma grande variedade de usos da terra, dentre os quais se destacam áreas com atividades agrícolas e pecuária doméstica, áreas industriais, bairros com inicio de processo de loteamento e instalação de infra-estrutura básica (Sol Nascente e Chica Luiza), áreas ocupadas por movimentos sociais organizados (Sem Terra), bairros em etapas mais avançadas de urbanização (Vila Sulina e São Domingos) e área indígena (Carneiro, 2002; PROJETO BIOTA-JARAGUÁ, 1999). Além disso, outras ameaças à área são a caça e a extração ilegal de recursos florestais, mineração, poluição atmosférica, deposição de lixo urbano e depredação do ambiente por indivíduos não conscientes (Instituto Florestal, 2007).

Vide Capítulo I, pág. 16 para visualizar a localização das nascentes amostradas, bem como do entorno do Parque. 


\section{Coleta de dados}

Foram amostradas quatro nascentes, cuja seleção baseou-se na facilidade de acesso, semelhança do substrato e presença de mata nas margens. Três nascentes ( $\mathrm{Na} 1, \mathrm{Na} 2, \mathrm{Na} 3$ ) localizavam-se no interior do Parque e uma (Na4), a aproximadamente 70 metros dos limites externos do mesmo. De todas as nascentes, a Na3 é a de mais difícil acesso, seguida pela Na1. A Na2 localiza-se em área de acesso muito fácil, enquanto a $\mathrm{Na} 4$ localiza-se fora do Parque, e próxima a residências, embora esparsas. Devido à dificuldade de acesso e à ausência de sinais visíveis de impacto antropogênico (Tab. I), em um primeiro momento, poder-se-ia esperar que a $\mathrm{Na} 3$ fosse uma condição referência para o Parque e que o grau de impacto antropogênico fosse $\mathrm{Na} 4>\mathrm{Na} 2>\mathrm{Na} 1>\mathrm{Na} 3$.

Quanto ao substrato do leito, em corredeiras este era composto de frações granulométricas compreendendo areia, cascalhos e pedras, enquanto que nos poções, além de areia e algumas pedras, havia grande acúmulo de detritos vegetais de origem alóctone. A localização e profundidade média destes habitats estão apresentadas na Tabela I.

As coletas foram realizadas em campanha única durante o mês de maio de 2004. Essa época foi escolhida por representar um período intermediário entre os meses mais chuvosos e mais secos do ano. Desta forma, evitou-se amostrar em períodos de estresse para a fauna, pois na época seca o volume de água nas nascentes diminui muito. Por outro lado, na época chuvosa, o grande volume de água pode deslocar os organismos do substrato.

Em cada nascente foi delimitado um trecho de 40 metros no qual foram amostrados 5 poções e 5 corredeiras. Em cada habitat, retirou-se uma unidade amostral com auxílio de um Surber com malha de $500 \mu \mathrm{m}$ e área de $0,04 \mathrm{~m}^{2}$. Após posicionar o amostrador sobre o substrato, este era agitado de forma padronizada durante um minuto. No caso dos poções, produziu-se uma correnteza artificial, forçando a passagem do material pela malha do amostrador. Em laboratório, as amostras foram submetidas à flutuação com solução saturada de $\mathrm{NaCl}$ (Brandimarte e Anaya, 1998) e selecionadas em rede com abertura de malha de 500 $\mu \mathrm{m}$. O material retido foi preservado em formalina $4 \%$ e corado com floxina-B, de modo a facilitar a triagem dos invertebrados.

Os organismos foram identificados até o nível de familia usando-se as chaves taxonômicas apresentadas em: Borror e Delong (1988), Pennak (1989), Merritt e Cummins (1996), Wiggins (1998), Costa et al. (2006). 
Tabela I - Localização das nascentes, profundidade média de poções e corredeiras amostrados e indícios de impacto antropogênico nas nascentes amostradas (Parque Estadual do Jaraguá, São Paulo, SP).

\begin{tabular}{|c|c|c|c|c|}
\hline \multirow[b]{2}{*}{ Ponto } & \multirow[b]{2}{*}{ Localização } & \multicolumn{2}{|c|}{ Profundidade média (m) } & \multirow[b]{2}{*}{ Indícios de Impacto Antropogênico } \\
\hline & & Poção (P) & Corredeira $(\mathbf{C})$ & \\
\hline Nascente 1 & $\begin{array}{l}23^{\circ} 27^{\prime} 57.6^{\prime \prime S} \\
46^{\circ} 46^{\prime} 44.6^{\prime \prime} \mathrm{W}\end{array}$ & 0,082 & 0,036 & $\begin{array}{l}\text { Restos de fogueira, papéis de bala e etiquetas } \\
\text { de refrigerantes, mancha de óleo. }\end{array}$ \\
\hline Nascente2 & $\begin{array}{l}23^{\circ} 27^{\prime} 17.8^{\prime \prime S} \\
46^{\circ} 45^{\prime} 29.9^{\prime \prime} \mathrm{W}\end{array}$ & 0,148 & 0,06 & Papéis, copos plásticos, latas de alumínio. \\
\hline Nascente3 & $\begin{array}{l}23^{\circ} 28^{\prime} 01.8^{\prime \prime} \mathrm{S} \\
46^{\circ} 46^{\prime} 03.0^{\prime \prime} \mathrm{W}\end{array}$ & 0,062 & 0,04 & Aparentemente nenhum. \\
\hline Nascente 4 & $\begin{array}{l}23^{\circ} 27.50 .5 ” \mathrm{~S} \\
46^{\circ} 45^{\prime \prime} 29.1 \text { " W }\end{array}$ & 0,108 & 0,05 & $\begin{array}{l}\text { Embalagens plásticas, entrada de esgoto } \\
\text { doméstico. }\end{array}$ \\
\hline
\end{tabular}

Além da análise visual dos indícios de impacto antropogênico, para a caracterização da qualidade da água, em cada nascente foram retiradas amostras de água para análise da concentração de fósforo total e nitrogênio total (Valderrama. 1981) e coliformes fecais (APHA/AWWA/WPCF, 1998).

\section{Tratamento de dados}

A fim de realizar a análise da comunidade e estabelecer as métricas adequadas a um futuro biomonitoramento foram calculadas as métricas apresentadas na Tabela II.

Os valores de tolerância para as famílias de macroinvertebrados bentônicos foram extraídos de Junqueira et al. (2000). No cálculo do IBFM (índice biótico de famílias modificado), foram excluídas as famílias não contempladas no trabalho de Junqueira et al. (2000): Leptophlebidae, Calamoceratidae, Empididae, Aeglidae, Cyclopidae, Talitridae e Paleomonidae. 
Tabela II - Métricas empregadas para a análise da comunidade de macroinvertebrados bentônicos (Parque Estadual do Jaraguá, São Paulo, SP).

\begin{tabular}{|c|c|c|}
\hline Métricas & Referencial Teórico e Bibliográfico & $\begin{array}{ll}\text { Resposta } & \\
\text { esperada ao } & \text { au } \\
\text { aumento de } \\
\text { poluição }\end{array}$ \\
\hline Densidade média total & $\begin{array}{l}\text { Somatória do número de indivíduos amostrados, dividida pelo total } \\
\text { de unidades amostrais. Quando há entrada de poluição orgânica, o } \\
\text { aumento da concentração de nutrientes, especialmente sob a forma } \\
\text { de FPOM, pode levar ao aumento do número de indivíduos, } \\
\text { especialmente dos mais tolerantes (Thorne e Williams, 1997, } \\
\text { Hellawell,1989; Plafkin et al., 1989; Resh e Jackson, } 1993 \text {. }\end{array}$ & $\begin{array}{l}\text { Variável, mas } \\
\text { em geral } \\
\text { aumenta } \\
\text { (Dahl et al., } \\
\text { 2004). }\end{array}$ \\
\hline Riqueza total de famílias & $\begin{array}{l}\text { Somatória do número de famílias amostradas em cada nascente. } \\
\text { Geralmente consiste na identificação ao nível de espécie, mas pode } \\
\text { ser usada para grupos taxonômicos maiores, como famílias } \\
\text { (Hughes, 1978). A riqueza é extremamente influenciada por } \\
\text { distúrbios antropogênicos (Brittain e Saltveit, 1989), sendo o seu } \\
\text { declínio um dos indicadores de degradação mais confiáveis para } \\
\text { muitos grupos aquáticos, inclusive para macroinvertebrados } \\
\text { bentônicos (EPA-OHIO, 1987; Resh e Jackson, 1993; Kerans e } \\
\text { Karr, 1994; DeShon, 1995; Dahl et al., 2004). }\end{array}$ & Decresce. \\
\hline $\begin{array}{l}\text { Diversidade de Shannon-Wiener para } \\
\text { famílias }\end{array}$ & $\begin{array}{l}\text { Criado para dados identificados até o nível taxonômico de espécie, } \\
\text { o índice pode ser aplicado a níveis taxonômicos maiores, como } \\
\text { família (Hughes, 1978). O aumento da diversidade relaciona-se } \\
\text { com o aumento da saúde do ecossistema e sugere que o habitat e os } \\
\text { recursos alimentares são adequados para suportar a sobrevivência e } \\
\text { a propagação das espécies (EPA-OHIO, 1987; Norris e Georges, } \\
\text { 1993). }\end{array}$ & Decresce \\
\hline Dominância & $\begin{array}{l}\text { Expressa pela proporção de indivíduos pertencentes à família mais } \\
\text { numerosa em relação ao número total de indivíduos; indica que } \\
\text { uma comunidade dominada por poucos táxons reflete um ambiente } \\
\text { em desequilíbrio (Plafkin et al., 1989; Barbour et al., 1999). }\end{array}$ & Aumenta \\
\hline Riqueza de EPT & $\begin{array}{l}\text { Número total de famílias pertencentes às ordens Ephemeroptera, } \\
\text { Plecoptera e Trichoptera. A maioria dos organismos destas ordens } \\
\text { é sensível à poluição, quanto maior o valor, melhor a qualidade } \\
\text { ambiental (EPA-OHIO, 1987; Plafkin et al., 1989). }\end{array}$ & Decresce \\
\hline EPT/TOTAL (\%EPT) & $\begin{array}{l}\text { Razão entre a densidade de indivíduos pertencentes às ordens de } \\
\text { EPT e o número total de indivíduos. A maioria dos organismos } \\
\text { destas ordens é sensível à poluição, quanto maior o valor, melhor a } \\
\text { qualidade ambiental (Resh e Jackson, 1993). }\end{array}$ & Decresce \\
\hline
\end{tabular}


Tabela II - Continuação

\begin{tabular}{|c|c|c|}
\hline $\begin{array}{l}\text { Porcentagem de EPT/Porcentagem } \\
\text { de Chironomidae }\end{array}$ & $\begin{array}{l}\text { Razão entre a abundância relativa (porcentagem) de EPT e } \\
\text { porcentagem de Chironomidae, que é considerada tolerante à } \\
\text { poluição, enquanto as famílias de EPT são sensíveis (Rosenberg e } \\
\text { Resh, 1993). }\end{array}$ & Decresce \\
\hline $\begin{array}{l}\text { Não Diptera/Total } \\
\text { (\% Não Diptera) }\end{array}$ & $\begin{array}{l}\text { Expressa como a razão entre a densidade de não Diptera e a } \\
\text { densidade total de indivíduos presentes na amostra. Reflete a baixa } \\
\text { tolerância dos grupos de não diptera comparados aos grupos de } \\
\text { Diptera, especialmente Chironomidae e Ceratopogonidae } \\
\text { (Rosenberg e Resh, 1993). }\end{array}$ & Decresce \\
\hline Odonata/Total (\% Odonata) & $\begin{array}{l}\text { Expressa como a razão entre a densidade de Odonata e a densidade } \\
\text { total de indivíduos presentes na amostra. Odonata pode ser } \\
\text { considerada sensível à poluição (Junqueira et al. 2000; Barbour et } \\
\text { al., 1996). }\end{array}$ & Decresce \\
\hline Oligoqueta/Total (\%Oligoqueta) & $\begin{array}{l}\text { Expressa pela a razão entre a densidade de Oligochaeta e a } \\
\text { densidade total de indivíduos presentes na amostra. Devido ao fato } \\
\text { de Oligochaeta ser beneficiada pela entrada de matéria orgânica, } \\
\text { quanto maior sua porcentagem, pior a qualidade do ambiente } \\
\text { (Gerritsen et al., 1999). }\end{array}$ & Aumenta \\
\hline $\begin{array}{l}\text { IBFM - Índice biótico para famílias } \\
\text { modificado, utilizando-se as } \\
\text { pontuações de Junqueira et al. } \\
(\mathbf{2 0 0 0 )}\end{array}$ & $\begin{array}{l}\text { Expressa pela fórmula: } \sum \mathrm{x}_{1} \mathrm{t}_{1} \text {, onde } \mathrm{x}_{1}=\text { abundância relativa da } \\
\text { família e } \mathrm{t}_{1}=\text { valor da tolerância atribuída à família por Junqueira et } \\
\text { al. (2000). Este índice considera a contribuição de cada família } \\
\text { para a comunidade, ao multiplicar a tolerância pela abundância } \\
\text { relativa de cada família presente na amostra (Plafkin et al., 1989). }\end{array}$ & Diminui \\
\hline
\end{tabular}

A fim de comparar o grau de dispersão das métricas, calculou-se o coeficiente de variação para os valores de cada métrica para a nascente referência, ou seja, Na3. O coeficiente de variação, definido como o desvio-padrão em porcentagem da média, é a medida estatística mais utilizada pelos pesquisadores na avaliação da precisão dos experimentos. Ele tem a vantagem de permitir a comparação entre experimentos, sem a necessidade de igualdade de unidades (Pimentel-Gomes, 1987).

Para a aprovação das métricas foram observados dois critérios. O primeiro era que o coeficiente de variação $(\mathrm{CV})$ da métrica calculado para o ponto de referência $(\mathrm{Na} 3)$, devia ser inferior a $50 \%$ e o segundo, que a métrica respondesse como o esperado de acordo com a literatura consultada, evidenciando o ponto de melhor qualidade ambiental (Na3) e o de pior qualidade (Na4). 


\section{Obtenção do Índice Multimétrico para as Nascentes do Parque Estadual do}

Jaraguá

As métricas individuais cujo coeficiente de variação foi inferior a $50 \%$ e que se mostraram úteis em evidenciar os pontos de melhor qualidade ambiental (Na3) do ponto mais degradado ( $\mathrm{Na} 4)$ foram agrupadas num índice multimétrico de acordo com o proposto por Barbour et al. (1996).

Para normalizar as diferentes escalas numéricas (por exemplo, número de táxons, porcentagens, etc) a valores sem unidades (Karr e Chu, 1999; Gerritsen, 1995), os valores de cada métrica foram agrupados em três pontuações possíveis. Para métricas que decrescem em resposta à perturbação, todos os valores maiores ou iguais aos do $1^{\circ}$ quartil da distribuição de referência receberam a pontuação mais alta, ou seja, 5; os valores mínimos receberam a pontuação 1, enquanto que os valores intermediários, entre o mínimo e o primeiro quartil receberam pontuação 3. Ao contrário, para aquelas métricas cujo valor aumenta em resposta à poluição, todos os valores menores ou iguais aos do $3^{\circ}$ quartil da distribuição de referência receberam a pontuação mais alta, 5; os valores superiores ou iguais ao máximo da distribuição receberam pontuação 1 , enquanto que os valores situados entre o máximo e o $3^{\circ}$ quartil receberam pontuação 3 (Tab V).

\section{RESULTADOS}

A Na4 apresentou os maiores valores para coliformes fecais e concentração de fósforo total. A concentração de nitrogênio total em todas as nascentes estava abaixo no nível de detecção do método (Tab III).

Tabela III - Valores de coliformes fecais, nitrogênio total e fósforo total encontrados nas nascentes localizadas no Parque Estadual do Jaraguá, São Paulo, SP.

\begin{tabular}{|c|c|c|c|c|}
\cline { 2 - 5 } \multicolumn{1}{c|}{} & Na1 & Na2 & Na3 & Na4 \\
\hline $\begin{array}{c}\text { Coliformes fecais } \\
\text { (NMP) }\end{array}$ & 1 & 213 & 1 & 3000 \\
Nitrogênio (mg/L) & $<0,008$ & $<0,008$ & $<0,008$ & $<0,008$ \\
Fósforo (mg/L) & 0,026 & 0,029 & 0,028 & 0,038 \\
\hline
\end{tabular}


Tabela IV - Valores das métricas aplicadas aos invertebrados bentônicos das nascentes amostradas (Parque Estadual do Jaraguá, São Paulo, SP).

\begin{tabular}{|c|c|c|c|c|c|c|c|}
\hline Métricas & Na1 & $\mathrm{Na} 2$ & $\mathrm{Na3}$ & $\mathbf{N a 4}$ & $\mathbf{C V}$ & $\begin{array}{l}\text { Responde } \\
\text { conforme } \\
\text { o } \\
\text { esperado? }\end{array}$ & Status \\
\hline Densidade média populacional & 3705 & 3320 & 3202,5 & 4705 & 83 & Sim & Rejeitada \\
\hline Riqueza total de famílias & 25 & 27 & 23 & 25 & $24 *$ & Não & Rejeitada \\
\hline Riqueza de EPT & 5 & 8 & 5 & 8 & $31 *$ & Não & Rejeitada \\
\hline $\begin{array}{l}\text { Diversidade de Shannon- } \\
\text { Wiener }\end{array}$ & 1,17 & 1,83 & 2,0 & 1,74 & $45^{*}$ & Sim & Aprovada \\
\hline Dominância (\%) & 58 & 58 & 55 & 70 & $45^{*}$ & Sim & Aprovada \\
\hline$\%$ EPT & 22 & 15 & 22 & 8 & $24 *$ & Sim & Aprovada \\
\hline$\%$ Odonata & 3 & 1 & 6 & 6 & $34 *$ & Não & Rejeitada \\
\hline$\%$ Oligoqueta & 2 & 4 & 1 & 2 & 159 & Não & Rejeitada \\
\hline \% não diptera & 33 & 36 & 41 & 25 & 67 & Sim & Rejeitada \\
\hline$\%$ EPT $/ \%$ Chironomidae & 38 & 27 & 4 & 11 & 139 & Sim & Rejeitada \\
\hline IBFM & 3,30 & 3,58 & 3,81 & 2,75 & $38 *$ & Sim & Aprovada \\
\hline
\end{tabular}

(*) Coeficiente de variação abaixo de $50 \%$.

Na tabela IV encontram-se os resultados obtidos para o cálculo das métricas aplicadas aos invertebrados bentônicos das nascentes do Parque Estadual do Jaraguá, o coeficiente de variação de cada métrica em Na3 e a consideração se a métrica em questão responde como o esperado e seu status final (aprovada ou rejeitada).

As métricas diversidade de Shannon-Wiener, dominância, porcentagem de EPT e IBFM foram as únicas aprovadas porque atenderam aos dois critérios estabelecidos (Tab IV). Portanto receberam pontuação para a construção do índice multimétrico (Tab. V).

Tabela V - Valores mínimo, do $1^{\circ}, 2^{\circ}$ e $3^{\circ}$ quartis e máximo da distribuição de referência das métricas cujo coeficiente de variação foi igual ou inferior a $50 \%$ e as pontuações atribuídas a cada uma delas na construção do índice multimétrico.

\begin{tabular}{|l|c|c|c|c|c|l|l|c|}
\hline Métricas & $\min$ & $\mathbf{1}^{\mathbf{0}}$ Quartil & $\mathbf{2}^{\mathbf{0}}$ Quartil & $\mathbf{3}^{\mathbf{0}}$ Quartil & $\mathbf{m a x}$ & $\mathbf{5}$ & $\mathbf{3}$ & $\mathbf{1}$ \\
\hline \%EPT & 8 & 13 & 19 & 22 & 22 & $\geq 13$ & $9-12$ & $\leq 8$ \\
Diversidade de & 1,17 & 1,60 & 1,79 & 1,87 & 2,00 & $\geq 1,6$ & $1,18-1,589$ & $\leq 1,17$ \\
Shannon-Wiener & & & & & & & & \\
IBFM & 2,75 & 3,16 & 3,44 & 3,64 & 3,81 & $\geq 3,16$ & $3,17-2,76$ & $\leq 2,75$ \\
Dominância & 0,55 & 0,57 & 0,58 & 0,61 & 0,70 & $\leq 0,61$ & $0,62-0,69$ & $\geq 0,7$ \\
\hline
\end{tabular}


Somando-se as pontuações atribuídas às métricas da forma indicada na tabela acima, os valores do índice multimético foram: $\mathrm{Na} 1=16 ; \mathrm{Na} 2=20 ; \mathrm{Na} 3=20 ; \mathrm{Na} 4=8$.

\section{DISCUSSÃO}

Apesar de terem sido observados, no momento da coleta, indícios de impactos antropogênico em três das quatro nascentes ( $\mathrm{Na} 1, \mathrm{Na} 2$ e $\mathrm{Na} 4)$, o resultado das análises de fósforo total e coliformes fecais nos fazem perceber que a Na4 está mais impactada que as demais. Portanto, as métricas selecionadas deveriam discriminar esta nascente em relação às de melhor qualidade da água, especialmente da $\mathrm{Na3}$, cujo acesso é mais difícil e que, portanto, teoricamente, deveria estar menos impactada.

Com relação às métricas utilizadas, medidas de densidade são questionadas por Resh et al. (1995) quanto à sua utilidade, uma vez que podem ser altamente variáveis. Além disso, muitos autores rejeitam sua eficiência, como Butcher et al. (2003), porque respondem positivamente ao aumento de matéria orgânica no ambiente até determinado ponto. Por exemplo, Thorne e Williams (1997), ao trabalharem em rios tropicais do Brasil, Gana e Tailândia, perceberam que grandes populações eram encontradas em níveis intermediários de poluição; mas em locais severamente poluídos, eram restringidas por condições tóxicas e anóxicas. No presente trabalho, a Na4 apresentou a densidade total mais elevada em relação às demais nascentes, o que deve ter ocorrido devido à entrada de esgotos. No nosso caso, tal métrica seria útil para discriminar a nascente mais impactada das demais, mas foi rejeitada porque seu coeficiente de variação ficou acima de $50 \%$.

Espera-se que ambientes naturais não degradados apresentem valores superiores para riqueza de táxons, pois esta diminui com a queda da qualidade do meio aquático (Resh e Jacskon, 1993). O que se observou na Na4 foi justamente o contrário, pois ali a riqueza de táxons apresentou o mesmo resultado que na $\mathrm{Na} 1$ e foi superior à $\mathrm{Na} 3$. Isso deve ter ocorrido devido ao aumento de matéria orgânica ocasionado pela entrada do efluente doméstico, pois estudos têm mostrado a elevação da riqueza de táxons, incluindo EPT, em resposta a um ligeiro aumento da poluição (Thorne e Williams, 1997; Pinder e Farr, 1987). O declínio da riqueza de táxons é um dos indicadores de degradação mais confiáveis para muitos grupos aquáticos (Ford, 1989; Barbour et al., 1995), inclusive para invertebrados bentônicos (EPAOHIO, 1987; Kerans e Karr, 1994, DeShon, 1995), porém, neste trabalho, optamos por rejeitar a métrica riqueza total de famílias, uma vez que seu resultado pode ter sido 
beneficiado pela maior quantidade de matéria orgânica em $\mathrm{Na} 4$, de forma que sua aceitação poderia levar a conclusões errôneas.

Da mesma forma que a riqueza total de famílias, a riqueza de famílias de EPT tem sido considerada efetiva em discriminar locais impactados de não impactados (Barbour et al., 1992; Resh e Jackson, 1993). Entretanto, neste trabalho, a métrica riqueza de EPT não discriminou eficientemente a nascente impactada das demais, apresentando seu valor mais alto em $\mathrm{Na} 4$, provavelmente, pelo mesmo motivo que influenciou a riqueza total de famílias. Assim, a riqueza de EPT também foi rejeitada.

Apesar da riqueza de EPT ter sido descartada, a abundância relativa de EPT foi considerada uma métrica adequada. Os valores inferiores atingidos em $\mathrm{Na} 4$ mostram que, apesar da maior riqueza de EPT, os indivíduos ali encontrados contribuem muito pouco para a composição da comunidade, indicando distúrbio ambiental nesta nascente.

Apesar de Na4 apresentar riqueza mais elevada, o alto valor de dominância, com Chironomidae representando $70 \%$ do total da fauna de macroinvertebrados bentônicos, levou à redução da diversidade de Shannon-Wiener. Nas demais nascentes, a dominância é menor, resultando em valores de diversidade maiores. Sabe-se que o aumento da diversidade relaciona-se ao aumento da saúde do ecossistema e que ecossistemas estáveis e saudáveis serão relativamente consistentes quanto à representação proporcional da fauna, apesar das densidades individuais variarem em magnitude (EPA-OHIO, 1987). Por isso, a dominância e a diversidade de Shannon-Wiener foram consideradas métricas úteis para a avaliação da comunidade de macroinvertebrados bentônicos das nascentes amostradas, diferenciando a nascente mais impactada das demais.

Neste trabalho, para o cálculo do índice biótico de família modificado (IBFM), optouse por utilizar os valores de tolerância atribuídos por Junqueira et al. (2000) em seu trabalho em rios do estado de Minas Gerais, por serem os desenvolvidos para a região geográfica mais próxima do presente trabalho. No nível taxonômico de família, tais escores baseiam-se numa média de tolerância à matéria orgânica de todas as espécies que a mesma apresenta em uma dada região. Assim, a aplicação do índice é restrita à localidade para a qual foi desenvolvido (Junqueira et al., 2000). Mesmo não tendo usado valores de tolerância especialmente desenvolvidos para o Parque Estadual do Jaraguá, o IBFM mostrou-se uma métrica apropriada para a análise das nascentes amostradas, pois automaticamente forneceu pesos às famílias ali presentes, ao utilizar os dados de abundância relativa em cada nascente. Como os índices de Junqueira et al. (2000) atribuem valores mais altos a famílias mais sensíveis, o esperado era que a nascente mais impactada, ao possuir mais famílias tolerantes com maiores 
abundâncias relativas, apresentasse os valores mais baixos. Essa métrica não só discriminou $\mathrm{Na} 4$ das demais, atribuindo-lhe o mais baixo dos valores, como tornou possível a ordenação das nascentes de acordo com o grau de impacto antropogênico imaginado, tanto pela presença dos indícios já citados, como devido ao acesso público a cada uma delas. Assim, o índice alcançou o valor mais elevado na $\mathrm{Na} 3$, sendo seguido pelas nascentes $\mathrm{Na} 2$ e $\mathrm{Na} 1$ e finalmente, com o valor mais baixo, pela Na4. De todas as métricas aplicadas esta foi, sem dúvida, a que melhor discriminou os pontos.

A utilização de um índice multimétrico levou em consideração o fato das métricas individuais não serem consideradas plenamente confiáveis (Gerritsen, 1995), por fornecerem informação apenas sobre um atributo da comunidade, enquanto que um índice multimétrico, ao incorporar várias métricas, oferece uma indicação geral das condições da comunidade biológica (Barbour et al., 1995). Ao somarmos as pontuações atribuídas de acordo a cada uma das métricas aprovadas para este trabalho (abundância relativa de EPT, diversidade de Shannon-Wiener, dominância e IBFM), percebemos que o índice multimétrico obtido não só discriminou a Na4 da nascente referência, mas também possibilitou a ordenação das quatro nascentes, da mesma forma que o IBFM.

\section{CONCLUSÃO}

Das onze métricas testadas neste trabalho para a análise da qualidade da água das nascentes do Parque Estadual do Jaraguá (São Paulo, SP), apenas quatro mostraram-se úteis para diferenciar a nascente impactada (Na4) das demais: diversidade de Shannon-Wiener, dominância, abundância relativa de táxons de EPT e IBFM, sendo esta última a melhor métrica individual. A reunião destas métricas resultou num índice multimétrico que colaborou para aumentar o poder de diferenciação entre as nascentes não impactadas e a impactada.

\section{REFERÊNCIAS BIBLIOGRÁFICAS}

\section{APHA/AWWA/WPCF. Standard methods for the examination of water and wastewater. 20th ed. APHA/AWWA/WPCF. 1998.}


BAPTISTA, D.F. et al. A multimetric index based on benthic macroinvertebrates for evaluation of Atlantic Forest streams at Rio de Janeiro State, Brazil. Hydrobiologia, v. 575, p. 83 - 94, 2007.

BARBOUR, M.T. et al. Evaluation of EPA's rapid bioassessment benthic metrics: metric redundancy and variability among reference streams site. Environmental Toxicology and Chemistry, v. 11, p 437 - 499, 1992.

BARBOUR, M. T.; STRIBLING, J.B.; KARR, J.R. The multimetric approach for stablishing biocriteria and measuring conditions. In: DAVIS, W.; SIMON, T (Eds.). Biological assessment and criteria: tools for water resource planning and decision-making. Lewis Publishers. Ann Arbor, Michingan, p. 63 - 76, 1995.

BARBOUR, M. T. et al. A framework for biological criteria for Florida streams using benthic macroinvertebrates. Journal of the North American Benthological Society, v. 15, p. 185 211, 1996.

BARBOUR, M. T. et al. Revision to rapid bioassessment protocols for use in streams and rivers: peryphiton, benthic macroinvertebrates and fish. Washington: Environmental Protection Agency; Office of Water. 1999. EPA 841-D-97002.

BORROR, D. J.; DELONG, D. M. Introdução ao estudo dos insetos. São Paulo: Edusp, 1988. 563 p.

BOURNARD, M. et al. Macroinvertebrate community structure and environmental characteristics along a large river: congruity of patterns of identification to species or family. Journal of the North American Benthological Society, v. 15, p. 232 - 253, 1996.

BRANDIMARTE, A. L.; ANAYA, M. Bottom fauna flotation using a solution of sodium chloride. Verhandlng für Internationale für Theoritische and Angewandte Limnologie, v. 26, p. $2358-2359,1998$.

BRITTAIN, J. E.; SALTVEIT, S. J. A review of the effects of river regulation on mayflies (Ephemeroptera). Regulated Rivers: Research and Management, v.3, p. 91 - 204, 1989.

BUTCHER, J.T.; STEWART, P.M.; SIMON, T.P. A benthic community index for streams in the northern lakes and forrests ecoregion. Ecological Indicators, v. 3, p. 181 - 193, 2003.

CAIRNS JR., J.; PRATT, J. A history of biological monitoring using benthic macroinvertebrates. In: ROSENBERG, D. M.; RESH, V. H. Freshwater bimonitoring and benthic macroinvertebrates. New York: Chapman e Hall, 1993. Cap.2, p. 10 - 27.

CARNEIRO, C.D.R. 2002. Cavas de Ouro Históricas do Jaraguá, SP - Os primórdios da mineração no Brasil. In: Schobbenhaus, C. et al. (Orgs.) Sítios Geológicos e Paleontológicos do Brasil. 1. ed. Brasilia: DNPM/CPRM - Comissão Brasileira de Sítios Geológicos e Paleobiológicos (SIGEP), v.01, p. 511-515, 2003. (Disponível em:

(http://www.unb.br/ig/sigep/sitio098/sitio098.pdf). Acesso em: 05/03/2007.

COSTA, C.; IDE, S.; SIMONKA, C. E. (Orgs.). Insetos Imaturos: Metamorfose e Identificação. Ribeirão Preto: Holos. 249p, 2006. 
DAHL, J.; JOHNSON R. K.; SANDIN L. Detection of organic pollution of streams in southern Sweden using benthic macroinvertebrates. Hydrobiologia, v. 516, p. 161 - 172, 2004.

DESHON, J.E. Development and application of the invertebrate community index (ICI). In: DAVIS, W.; SIMON, T (Orgs.). Biological assessment and decision making. Lewis Publishers, Boca Raton: Florida, 1995. cap. 8, p. 217 - 243.

EPA-OHIO. 1987. Biological criteria for the protection of aquatic life: User's manual for biological field assessment of Ohio surface waters. Columbus: Division of water quality monitoring and assessment, 1987.

FORD, J. The effects of chemical stress on aquatic species composition and community strutucture. In: LEVIN, S.A. et al. (Orgs.). Ecotoxicology: problems and approaches. Springer Verlag, New York. 1989. cap. 4. p. 99-144.

FURSE, M.T. et al. 1984. The influence of seasonal and taxonomy factors on the ordination and classification of running-water sites in Great Britain and on the prediction of their macroinvertebrate communities. Freshwater Biology, v. 14, p. 257-280, 1984.

GERRITSEN, J. Additive biological indices for resource management. Journal of the North American Benthological Society, v. 14, p. 451 - 457, 1995.

GERRITSEN, J. et al. Lake and reservoir bioassessment and biocriteria - technical guidance document. Washington: U.S.E.P.A Office of Water. EPA 841-b-98-0007, 1999. Disponivel em: < http://www.epa.gov.owow/monitoring/tech/lakes.html>. Acesso em: 01/09/2007.

GOODYEAR, K. L.; McNEILL, S. Bioaccumulation of heavy metals by aquatic macroinvertebrates of different feeding guilds: a review. The Science of the Total Environment, v. 229, p.1 - 19, 1999.

HARE, L.; CAMPBELL, P.G.C. Temporal variations of trace metals in aquatic insects. Freshwater Biology, v. 27, p. 13 - 27, 1992.

HELLAWELL, J.M. Biological Indicators of Freshwater Pollution and Environmental Management. Pollution Monitoring Series. New York: Elsevier Applied Science, 1989. 546p.

HERING, D. et al. Overview and application of the AQEM assessment system. Hydrobiologia, v. 516, p. 1 - 20, 2004.

HUGHES, B.D. The influence of factor other than pollution on the value of the Shannon's diversity index for benthic macroinvertebrates. Water Research, v.12, p. 359 - 364, 1978.

HYNES, H.A. 1970. The ecology of running waters. Liverpool: Liverpool University Press, 1970. $555 \mathrm{p}$.

INSTITUTO FLORESTAL. 2007. Unidades do Instituto Florestal. São Paulo, Instituto Florestal da Secretaria de Estado do Meio Ambiente. Disponível em: http://www.iflorestal.sp.gov.br/unidades_conservacao/informacoes.asp?cod=13. Acesso em: 20/01/2007. 
JUNQUEIRA, M.V. et al. Biomonitoramento da qualidade das águas da bacia do alto Rio das Velhas (MG/Brasil) através de macroinvertebrados. Acta Limnologica Brasiliencia. v. 12, p. 73 - 87, 2000.

KARR, J.R.; CHU, E.W. Restoring life in running waters: better biological monitoring. Island Press, Covelo, CA. 1999. 206p.

KERANS, B. L.; J. R. KARR. A benthic index of biotic integrity (B-IBI) for rivers of the Tennessee Valley. Ecol. Appl., v. 4, 768 - 785, 1994.

KLEMM, D.J.; BLOCKSOM; K. A.; FULK, F. A. Development and Evaluation of a Macroinvertebrate Biotic Integrity Index (MBII) for Regionally Assessing Mid-Atlantic Highlands Streams. Environmental Management, v. 31, p. 656 - 669, 2003.

LYNCH, T. R.; POPP, C. J.; JACOBI, G. Z. Aquatic insects as environmental monitors of trace metal contamination: Red River, New Mexico. Water, Air, e Soil Pollution, v. 42, p.19 - 31, 1988.

LOEB, S.L. An ecological context for biological monitoring. In LOEB, S.L.; SPACIE, A. (Orgs.). Biological monotoring aquatic system. Boca Roton: Lewis Publishers, 1994. cap 1, p $3-7$.

MARQUES, M. M; BARBOSA, F. Biological quality of waters from an impacted tropical watershed (middle Rio Doce basin, southeast Brazil), using benthic macroinvertebrate communities as an indicator. Hydrobiologia, v. 457, p. 9 - 76, 2001.

MERRITT, R.W.; CUMMINS, K.W. (Orgs.). An introduction to the aquatic insects of North America. $3^{\text {a }}$ ed. Dubuque: Kendall/Hunt Publishers, 1996. 862 p.

MORETTI, M.; CALLISTO, M. Biomonitoriung of the benthic macroivertebrates in the middle Doce River watershed. Acta Limnologica Brasiliensia, v. 17, p. 267 - 281, 2005.

MYSLINSKI, E.; GINSBURG, W. Macro-invertebrates as indicators of pollution. Journal of the American Water Works Association, v. 69, p. 538 - 544, 1977.

NORRIS, R.H.; GEORGES, A. Analysis and interpretation of benthic macroinvertebrates survyes. In: In: ROSENBERG, D.M.; RESH, V.H. (Orgs.) Freshwater biomonitoring and benthic macroinvertebrates. New York: Chapman e Hall, 1993. cap. 7, p 234 - 286.

PAUL, M.J.; MEYER, J.L. Streams in the urban landscape. Annual Review of Ecology and Systematics, v. 32, p. 333 - 365, 2001.

PENNAK, R. W. Fresh-water invertebrates of the United States. Protozoa to Mollusca. $3^{\mathrm{a}}$. ed. New York: Wiley, 1989. 628 p.

PIMENTEL-GOMES, F. Curso de Estatística Experimental. 12 a ed. Piracicaba: Livraria Nobel, 1987. 467p. 
PINDER, L.C.V.; FARR; I.S. Biological surveillance of water quality-3. The influence of organic enrichment on the macroinvertebrates of a small chalk stream. Archiv. fur

Hydrobiologie, v. 109, p. 619 - 637, 1987.

PLAFKIN, J.L. et al. Rapid bioassessment protocols for use in streams and rivers: benthic macroinvertebrates and fish. Washington: Environmental Protection Agency; Assessment and watershed division. 1989.

PROJETO BIOTA-JARAGUÁ, Parque Estadual do Jaraguá. Relatório Técnico Cientifico, PPG-ERN, Ciências Biológicas - UFSCAR, Movimento Ecocultural e Instituto Florestal do Jaraguá, 1999. 162 pp.

RESH, V.H.; JACKSON, J.K. Rapid assessment approaches to biomonitoring using benthic macroinvertebrates. In: ROSENBERG, D.M.; RESH, V.M. (Orgs.) Freshwater biomonitoring and benthic macroinvertebrares. New York: Chapman e Hall, 1993. cap.1, p 1-9.

RESH, V.H.; NORRIS, R.H.; BARBOUR, M.T. Design and implementation of rapid assessment approaches for water resource monitoring using benthic macroinvertebrates. Australian Journal of Ecology, v. 20, p. 108 - 121, 1995.

RICO, E. et al. Comparison of several biological índices base don river macroinvertebrate benthic community for assessment of running water quality. Ann. Limnol., v.28, p. 146 - 156, 1992.

ROSENBERG, D.M.; RESH, V.H. Intruduction to freshwater biomonitoring and benthic macroinvertebrates. In: ROSENBERG, D.M.; RESH, V.H. (Orgs.) Freshwater biomonitoring and benthic macroinvertebrates. New York: Chapman e Hall, 1993. cap.1, p. 1 - 9.

ROSENBERG, D. M.; WIENS, A. P. Community and species responses of Chironomidae (Diptera) to contamination of freshwaters by crude oil and petroleum products, with special reference to the trail river, Northwest Territories. Journal of the Fisheries Research Board of Canada, v. 33, p. 1955 - 1963, 1976.

THORNE, R.S.J.; WILLIAMS, P. The response of benthic macroinvertebrates to pollution in developing countries: a multimétrico system of bioassessment. Freshwater Biology, v. 37, p. $671-86,1997$.

TOMANOVA, S.; GOITIA, E., HELESIC, J. Trophic levels and functional groups of macroinvertebrates in neotropical streams. Hydrobiologia, v.556, p.251 - 264, 2006.

VALDERRAMA, J.C. The simultaneous analysis of total nitrogen and phosphorus in natural waters. Mar. Chem., v. 10, p. 109-122, 1981.

WALSH, C.J. Urban impacts on the ecology receiving waters: a framework for assessment, conservation and restoration. Hydrobiologia, v. 431, p. 107 - 114, 2000.

WIGGINS, G. B. Larvae of the North American caddisfly genera (Trichoptera). $2^{\mathrm{a}}$ ed. Toronto: Univ. Toronto Press, 1998. 457p. 


\section{CONSIDERAÇÕES FINAIS}

Considerando a importância do Parque Estadual do Jaraguá como um dos últimos remanescentes de mata atlântica localizada na área urbana do município de São Paulo, as pressões antropogênicas a que está sujeito e o seu valor como opção de lazer para a população do entorno, a preocupação com o biomonitoramento das nascentes é essencial.

Neste sentido, as informações trazidas pelo presente trabalho são valorosas pelo seu pioneirismo e apontam para novos trabalhos, pois as nascentes do Parque Estadual do Jaraguá já demonstram sinais impactos causados tanto pela visitação pública, quanto pelos diferentes tipos de pressões sofridos pelo entorno, tal como mostrado neste trabalho.

Embora algumas métricas tenham se revelado úteis para o biomonitoramento destas nascentes, é importante que se realizem novos trabalhos que amostrem um maior um maior número de nascentes a fim de melhorar e ampliar o conjunto de métricas aplicáveis para a área e também para determinar os valores regionais de tolerância para as famílias de macroinvertebrados

bentônicos ali

existentes. 
ANEXOS 
Anexo 1- Densidade total de cada táxon de macroinvertebrados bentônicos amostrado em poções e corredeiras da nascente 1 do Parque Estadual do Jaraguá, São Paulo, SP.

\begin{tabular}{|c|c|c|c|c|c|c|c|c|c|c|}
\hline & Na1P1 & $\mathrm{Na} 1 \mathrm{C} 1$ & Na1P2 & $\mathrm{Na} 1 \mathrm{C} 2$ & Na1P3 & Na1C3 & Na1P4 & $\mathrm{Na} 1 \mathrm{C} 4$ & Na1P5 & $\mathrm{Na} 1 \mathrm{C} 5$ \\
\hline Hydracarina (ni) & 0 & 0 & 0 & 0 & 0 & 0 & 0 & 0 & 0 & 0 \\
\hline Bivalvia (ni) & 0 & 0 & 0 & 0 & 0 & 0 & 0 & 0 & 0 & 0 \\
\hline Tubificidae & 175 & 0 & 25 & 0 & 300 & 50 & 150 & 0 & 50 & 0 \\
\hline Cyclopidae & 125 & 0 & 50 & 0 & 75 & 0 & 25 & 0 & 0 & 0 \\
\hline Talitridae & 0 & 0 & 25 & 0 & 0 & 0 & 25 & 0 & 0 & 0 \\
\hline Paleomonidae & 0 & 0 & 0 & 0 & 0 & 0 & 0 & 0 & 0 & 0 \\
\hline Aeglidae & 125 & 0 & 150 & 0 & 50 & 25 & 100 & 0 & 150 & 75 \\
\hline Baetidae & 350 & 0 & 75 & 125 & 0 & 75 & 150 & 50 & 50 & 150 \\
\hline Leptophlebidae & 250 & 0 & 0 & 0 & 25 & 50 & 50 & 0 & 0 & 100 \\
\hline Aeshnidae & 100 & 0 & 0 & 0 & 25 & 0 & 0 & 0 & 0 & 0 \\
\hline Coenagrionidae & 0 & 0 & 25 & 0 & 0 & 0 & 0 & 0 & 0 & 25 \\
\hline Gomphidae & 25 & 0 & 0 & 0 & 100 & 0 & 75 & 0 & 0 & 0 \\
\hline Libellulidae & 0 & 25 & 0 & 25 & 0 & 0 & 0 & 0 & 0 & 0 \\
\hline Grypopterigidae & 0 & 50 & 75 & 25 & 0 & 75 & 175 & 0 & 75 & 100 \\
\hline Perlidae & 0 & 25 & 0 & 0 & 0 & 0 & 0 & 0 & 0 & 0 \\
\hline Calamoceratidae & 0 & 0 & 0 & 0 & 0 & 0 & 0 & 0 & 0 & 0 \\
\hline Hydrobiosidae & 0 & 0 & 0 & 0 & 0 & 0 & 0 & 0 & 0 & 0 \\
\hline Hydropsychidae & 0 & 0 & 0 & 0 & 0 & 0 & 0 & 0 & 0 & 0 \\
\hline Hydroptilidae & 0 & 0 & 75 & 0 & 50 & 0 & 0 & 0 & 0 & 0 \\
\hline Leptoceridae & 375 & 0 & 200 & 0 & 425 & 0 & 75 & 0 & 25 & 0 \\
\hline Philopotamidae & 0 & 0 & 0 & 0 & 0 & 0 & 0 & 0 & 0 & 0 \\
\hline Polycentropodidae & 0 & 0 & 0 & 0 & 0 & 0 & 0 & 0 & 0 & 0 \\
\hline Dytiscidae & 50 & 0 & 0 & 0 & 0 & 0 & 0 & 0 & 0 & 0 \\
\hline Elmidae & 25 & 25 & 50 & 0 & 200 & 0 & 25 & 0 & 25 & 100 \\
\hline Psephenidae & 25 & 0 & 25 & 0 & 25 & 0 & 0 & 0 & 0 & 0 \\
\hline Ceratopogonidae & 175 & 0 & 0 & 0 & 50 & 100 & 50 & 0 & 0 & 0 \\
\hline Chironomidae & 8450 & 75 & 7325 & 75 & 8625 & 300 & 2075 & 50 & 2275 & 375 \\
\hline Dolichopodidae & 0 & 0 & 0 & 0 & 0 & 0 & 0 & 0 & 0 & 0 \\
\hline Empididae & 100 & 0 & 25 & 0 & 25 & 0 & 0 & 0 & 0 & 0 \\
\hline Psychodidae & 25 & 0 & 0 & 0 & 0 & 0 & 0 & 0 & 0 & 0 \\
\hline Simulidae & 0 & 25 & 0 & 25 & 0 & 0 & 0 & 25 & 0 & 250 \\
\hline Stratyomidae & 25 & 0 & 0 & 0 & 25 & 0 & 25 & 0 & 75 & 0 \\
\hline Tabanidae & 25 & 0 & 0 & 0 & 75 & 0 & 0 & 0 & 0 & 0 \\
\hline Tipulidae & 100 & 0 & 0 & 25 & 25 & 0 & 50 & 0 & 25 & 0 \\
\hline TOTAL & 10525 & 225 & 8125 & 300 & 10100 & 675 & 3050 & 125 & 2750 & 1175 \\
\hline
\end{tabular}


Anexo 2- Densidade total de cada táxon de macroinvertebrados bentônicos amostrado em poções e corredeiras da nascente 2 do Parque Estadual do Jaraguá, São Paulo, SP.

\begin{tabular}{|c|c|c|c|c|c|c|c|c|c|c|}
\hline & $\mathrm{Na} 2 \mathrm{P} 1$ & $\mathrm{Na} 2 \mathrm{C} 1$ & $\mathrm{Na} 2 \mathrm{P} 2$ & $\mathrm{Na} 2 \mathrm{C} 2$ & $\mathrm{Na} 2 \mathrm{P} 3$ & $\mathrm{Na} 2 \mathrm{C} 3$ & $\mathrm{Na} 2 \mathrm{P} 4$ & $\mathrm{Na} 2 \mathrm{C} 4$ & $\mathrm{Na} 2 \mathrm{P} 5$ & $\mathrm{Na} 2 \mathrm{C} 5$ \\
\hline Hydracarina (ni) & 75 & 0 & 25 & 0 & 150 & 0 & 0 & 25 & 150 & 0 \\
\hline Bivalvia (ni) & 0 & 0 & 175 & 0 & 25 & 0 & 0 & 0 & 0 & 100 \\
\hline Tubificidae & 700 & 0 & 375 & 25 & 25 & 0 & 75 & 0 & 200 & 50 \\
\hline Cyclopidae & 0 & 0 & 0 & 0 & 0 & 0 & 0 & 0 & 0 & 0 \\
\hline Talitridae & 75 & 0 & 150 & 0 & 0 & 0 & 50 & 0 & 0 & 0 \\
\hline Paleomonidae & 0 & 0 & 0 & 0 & 0 & 25 & 0 & 25 & 0 & 50 \\
\hline Aeglidae & 0 & 0 & 25 & 0 & 0 & 0 & 0 & 0 & 0 & 0 \\
\hline Baetidae & 150 & 75 & 350 & 50 & 0 & 25 & 225 & 50 & 50 & 0 \\
\hline Leptophlebidae & 25 & 50 & 125 & 0 & 0 & 0 & 100 & 0 & 25 & 25 \\
\hline Aeshnidae & 0 & 0 & 0 & 0 & 0 & 0 & 25 & 0 & 25 & 0 \\
\hline Coenagrionidae & 0 & 0 & 0 & 0 & 0 & 0 & 0 & 0 & 25 & 0 \\
\hline Gomphidae & 150 & 0 & 25 & 0 & 25 & 0 & 50 & 0 & 0 & 0 \\
\hline Libellulidae & 0 & 25 & 25 & 0 & 0 & 25 & 0 & 25 & 0 & 0 \\
\hline Grypopterigidae & 200 & 225 & 250 & 0 & 775 & 50 & 75 & 125 & 225 & 50 \\
\hline Perlidae & 0 & 0 & 0 & 0 & 0 & 0 & 0 & 0 & 0 & 0 \\
\hline Calamoceratidae & 0 & 0 & 75 & 0 & 0 & 0 & 0 & 0 & 0 & 0 \\
\hline Hydrobiosidae & 0 & 0 & 0 & 0 & 0 & 0 & 0 & 0 & 0 & 0 \\
\hline Hydropsychidae & 0 & 25 & 0 & 0 & 0 & 0 & 0 & 0 & 0 & 0 \\
\hline Hydroptilidae & 25 & 25 & 25 & 0 & 0 & 0 & 0 & 0 & 0 & 0 \\
\hline Leptoceridae & 250 & 0 & 475 & 0 & 175 & 0 & 100 & 0 & 250 & 0 \\
\hline Philopotamidae & 0 & 25 & 0 & 0 & 0 & 0 & 0 & 0 & 0 & 0 \\
\hline Polycentropodidae & 50 & 0 & 0 & 0 & 0 & 0 & 0 & 0 & 0 & 0 \\
\hline Dytiscidae & 0 & 0 & 25 & 0 & 25 & 0 & 0 & 0 & 0 & 0 \\
\hline Elmidae & 25 & 100 & 175 & 0 & 375 & 0 & 150 & 0 & 75 & 0 \\
\hline Psephenidae & 25 & 275 & 0 & 150 & 0 & 125 & 0 & 25 & 25 & 25 \\
\hline Ceratopogonidae & 0 & 0 & 25 & 0 & 25 & 0 & 0 & 25 & 0 & 0 \\
\hline Chironomidae & 5450 & 650 & 4475 & 25 & 2575 & 175 & 5400 & 825 & 2875 & 550 \\
\hline Empididae & 0 & 25 & 0 & 0 & 50 & 0 & 0 & 0 & 0 & 0 \\
\hline Psychodidae & 0 & 0 & 25 & 0 & 0 & 0 & 0 & 0 & 0 & 0 \\
\hline Simulidae & 0 & 500 & 0 & 0 & 0 & 25 & 0 & 0 & 0 & 25 \\
\hline Stratyomidae & 0 & 0 & 0 & 0 & 0 & 0 & 0 & 0 & 0 & 0 \\
\hline Tabanidae & 0 & 0 & 25 & 0 & 0 & 0 & 0 & 0 & 0 & 0 \\
\hline Tipulidae & 125 & 0 & 50 & 0 & 25 & 0 & 0 & 25 & 0 & 0 \\
\hline TOTAL & 7325 & 2000 & 6900 & 250 & 4250 & 450 & 6250 & 1150 & 3925 & 875 \\
\hline
\end{tabular}


Anexo 3- Densidade total de cada táxon de macroinvertebrados bentônicos amostrado em poções e corredeiras da nascente 3 do Parque Estadual do Jaraguá, São Paulo, SP.

\begin{tabular}{|c|c|c|c|c|c|c|c|c|c|c|}
\hline & $\mathrm{Na3P} 1$ & $\mathrm{Na} 3 \mathrm{C} 1$ & $\mathrm{Na3P} 2$ & $\mathrm{Na} 3 \mathrm{C} 2$ & Na3P3 & $\mathrm{Na} 3 \mathrm{C} 3$ & Na3P4 & $\mathrm{Na} 3 \mathrm{C} 4$ & Na3P5 & $\mathrm{Na3C5}$ \\
\hline Hydracarina (ni) & 100 & 0 & 0 & 0 & 0 & 0 & 575 & 25 & 100 & 0 \\
\hline Bivalvia (ni) & 0 & 0 & 0 & 0 & 0 & 0 & 0 & 0 & 0 & 0 \\
\hline Tubificidae & 150 & 25 & 125 & 0 & 100 & 0 & 25 & 0 & 25 & 0 \\
\hline Cyclopidae & 0 & 0 & 0 & 0 & 0 & 0 & 50 & 0 & 0 & 0 \\
\hline Talitridae & 0 & 0 & 0 & 0 & 0 & 0 & 0 & 0 & 0 & 0 \\
\hline Paleomonidae & 0 & 25 & 0 & 0 & 25 & 0 & 50 & 125 & 0 & 0 \\
\hline Aeglidae & 0 & 0 & 0 & 0 & 0 & 0 & 0 & 25 & 0 & 0 \\
\hline Baetidae & 50 & 575 & 100 & 275 & 0 & 100 & 0 & 100 & 0 & 150 \\
\hline Leptophlebidae & 50 & 150 & 0 & 100 & 75 & 50 & 25 & 0 & 0 & 25 \\
\hline Aeshnidae & 0 & 0 & 0 & 0 & 50 & 0 & 0 & 25 & 0 & 0 \\
\hline Coenagrionidae & 50 & 0 & 50 & 50 & 0 & 25 & 0 & 0 & 100 & 0 \\
\hline Gomphidae & 150 & 0 & 25 & 50 & 50 & 0 & 25 & 75 & 100 & 0 \\
\hline Libellulidae & 50 & 100 & 25 & 25 & 25 & 75 & 75 & 50 & 0 & 0 \\
\hline Grypopterigidae & 0 & 100 & 25 & 25 & 50 & 50 & 50 & 50 & 0 & 25 \\
\hline Perlidae & 0 & 0 & 0 & 125 & 0 & 25 & 0 & 75 & 0 & 100 \\
\hline Calamoceratidae & 0 & 0 & 0 & 0 & 0 & 0 & 0 & 0 & 0 & 0 \\
\hline Hydrobiosidae & 0 & 0 & 0 & 0 & 0 & 0 & 0 & 0 & 0 & 0 \\
\hline Hydropsychidae & 25 & 0 & 0 & 0 & 0 & 0 & 0 & 0 & 0 & 0 \\
\hline Hydroptilidae & 25 & 0 & 0 & 0 & 0 & 0 & 0 & 0 & 0 & 0 \\
\hline Leptoceridae & 50 & 0 & 25 & 0 & 250 & 0 & 325 & 0 & 875 & 0 \\
\hline Philopotamidae & 0 & 0 & 0 & 0 & 0 & 0 & 0 & 0 & 0 & 0 \\
\hline Polycentropodidae & 0 & 0 & 0 & 0 & 0 & 0 & 0 & 0 & 0 & 0 \\
\hline Dytiscidae & 0 & 0 & 0 & 0 & 0 & 0 & 0 & 0 & 0 & 0 \\
\hline Elmidae & 0 & 150 & 0 & 0 & 0 & 0 & 25 & 25 & 25 & 125 \\
\hline Psephenidae & 0 & 75 & 0 & 50 & 0 & 175 & 0 & 50 & 0 & 150 \\
\hline Ceratopogonidae & 50 & 50 & 0 & 25 & 25 & 75 & 100 & 75 & 75 & 0 \\
\hline Chironomidae & 4250 & 400 & 1250 & 200 & 4000 & 425 & 5400 & 700 & 6925 & 75 \\
\hline Empididae & 50 & 0 & 0 & 0 & 0 & 0 & 0 & 0 & 0 & 25 \\
\hline Psychodidae & 50 & 0 & 0 & 0 & 0 & 0 & 25 & 0 & 0 & 0 \\
\hline Simulidae & 0 & 0 & 0 & 0 & 0 & 0 & 0 & 0 & 0 & 0 \\
\hline Stratyomidae & 75 & 0 & 0 & 0 & 0 & 0 & 0 & 0 & 0 & 0 \\
\hline Tabanidae & 0 & 0 & 0 & 0 & 0 & 0 & 0 & 0 & 0 & 0 \\
\hline Tipulidae & 50 & 50 & 75 & 50 & 0 & 25 & 75 & 100 & 0 & 25 \\
\hline TOTAL & 5225 & 1700 & 1700 & 975 & 4650 & 1025 & 6825 & 1500 & 8225 & 700 \\
\hline
\end{tabular}


Anexo 4- Densidade total de cada táxon de macroinvertebrados bentônicos amostrado em poções e corredeiras da nascente 4 do Parque Estadual do Jaraguá, São Paulo, SP.

\begin{tabular}{|c|c|c|c|c|c|c|c|c|c|c|}
\hline & $\mathrm{Na} 4 \mathrm{P} 1$ & $\mathrm{Na} 4 \mathrm{C} 1$ & $\mathrm{Na} 4 \mathrm{P} 2$ & $\mathrm{Na} 4 \mathrm{C} 2$ & $\mathrm{Na} 4 \mathrm{P} 3$ & $\mathrm{Na} 4 \mathrm{C} 3$ & $\mathrm{Na} 4 \mathrm{P} 4$ & $\mathrm{Na} 4 \mathrm{C} 4$ & Na4P5 & $\mathrm{Na} 4 \mathrm{C} 5$ \\
\hline Hydracarina (ni) & 0 & 0 & 0 & 0 & 25 & 50 & 0 & 100 & 50 & 25 \\
\hline Bivalvia (ni) & 125 & 0 & 100 & 0 & 175 & 0 & 475 & 200 & 100 & 150 \\
\hline Tubificidae & 75 & 0 & 0 & 75 & 50 & 25 & 75 & 25 & 125 & 200 \\
\hline Cyclopidae & 25 & 0 & 0 & 0 & 0 & 0 & 0 & 0 & 0 & 0 \\
\hline Talitridae & 0 & 0 & 0 & 0 & 0 & 0 & 0 & 0 & 0 & 0 \\
\hline Paleomonidae & 0 & 0 & 0 & 0 & 0 & 0 & 0 & 0 & 0 & 25 \\
\hline Aeglidae & 0 & 0 & 0 & 0 & 0 & 0 & 0 & 0 & 0 & 0 \\
\hline Baetidae & 175 & 50 & 75 & 50 & 0 & 0 & 375 & 200 & 25 & 100 \\
\hline Leptophlebidae & 25 & 100 & 0 & 75 & 0 & 50 & 25 & 125 & 0 & 100 \\
\hline Aeshnidae & 0 & 0 & 0 & 0 & 0 & 0 & 0 & 0 & 125 & 0 \\
\hline Coenagrionidae & 25 & 25 & 0 & 50 & 0 & 50 & 50 & 0 & 0 & 0 \\
\hline Gomphidae & 0 & 0 & 0 & 25 & 0 & 0 & 25 & 0 & 0 & 0 \\
\hline Libellulidae & 500 & 75 & 375 & 200 & 50 & 75 & 125 & 525 & 150 & 125 \\
\hline Grypopterigidae & 0 & 25 & 0 & 0 & 0 & 0 & 0 & 0 & 0 & 0 \\
\hline Perlidae & 0 & 0 & 0 & 0 & 0 & 0 & 0 & 0 & 0 & 0 \\
\hline Calamoceratidae & 0 & 0 & 0 & 0 & 0 & 0 & 0 & 0 & 0 & 0 \\
\hline Hydrobiosidae & 0 & 25 & 0 & 25 & 0 & 0 & 0 & 0 & 0 & 25 \\
\hline Hydropsychidae & 0 & 150 & 0 & 175 & 0 & 0 & 0 & 200 & 0 & 50 \\
\hline Hydroptilidae & 0 & 25 & 0 & 0 & 0 & 0 & 0 & 0 & 0 & 0 \\
\hline Leptoceridae & 25 & 0 & 100 & 0 & 25 & 0 & 100 & 0 & 75 & 0 \\
\hline Philopotamidae & 0 & 0 & 0 & 0 & 0 & 0 & 0 & 0 & 25 & 0 \\
\hline Polycentropodidae & 100 & 0 & 0 & 25 & 75 & 0 & 0 & 50 & 0 & 25 \\
\hline Dytiscidae & 0 & 0 & 0 & 25 & 25 & 0 & 125 & 25 & 0 & 50 \\
\hline Elmidae & 125 & 100 & 50 & 50 & 150 & 75 & 175 & 50 & 75 & 100 \\
\hline Psephenidae & 0 & 0 & 0 & 0 & 0 & 0 & 0 & 25 & 0 & 0 \\
\hline Ceratopogonidae & 25 & 0 & 0 & 25 & 25 & 0 & 25 & 50 & 250 & 50 \\
\hline Chironomidae & 1400 & 2750 & 1925 & 675 & 4425 & 1225 & 10750 & 5825 & 4350 & 2625 \\
\hline Empididae & 0 & 125 & 0 & 0 & 0 & 0 & 0 & 0 & 0 & 0 \\
\hline Psychodidae & 0 & 0 & 0 & 0 & 0 & 0 & 0 & 0 & 0 & 0 \\
\hline Simulidae & 0 & 350 & 0 & 25 & 0 & 0 & 0 & 0 & 0 & 25 \\
\hline Stratyomidae & 25 & 0 & 0 & 0 & 50 & 0 & 0 & 0 & 0 & 0 \\
\hline Tabanidae & 0 & 0 & 0 & 0 & 0 & 0 & 0 & 0 & 0 & 0 \\
\hline Tipulidae & 225 & 50 & 225 & 50 & 75 & 300 & 125 & 100 & 200 & 100 \\
\hline TOTAL & 2875 & 3850 & 2850 & 1550 & 5150 & 1850 & 12450 & 7500 & 5550 & 3775 \\
\hline
\end{tabular}


Anexo 5 - Abundância relativa de cada táxon de macroinvertebrados bentônicos amostrado em poções e corredeiras da nascente 1 do Parque Estadual do Jaraguá, São Paulo, SP.

\begin{tabular}{|c|c|c|c|c|c|c|c|c|c|c|}
\hline & Na1P1 & $\mathrm{Na} 1 \mathrm{C} 1$ & Na1P2 & $\mathrm{Na} 1 \mathrm{C} 2$ & Na1P3 & Na1C3 & Na1P4 & Na1C4 & Na1P5 & Na1C5 \\
\hline Hydracarina (ni) & 0,00 & 0,00 & 0,00 & 0,00 & 0,00 & 0,00 & 0,00 & 0,00 & 0,00 & 0,00 \\
\hline Bivalvia (ni) & 0,00 & 0,00 & 0,00 & 0,00 & 0,00 & 0,00 & 0,00 & 0,00 & 0,00 & 0,00 \\
\hline Tubificidae & 0,02 & 0,00 & 0,00 & 0,00 & 0,03 & 0,07 & 0,05 & 0,00 & 0,02 & 0,00 \\
\hline Cyclopidae & 0,01 & 0,00 & 0,01 & 0,00 & 0,01 & 0,00 & 0,01 & 0,00 & 0,00 & 0,00 \\
\hline Talitridae & 0,00 & 0,00 & 0,00 & 0,00 & 0,00 & 0,00 & 0,01 & 0,00 & 0,00 & 0,00 \\
\hline Paleomonidae & 0,00 & 0,00 & 0,00 & 0,00 & 0,00 & 0,00 & 0,00 & 0,00 & 0,00 & 0,00 \\
\hline Aeglidae & 0,01 & 0,00 & 0,02 & 0,00 & 0,00 & 0,04 & 0,03 & 0,00 & 0,05 & 0,06 \\
\hline Baetidae & 0,03 & 0,00 & 0,01 & 0,42 & 0,00 & 0,11 & 0,05 & 0,40 & 0,02 & 0,13 \\
\hline Leptophlebidae & 0,02 & 0,00 & 0,00 & 0,00 & 0,00 & 0,07 & 0,02 & 0,00 & 0,00 & 0,09 \\
\hline Aeshnidae & 0,01 & 0,00 & 0,00 & 0,00 & 0,00 & 0,00 & 0,00 & 0,00 & 0,00 & 0,00 \\
\hline Coenagrionidae & 0,00 & 0,00 & 0,00 & 0,00 & 0,00 & 0,00 & 0,00 & 0,00 & 0,00 & 0,02 \\
\hline Gomphidae & 0,00 & 0,00 & 0,00 & 0,00 & 0,01 & 0,00 & 0,02 & 0,00 & 0,00 & 0,00 \\
\hline Libellulidae & 0,00 & 0,11 & 0,00 & 0,08 & 0,00 & 0,00 & 0,00 & 0,00 & 0,00 & 0,00 \\
\hline Grypopterigidae & 0,00 & 0,22 & 0,01 & 0,08 & 0,00 & 0,11 & 0,06 & 0,00 & 0,03 & 0,09 \\
\hline Perlidae & 0,00 & 0,11 & 0,00 & 0,00 & 0,00 & 0,00 & 0,00 & 0,00 & 0,00 & 0,00 \\
\hline Calamoceratidae & 0,00 & 0,00 & 0,00 & 0,00 & 0,00 & 0,00 & 0,00 & 0,00 & 0,00 & 0,00 \\
\hline Hydrobiosidae & 0,00 & 0,00 & 0,00 & 0,00 & 0,00 & 0,00 & 0,00 & 0,00 & 0,00 & 0,00 \\
\hline Hydropsychidae & 0,00 & 0,00 & 0,00 & 0,00 & 0,00 & 0,00 & 0,00 & 0,00 & 0,00 & 0,00 \\
\hline Hydroptilidae & 0,00 & 0,00 & 0,01 & 0,00 & 0,00 & 0,00 & 0,00 & 0,00 & 0,00 & 0,00 \\
\hline Leptoceridae & 0,04 & 0,00 & 0,02 & 0,00 & 0,04 & 0,00 & 0,02 & 0,00 & 0,01 & 0,00 \\
\hline Philopotamidae & 0,00 & 0,00 & 0,00 & 0,00 & 0,00 & 0,00 & 0,00 & 0,00 & 0,00 & 0,00 \\
\hline Polycentropodidae & 0,00 & 0,00 & 0,00 & 0,00 & 0,00 & 0,00 & 0,00 & 0,00 & 0,00 & 0,00 \\
\hline Dytiscidae & 0,00 & 0,00 & 0,00 & 0,00 & 0,00 & 0,00 & 0,00 & 0,00 & 0,00 & 0,00 \\
\hline Elmidae & 0,00 & 0,11 & 0,01 & 0,00 & 0,02 & 0,00 & 0,01 & 0,00 & 0,01 & 0,09 \\
\hline Psephenidae & 0,00 & 0,00 & 0,00 & 0,00 & 0,00 & 0,00 & 0,00 & 0,00 & 0,00 & 0,00 \\
\hline Ceratopogonidae & 0,02 & 0,00 & 0,00 & 0,00 & 0,00 & 0,15 & 0,02 & 0,00 & 0,00 & 0,00 \\
\hline Chironomidae & 0,80 & 0,33 & 0,90 & 0,25 & 0,85 & 0,44 & 0,68 & 0,40 & 0,83 & 0,32 \\
\hline Empididae & 0,01 & 0,00 & 0,00 & 0,00 & 0,00 & 0,00 & 0,00 & 0,00 & 0,00 & 0,00 \\
\hline Psychodidae & 0,00 & 0,00 & 0,00 & 0,00 & 0,00 & 0,00 & 0,00 & 0,00 & 0,00 & 0,00 \\
\hline Simuliidae & 0,00 & 0,11 & 0,00 & 0,08 & 0,00 & 0,00 & 0,00 & 0,20 & 0,00 & 0,21 \\
\hline Stratiomyidae & 0,00 & 0,00 & 0,00 & 0,00 & 0,00 & 0,00 & 0,01 & 0,00 & 0,03 & 0,00 \\
\hline Tabanidae & 0,00 & 0,00 & 0,00 & 0,00 & 0,01 & 0,00 & 0,00 & 0,00 & 0,00 & 0,00 \\
\hline Tipulidae & 0,01 & 0,00 & 0,00 & 0,08 & 0,00 & 0,00 & 0,02 & 0,00 & 0,01 & 0,00 \\
\hline
\end{tabular}


Anexo 6 - Abundância relativa de cada táxon de macroinvertebrados bentônicos amostrado em poções e corredeiras da nascente 2 do Parque Estadual do Jaraguá, São Paulo, SP.

\begin{tabular}{|c|c|c|c|c|c|c|c|c|c|c|}
\hline & $\mathrm{Na} 2 \mathrm{P} 1$ & $\mathrm{Na} 2 \mathrm{C} 1$ & $\mathrm{Na} 2 \mathrm{P} 2$ & $\mathrm{Na} 2 \mathrm{C} 2$ & $\mathrm{Na} 2 \mathrm{P} 3$ & $\mathrm{Na} 2 \mathrm{C} 3$ & $\mathrm{Na} 2 \mathrm{P} 4$ & $\mathrm{Na} 2 \mathrm{C} 4$ & $\mathrm{Na} 2 \mathrm{P} 5$ & $\mathrm{Na} 2 \mathrm{C} 5$ \\
\hline Hydracarina (ni) & 0,01 & 0,00 & 0,00 & 0,00 & 0,04 & 0,00 & 0,00 & 0,02 & 0,04 & 0,00 \\
\hline Bivalvia (ni) & 0,00 & 0,00 & 0,03 & 0,00 & 0,01 & 0,00 & 0,00 & 0,00 & 0,00 & 0,11 \\
\hline Tubificidae & 0,10 & 0,00 & 0,05 & 0,10 & 0,01 & 0,00 & 0,01 & 0,00 & 0,05 & 0,06 \\
\hline Cyclopidae & 0,00 & 0,00 & 0,00 & 0,00 & 0,00 & 0,00 & 0,00 & 0,00 & 0,00 & 0,00 \\
\hline Talitridae & 0,01 & 0,00 & 0,02 & 0,00 & 0,00 & 0,00 & 0,01 & 0,00 & 0,00 & 0,00 \\
\hline Paleomonidae & 0,00 & 0,00 & 0,00 & 0,00 & 0,00 & 0,06 & 0,00 & 0,02 & 0,00 & 0,06 \\
\hline Aeglidae & 0,00 & 0,00 & 0,00 & 0,00 & 0,00 & 0,00 & 0,00 & 0,00 & 0,00 & 0,00 \\
\hline Baetidae & 0,02 & 0,04 & 0,05 & 0,20 & 0,00 & 0,06 & 0,04 & 0,04 & 0,01 & 0,00 \\
\hline Leptophlebidae & 0,00 & 0,03 & 0,02 & 0,00 & 0,00 & 0,00 & 0,02 & 0,00 & 0,01 & 0,03 \\
\hline Aeshnidae & 0,00 & 0,00 & 0,00 & 0,00 & 0,00 & 0,00 & 0,00 & 0,00 & 0,01 & 0,00 \\
\hline Coenagrionidae & 0,00 & 0,00 & 0,00 & 0,00 & 0,00 & 0,00 & 0,00 & 0,00 & 0,01 & 0,00 \\
\hline Gomphidae & 0,02 & 0,00 & 0,00 & 0,00 & 0,01 & 0,00 & 0,01 & 0,00 & 0,00 & 0,00 \\
\hline Libellulidae & 0,00 & 0,01 & 0,00 & 0,00 & 0,00 & 0,06 & 0,00 & 0,02 & 0,00 & 0,00 \\
\hline Grypopterigidae & 0,03 & 0,11 & 0,04 & 0,00 & 0,18 & 0,11 & 0,01 & 0,11 & 0,06 & 0,06 \\
\hline Perlidae & 0,00 & 0,00 & 0,00 & 0,00 & 0,00 & 0,00 & 0,00 & 0,00 & 0,00 & 0,00 \\
\hline Calamoceratidae & 0,00 & 0,00 & 0,01 & 0,00 & 0,00 & 0,00 & 0,00 & 0,00 & 0,00 & 0,00 \\
\hline Hydrobiosidae & 0,00 & 0,00 & 0,00 & 0,00 & 0,00 & 0,00 & 0,00 & 0,00 & 0,00 & 0,00 \\
\hline Hydropsychidae & 0,00 & 0,01 & 0,00 & 0,00 & 0,00 & 0,00 & 0,00 & 0,00 & 0,00 & 0,00 \\
\hline Hydroptilidae & 0,00 & 0,01 & 0,00 & 0,00 & 0,00 & 0,00 & 0,00 & 0,00 & 0,00 & 0,00 \\
\hline Leptoceridae & 0,03 & 0,00 & 0,07 & 0,00 & 0,04 & 0,00 & 0,02 & 0,00 & 0,06 & 0,00 \\
\hline Philopotamidae & 0,00 & 0,01 & 0,00 & 0,00 & 0,00 & 0,00 & 0,00 & 0,00 & 0,00 & 0,00 \\
\hline Polycentropodidae & 0,01 & 0,00 & 0,00 & 0,00 & 0,00 & 0,00 & 0,00 & 0,00 & 0,00 & 0,00 \\
\hline Dytiscidae & 0,00 & 0,00 & 0,00 & 0,00 & 0,01 & 0,00 & 0,00 & 0,00 & 0,00 & 0,00 \\
\hline Elmidae & 0,00 & 0,05 & 0,03 & 0,00 & 0,09 & 0,00 & 0,02 & 0,00 & 0,02 & 0,00 \\
\hline Psephenidae & 0,00 & 0,14 & 0,00 & 0,60 & 0,00 & 0,28 & 0,00 & 0,02 & 0,01 & 0,03 \\
\hline Ceratopogonidae & 0,00 & 0,00 & 0,00 & 0,00 & 0,01 & 0,00 & 0,00 & 0,02 & 0,00 & 0,00 \\
\hline Chironomidae & 0,74 & 0,33 & 0,65 & 0,10 & 0,61 & 0,39 & 0,86 & 0,72 & 0,73 & 0,63 \\
\hline Empididae & 0,00 & 0,01 & 0,00 & 0,00 & 0,01 & 0,00 & 0,00 & 0,00 & 0,00 & 0,00 \\
\hline Psychodidae & 0,00 & 0,00 & 0,00 & 0,00 & 0,00 & 0,00 & 0,00 & 0,00 & 0,00 & 0,00 \\
\hline Simuliidae & 0,00 & 0,25 & 0,00 & 0,00 & 0,00 & 0,06 & 0,00 & 0,00 & 0,00 & 0,03 \\
\hline Stratiomyidae & 0,00 & 0,00 & 0,00 & 0,00 & 0,00 & 0,00 & 0,00 & 0,00 & 0,00 & 0,00 \\
\hline Tabanidae & 0,00 & 0,00 & 0,00 & 0,00 & 0,00 & 0,00 & 0,00 & 0,00 & 0,00 & 0,00 \\
\hline Tipulidae & 0,02 & 0,00 & 0,01 & 0,00 & 0,01 & 0,00 & 0,00 & 0,02 & 0,00 & 0,00 \\
\hline
\end{tabular}


Anexo 7 - Abundância relativa de cada táxon de macroinvertebrados bentônicos amostrado em poções e corredeiras da nascente 3 do Parque Estadual do Jaraguá, São Paulo, SP.

\begin{tabular}{|c|c|c|c|c|c|c|c|c|c|c|}
\hline & $\mathrm{Na3P} 1$ & $\mathrm{Na} 3 \mathrm{C} 1$ & $\mathrm{Na3P} 2$ & $\mathrm{Na} 3 \mathrm{C} 2$ & Na3P3 & $\mathrm{Na} 3 \mathrm{C} 3$ & $\mathrm{Na} 3 \mathrm{P} 4$ & $\mathrm{Na} 3 \mathrm{C} 4$ & Na3P5 & $\mathrm{Na3C5}$ \\
\hline Hydracarina (ni) & 0,02 & 0,00 & 0,00 & 0,00 & 0,00 & 0,00 & 0,08 & 0,02 & 0,01 & 0,00 \\
\hline Bivalvia (ni) & 0,00 & 0,00 & 0,00 & 0,00 & 0,00 & 0,00 & 0,00 & 0,00 & 0,00 & 0,00 \\
\hline Tubificidae & 0,03 & 0,01 & 0,07 & 0,00 & 0,02 & 0,00 & 0,00 & 0,00 & 0,00 & 0,00 \\
\hline Cyclopidae & 0,00 & 0,00 & 0,00 & 0,00 & 0,00 & 0,00 & 0,01 & 0,00 & 0,00 & 0,00 \\
\hline Talitridae & 0,00 & 0,00 & 0,00 & 0,00 & 0,00 & 0,00 & 0,00 & 0,00 & 0,00 & 0,00 \\
\hline Paleomonidae & 0,00 & 0,01 & 0,00 & 0,00 & 0,01 & 0,00 & 0,01 & 0,08 & 0,00 & 0,00 \\
\hline Aeglidae & 0,00 & 0,00 & 0,00 & 0,00 & 0,00 & 0,00 & 0,00 & 0,02 & 0,00 & 0,00 \\
\hline Baetidae & 0,01 & 0,34 & 0,06 & 0,28 & 0,00 & 0,10 & 0,00 & 0,07 & 0,00 & 0,21 \\
\hline Leptophlebidae & 0,01 & 0,09 & 0,00 & 0,10 & 0,02 & 0,05 & 0,00 & 0,00 & 0,00 & 0,04 \\
\hline Aeshnidae & 0,00 & 0,00 & 0,00 & 0,00 & 0,01 & 0,00 & 0,00 & 0,02 & 0,00 & 0,00 \\
\hline Coenagrionidae & 0,01 & 0,00 & 0,03 & 0,05 & 0,00 & 0,02 & 0,00 & 0,00 & 0,01 & 0,00 \\
\hline Gomphidae & 0,03 & 0,00 & 0,01 & 0,05 & 0,01 & 0,00 & 0,00 & 0,05 & 0,01 & 0,00 \\
\hline Libellulidae & 0,01 & 0,06 & 0,01 & 0,03 & 0,01 & 0,07 & 0,01 & 0,03 & 0,00 & 0,00 \\
\hline Grypopterigidae & 0,00 & 0,06 & 0,01 & 0,03 & 0,01 & 0,05 & 0,01 & 0,03 & 0,00 & 0,04 \\
\hline Perlidae & 0,00 & 0,00 & 0,00 & 0,13 & 0,00 & 0,02 & 0,00 & 0,05 & 0,00 & 0,14 \\
\hline Calamoceratidae & 0,00 & 0,00 & 0,00 & 0,00 & 0,00 & 0,00 & 0,00 & 0,00 & 0,00 & 0,00 \\
\hline Hydrobiosidae & 0,00 & 0,00 & 0,00 & 0,00 & 0,00 & 0,00 & 0,00 & 0,00 & 0,00 & 0,00 \\
\hline Hydropsychidae & 0,00 & 0,00 & 0,00 & 0,00 & 0,00 & 0,00 & 0,00 & 0,00 & 0,00 & 0,00 \\
\hline Hydroptilidae & 0,00 & 0,00 & 0,00 & 0,00 & 0,00 & 0,00 & 0,00 & 0,00 & 0,00 & 0,00 \\
\hline Leptoceridae & 0,01 & 0,00 & 0,01 & 0,00 & 0,05 & 0,00 & 0,05 & 0,00 & 0,11 & 0,00 \\
\hline Philopotamidae & 0,00 & 0,00 & 0,00 & 0,00 & 0,00 & 0,00 & 0,00 & 0,00 & 0,00 & 0,00 \\
\hline Polycentropodidae & 0,00 & 0,00 & 0,00 & 0,00 & 0,00 & 0,00 & 0,00 & 0,00 & 0,00 & 0,00 \\
\hline Dytiscidae & 0,00 & 0,00 & 0,00 & 0,00 & 0,00 & 0,00 & 0,00 & 0,00 & 0,00 & 0,00 \\
\hline Elmidae & 0,00 & 0,09 & 0,00 & 0,00 & 0,00 & 0,00 & 0,00 & 0,02 & 0,00 & 0,18 \\
\hline Psephenidae & 0,00 & 0,04 & 0,00 & 0,05 & 0,00 & 0,17 & 0,00 & 0,03 & 0,00 & 0,21 \\
\hline Ceratopogonidae & 0,01 & 0,03 & 0,00 & 0,03 & 0,01 & 0,07 & 0,01 & 0,05 & 0,01 & 0,00 \\
\hline Chironomidae & 0,81 & 0,24 & 0,74 & 0,21 & 0,86 & 0,41 & 0,79 & 0,47 & 0,84 & 0,11 \\
\hline Empididae & 0,01 & 0,00 & 0,00 & 0,00 & 0,00 & 0,00 & 0,00 & 0,00 & 0,00 & 0,04 \\
\hline Psychodidae & 0,01 & 0,00 & 0,00 & 0,00 & 0,00 & 0,00 & 0,00 & 0,00 & 0,00 & 0,00 \\
\hline Simuliidae & 0,00 & 0,00 & 0,00 & 0,00 & 0,00 & 0,00 & 0,00 & 0,00 & 0,00 & 0,00 \\
\hline Stratiomyidae & 0,01 & 0,00 & 0,00 & 0,00 & 0,00 & 0,00 & 0,00 & 0,00 & 0,00 & 0,00 \\
\hline Tabanidae & 0,00 & 0,00 & 0,00 & 0,00 & 0,00 & 0,00 & 0,00 & 0,00 & 0,00 & 0,00 \\
\hline Tipulidae & 0,01 & 0,03 & 0,04 & 0,05 & 0,00 & 0,02 & 0,01 & 0,07 & 0,00 & 0,04 \\
\hline
\end{tabular}


Anexo 8 - Abundância relativa de cada táxon de macroinvertebrados bentônicos amostrado em poções e corredeiras da nascente 4 do Parque Estadual do Jaraguá, São Paulo, SP.

\begin{tabular}{|c|c|c|c|c|c|c|c|c|c|c|}
\hline & Na4P1 & $\mathrm{Na} 4 \mathrm{C} 1$ & Na4P2 & $\mathrm{Na} 4 \mathrm{C} 2$ & Na4P3 & $\mathrm{Na} 4 \mathrm{C} 3$ & $\mathrm{Na} 4 \mathrm{P} 4$ & $\mathrm{Na} 4 \mathrm{C} 4$ & $\mathrm{Na} 4 \mathrm{P} 5$ & $\mathrm{Na} 4 \mathrm{C} 5$ \\
\hline Hydracarina (ni) & 0,00 & 0,00 & 0,00 & 0,00 & 0,00 & 0,03 & 0,00 & 0,01 & 0,01 & 0,01 \\
\hline Bivalvia (ni) & 0,04 & 0,00 & 0,04 & 0,00 & 0,03 & 0,00 & 0,04 & 0,03 & 0,02 & 0,04 \\
\hline Tubificidae & 0,03 & 0,00 & 0,00 & 0,05 & 0,01 & 0,01 & 0,01 & 0,00 & 0,02 & 0,05 \\
\hline Cyclopidae & 0,01 & 0,00 & 0,00 & 0,00 & 0,00 & 0,00 & 0,00 & 0,00 & 0,00 & 0,00 \\
\hline Talitridae & 0,00 & 0,00 & 0,00 & 0,00 & 0,00 & 0,00 & 0,00 & 0,00 & 0,00 & 0,00 \\
\hline Paleomonidae & 0,00 & 0,00 & 0,00 & 0,00 & 0,00 & 0,00 & 0,00 & 0,00 & 0,00 & 0,01 \\
\hline Aeglidae & 0,00 & 0,00 & 0,00 & 0,00 & 0,00 & 0,00 & 0,00 & 0,00 & 0,00 & 0,00 \\
\hline Baetidae & 0,06 & 0,01 & 0,03 & 0,03 & 0,00 & 0,00 & 0,03 & 0,03 & 0,00 & 0,03 \\
\hline Leptophlebidae & 0,01 & 0,03 & 0,00 & 0,05 & 0,00 & 0,03 & 0,00 & 0,02 & 0,00 & 0,03 \\
\hline Aeshnidae & 0,00 & 0,01 & 0,00 & 0,00 & 0,00 & 0,00 & 0,00 & 0,00 & 0,00 & 0,00 \\
\hline Coenagrionidae & 0,01 & 0,00 & 0,04 & 0,00 & 0,00 & 0,00 & 0,01 & 0,00 & 0,01 & 0,00 \\
\hline Gomphidae & 0,00 & 0,00 & 0,00 & 0,00 & 0,00 & 0,00 & 0,00 & 0,00 & 0,00 & 0,00 \\
\hline Libellulidae & 0,03 & 0,00 & 0,00 & 0,02 & 0,01 & 0,00 & 0,00 & 0,01 & 0,00 & 0,01 \\
\hline Grypopterigidae & 0,00 & 0,00 & 0,00 & 0,00 & 0,00 & 0,00 & 0,00 & 0,00 & 0,02 & 0,00 \\
\hline Perlidae & 0,01 & 0,01 & 0,00 & 0,03 & 0,00 & 0,03 & 0,00 & 0,00 & 0,00 & 0,00 \\
\hline Calamoceratidae & 0,00 & 0,00 & 0,00 & 0,02 & 0,00 & 0,00 & 0,00 & 0,00 & 0,00 & 0,00 \\
\hline Hydrobiosidae & 0,17 & 0,02 & 0,13 & 0,13 & 0,01 & 0,04 & 0,01 & 0,07 & 0,03 & 0,03 \\
\hline Hydropsychidae & 0,00 & 0,01 & 0,00 & 0,00 & 0,00 & 0,00 & 0,00 & 0,00 & 0,00 & 0,00 \\
\hline Hydroptilidae & 0,00 & 0,00 & 0,00 & 0,00 & 0,00 & 0,00 & 0,00 & 0,00 & 0,00 & 0,00 \\
\hline Leptoceridae & 0,00 & 0,00 & 0,00 & 0,00 & 0,00 & 0,00 & 0,00 & 0,00 & 0,00 & 0,00 \\
\hline Philopotamidae & 0,00 & 0,01 & 0,00 & 0,02 & 0,00 & 0,00 & 0,00 & 0,00 & 0,00 & 0,01 \\
\hline Polycentropodidae & 0,00 & 0,04 & 0,00 & 0,11 & 0,00 & 0,00 & 0,00 & 0,03 & 0,00 & 0,01 \\
\hline Dytiscidae & 0,00 & 0,00 & 0,00 & 0,02 & 0,00 & 0,00 & 0,01 & 0,00 & 0,00 & 0,01 \\
\hline Elmidae & 0,04 & 0,03 & 0,02 & 0,03 & 0,03 & 0,04 & 0,01 & 0,01 & 0,01 & 0,03 \\
\hline Psephenidae & 0,00 & 0,00 & 0,00 & 0,00 & 0,00 & 0,00 & 0,00 & 0,00 & 0,00 & 0,00 \\
\hline Ceratopogonidae & 0,01 & 0,00 & 0,00 & 0,02 & 0,00 & 0,00 & 0,00 & 0,01 & 0,05 & 0,01 \\
\hline Chironomidae & 0,49 & 0,71 & 0,68 & 0,44 & 0,86 & 0,66 & 0,86 & 0,78 & 0,78 & 0,70 \\
\hline Empididae & 0,00 & 0,03 & 0,00 & 0,00 & 0,00 & 0,00 & 0,00 & 0,00 & 0,00 & 0,00 \\
\hline Psychodidae & 0,00 & 0,00 & 0,00 & 0,00 & 0,00 & 0,00 & 0,00 & 0,00 & 0,00 & 0,00 \\
\hline Simuliidae & 0,00 & 0,09 & 0,00 & 0,02 & 0,00 & 0,00 & 0,00 & 0,00 & 0,00 & 0,01 \\
\hline Stratiomyidae & 0,01 & 0,00 & 0,00 & 0,00 & 0,01 & 0,00 & 0,00 & 0,00 & 0,00 & 0,00 \\
\hline Tabanidae & 0,00 & 0,00 & 0,00 & 0,00 & 0,00 & 0,00 & 0,00 & 0,00 & 0,00 & 0,00 \\
\hline Tipulidae & 0,08 & 0,01 & 0,08 & 0,03 & 0,01 & 0,16 & 0,01 & 0,01 & 0,04 & 0,03 \\
\hline
\end{tabular}


